\title{
AN ARCHITECTURE FOR PEOPLE
}

\author{
A VERTICAL NEIGHBOURHOOD \\ FOR FOSTERING SOCIAL INTERACTIONS
}

by

Joanne Gust

B.Arch. Sci, Ryerson University, 2012

A thesis

presented to Ryerson University

In partial fulfillment of the requirements

for the degree of

Master of Architecture

in the Program of

The Department of Architectural Science

Toronto, Ontario Canada, 2014

(c) Joanne Gust 2014 



\section{| AUTHOR'S DECLARATION |}

I hereby declare that I am the sole author of this thesis. This is a true copy of the thesis, including any required final revisions, as accepted by my examiners.

I authorize Ryerson University to lend this thesis to other institutions or individuals for the purpose of scholarly research.

I further authorize Ryerson University to reproduce this thesis by photocopying or by other means, in total or in part, at the request of other institutions or individuals for the purpose of scholarly research.

I understand that my thesis may be made electronically available to the public. 



\section{AN ARCHITECTURE FOR PEOPLE}

| A VERTICAL NEIGHBOURHOOD FOR FOSTERING SOCIAL INTERACTION |

Joanne Gust

Ryerson University

Master Of Architecture 2014

\section{| ABSTRACT |}

Architecture should respond to the human need for social interaction, which can contribute to human health and well - being and support the sustainable growth and development of cities. Currently, world -wide, high-density developments are recognized as a way to grow sustainably. Similarly, this has been recognized in the City of Toronto. However. current condominium developments have primarily responded to the influx of young professionals and have overlooked the necessity for social interaction, and consequently these facets have contributed to creating a monoculture in the downtown core.

Nevertheless, to grow sustainably, the City of Toronto should focus on making densification a viable solution for a greater number of people, by accommodating for a variety of family types, and by responding to peoples' need to interact socially. To achieve both of these goals requires: the management of large populations through the generation of clusters, the integration of communal spaces, a circulation system to provide choice and generate encounters, and a response to context. 



\section{| ACKNOWLEDGMENTS |}

Firstly, I would like to begin by thanking and expressing my sincere gratitude to my supervision Paul Floerke, for his patience, wisdom and motivation, during the course of this thesis project. This work would not have been possible without his knowledge on the subject and passion for creating opportunities for social interaction, which provided me with the guidance and tools I needed to complete this work. Thank you for believing in me and seeing the strength of my work when I had difficulties seeing it myself. You not only guided me in my research and design process but also helped me express my ideas with confidence.

I would also like to thank my thesis committee members Cheryl Atkinson and Vincent Hui, who challenged and encouraged me throughout the process. They each brought their own insights and perspectives to this project that helped shape its development. Cheryl Atkinson, helped to ground my work by bringing fourth pragmatic concerns. Her guidance helped me to respond and reach a realistic design solution for a condominium in the City of Toronto. Thank you to Vincent Hui, whose time and continued support exceeded his role as my program representative. Thank you for challenging me yzour inquisitive nature truly helped me advance my ideas and position. Thank you for your continued encouragement, knowledge and time throughout this process.

In addition I would also like to thank Arthur Wigglesworth, my Masters of Architecture Program director, for his support encouragement and inspiration to continue to think, draw and create. To the other professors that I had the pleasure of discussing my thesis with during the course of this year, thank you for your interest and insight.

Thank you to my family. Michael and Sam for their daily support, patience and continuous encouragement at each milestone.

Lastly, I would like to thank my amazing colleagues. This past year has had many tough times, and even with overwhelming deadlines we each made the time to support and encourage one another. Thank you for the guidance and laughs throughout the year, you truly contributed to making it a memorable experience. 

to my family, michael \& sam 


\section{| DEFINITIONS |}

FORMAL ENCOUNTERS: When people plan to meet with each other, or when conversations are brief and simply for the purpose of being polite.

INFORMAL ENCOUNTERS: When encounters happen spontaneously as a result of people going about their business. This can only occur when people have significant opportunities for encounter.

INTEGRATION: Where there are various activities and categories of people that are permitted to function together or side-by-side as a result of architectural form and visibility between spaces.

SEGREGATION: Where there is a distinct divide between different functions and groups of people that does not enable them to come together.

FAMILY TYPE: Includes all categories of people,

singles, couples, adults with children.

COMMON SPACE FOR CLUSTERS: Common spaces designed within the clusters and directly in front of people's units. They are intended for the use of the residents belonging to a particular cluster (but not limited to) and their purpose is to give residents the opportunity to interact comfortably with their neighbours

(Chapter 5).

COMMUNAL SPACES (AMENITY SPACE): Spaces that are similar in function to amenity spaces provided in condominium design. The purpose of these spaces is to bring residents from the whole neighbourhood to come together (Chapter 6). 


\section{| TABLE OF CONTENTS |}

| 1 | INTRODUCTION 1

| 2 | THE SIGNIFICANCE OF SOCIAL 5 INTERACTION

| 3 | PAST AND PRESENT TRENDS 9

| 4 | PROPOSING A SOLUTION 17

| 5 | GENERATING CLUSTERS 25

| 6 | INTEGRATION OF COMMUNAL SPACES 39

I 7 | CIRCULATION TO PROVIDE CHOICE \& 49 GENERATING ENCOUNTERS

| 8 | RESPONSE TO CONTEXT 57

| 9| CONCLUSION 67

| 10| REFLECTION

| 11 | APPENDIX 73

| 12 | LIST OF FIGURES 91

| 13 | LIST OF REFERENCES 95

** Please note that all figures identified with a pink shade are design work by the author 


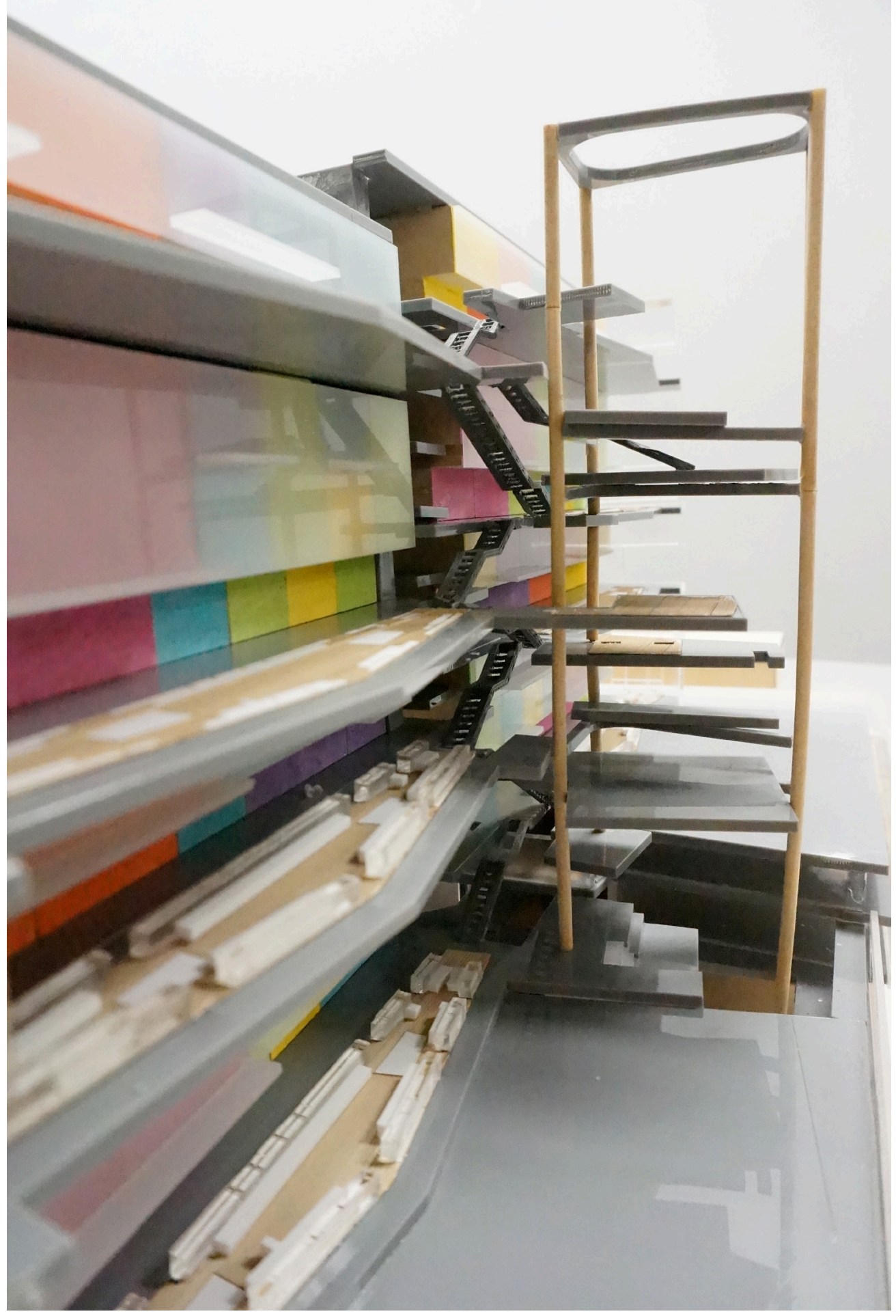

Figure 1: View looking inside of the physical model 


\section{| 1 | INTRODUCTION}

"people gather where things are happening and spontaneously seek the presence of other people"

(Gehl, Cities for People, 2010, p. 25)

Architecture should focus on facilitating opportunities for social interaction, as the need to interact socially has been identified as one of the basic human necessities to achieving psychological health and well - being. Providing people with opportunities for interaction not only contributes to the health of individuals but it also contributes to the health and sustainability of cities. However, many architectural responses do not start with people in mind or with a response to their basic human needs.

With an increased focus on the development of sustainable cities, there is a paradigm shift worldwide in the construction of high-density residential buildings in response to anticipated predictions in population. The City of Toronto has taken a similar step in response to developing sustainably. The city core is undergoing intensification through high-density condominium developments. These developments have been recognized by city officials as an opportunity to mitigate the growth of suburban cities. However, these developments have contributed to creating a monoculture in the city's downtown core. This has been a result of a number of factors: first, the condominium market has responded to the influx of young professionals into the city core, thus small units are built to maximize profit; second, the lack of variety in accommodations are unappealing to families who also understand the absence of communal spaces as a physical and emotional barrier. Consequently, these developments are primarily providing temporary housing for young professionals before they have children and migrate to the suburbs. Evidence from The City of Toronto profile supports that developments in the core, are usually small and relatively expensive. and as family needs evolve, numerous people will "place a higher priority on larger and more affordable housing, and this may mean moving away from Downtown or the Centre in which they live" (Toronto City Planning, 2012, p. 19). As such, census supports that there are large numbers of residents in their twenties and thirties and comparatively small numbers of children and teens (Toronto City Planning, 2012). Thus, despite the intentions for using densification to migrate sprawl, these high-density developments are rather fueling its growth.

However, in addition to a demand for accommodations for a growing population, there will also be increasing demands for productive land (Maas. 
2003, 15). Therefore, efficient forms of development, such as the densification of existing cities should continue to be the primary form of growth and development for a variety of people, as it can truly help cities develop sustainably.

This architectural thesis will deal primarily with the design constraints that inhibit social interaction in current residential developments, rather than those that inhibit access to this typology due to cost. Therefore, a key question that this thesis will address is; how can a multi-story residential building be designed to foster social interaction is a vertical neighborhood that provides variety in housing for a diverse demographic to reside in the city?

The design for this thesis project challenges the current development of condominiums in the city. This thesis project uses the mid-rise typology as a point of departure, for the experimentation and insertion of social spaces. Through the study and analysis of precedents, four principles have been developed that can be applied in combination to facilitate community growth and neighbourly engagement. These principles include the generation of unit clusters, the integration of communal spaces, circulation to provide choice and generate encounters and a response to context. These principles will be combined with strategies and tactics that have been identified for encouraging interaction which include, designing to allow for visibility, responding to human behavior, and lastly responding to demographics. This thesis will demonstrate the application of these principles and strategies in the design of a mid-rise residential building in the City of Toronto. The principles and strategies used in this thesis have been derived from both past and present precedents, which have made attempts to create interactions between neighbours, as well as theoretical concepts derived from scholars and architects who have studied and observed how to successfully create social spaces for interaction.

The first principle, the generation of clusters, is a response to the larger number of units housed in current condominium developments. Although there is a need for densification, high levels of population can be intimidating and reduce the potential for social interaction. Generating clusters is a way to manage densities by grouping small numbers of units together to enable interaction to develop at a smaller scale. Furthermore, opportunities for social interaction can be increased with accommodations for a diversity of people. In addition, for interactions to occur between residents, they require the integration of a communal space, that can allow residents to gather. The design of units can facilitate the easy flow and movement of people out of their private units and into communal spaces, however transitions to communal spaces should be gradual. Lastly, communal spaces should be designed in response to people of all ages. Thus, this design principle -- the generation of clusters, is the first scale of interaction in the building aiming to create social interaction between residents at a manageable scale.

Second, the integration of communal spaces is intended to create opportunities for social interaction at the community scale where residents from the various clusters have the opportunity to engage with one another. This design principle was derived from an analysis of current condominium developments where amenity spaces are highly segregated from the units, as they are typically programmed in the podium or on the roof. In addition, programed spaces in the podium are also segregated from one another where various functions and groups of people are disenabled from 
contacting one another. For this reason, to allow for interactions between residents at the neighbourhood scale, is it is important that amenity spaces are directly integrated with the housing units to allow for proximity and visibility to these spaces. In addition, it is important that these communal spaces are concentrated together and are in response to (or appeal to) various age groups, so that they can function and support one another. This design principle, the Integration of Communal Spaces, is intended for all residents to partake in active and social environments together.

The third principle is circulation for providing choice and generating encounters. Often times, circulation is regarded simply as a functional design feature, minimally consisting of a corridor system that links units to and from elevator cores. In these spaces, opportunities for social interaction are greatly reduced. Yet, circulation systems have great potential to enable social interaction-by being placed centrally to connect all activity nodes (in this instance the clusters and communal spaces) enabling residents to flow easily from one space into another. Lastly, circulation networks requires a response to human behavior to allow for people to flow easily in and out of spaces, enabling choice in design were people have the option to by-pass spaces for social interaction. This principle. circulation to provide choice and generate encounters, is intended to both bring residents together from various parts of the building while also allowing for easy flows and connections between various spaces.

Lastly, the fourth principle requires a response to context. Often times, condominium podiums are developed to house big-box stores or often times house the private amenities for condominium residents. Yet, these responses neglect the history and character of a site and also poorly contribute to city at large. It is believed that each building is part of a greater network, the city, and as such the base of buildings should contribute to the surrounding context. The design of a residential building at grade introduces the opportunity for a third level of social interaction. This is the interaction between building residents and members of the larger community. Thus, a response to context requires opportunities to attract residents from the wider community. This can be articulated by creating a public podium that enables for crossovers, where the organization of programming in the podium is integrated so that these two groups of people (building residents and members of the community) have the opportunity to interact with one another by inhabiting the same space. This principle, the response to context, is intended to facilitate interactions at a third scale while contributing to the city through a response to site and by enabling opportunities for social interaction.

As such, architecture should focus on designing spaces that promote human health and well-being, as this response could contribute to overall sustainability of cities. Thus, this thesis will address the absence of accommodations for a wider range of families and respond to the human need for social interaction. Currently, the absence of these factors have created a monoculture in the downtown core that has further reduced contact between people. Therefore, through the generation of clusters, the integration of communal spaces, the design of circulation system to provide choice and generate encounters and with a response to context, in the design of a multistory residential building, this thesis will demonstrate how densification could become a viable option for a greater number of people, than could aid in the sustainable growth of the city. 



\section{| 2 | THE SIGNIFICANCE OF SOCIAL INTERACTION}

The purpose of this chapter is to identity the significance of social interaction to human health and well-being, and to emphasize that architecture should facilitate opportunities for encounter. Keith Bradley states, "sociologists and anthropologists confirm what most of us feel, that humans are inherently social beings and our happiness depends above all on the quality of our relationships with each other," (Bradley, 2008, p. 20). Having opportunities for social encounter can fulfill the human need for love and belonging: that was identified in the early 1900's by American psychologist, Abraham Maslow, as one of five basic human needs essential to psychological health and fulfillment in life (The Pursuit of Happiness, 2013).

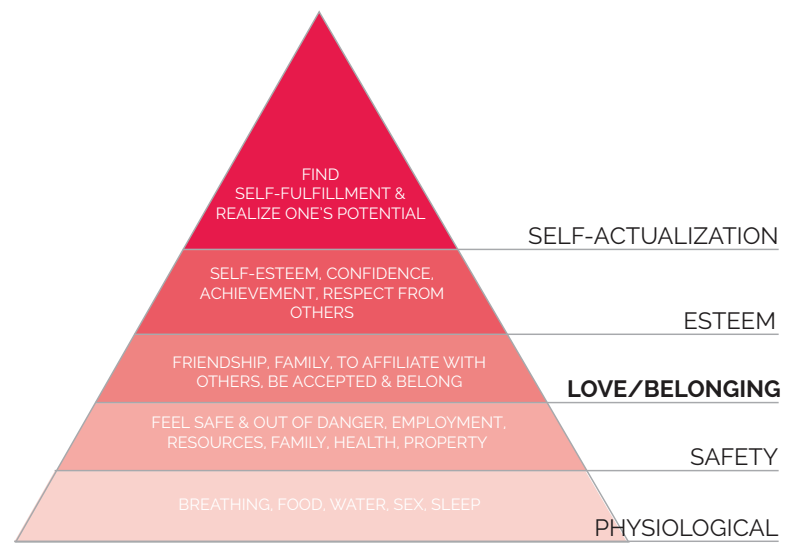

Figure 2: Abraham Maslow Hierarchy of Needs
Although Maslow's theory brought to light the significance of social interaction in people's lives, the organization of human needs in the "pyramid's" bottom-up organization implied that one human need was a prerequisite for another; thus suggesting that each need was to be fulfilled in that particular order and one at a time. However, according to Chilean economist and environmentalist Manfred Max-Neef, people should actively live out their needs on a daily basis; by being, having, doing, and interacting through; subsistence, protection, affection, understanding. participation, leisure, creation, identity, and freedom.

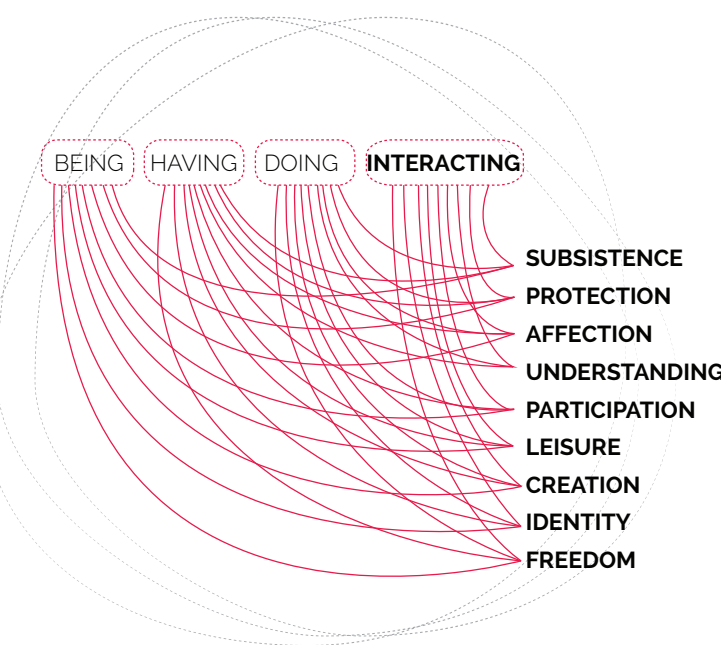

Figure 3: Manfred Max - Neef 
Further to this point, because people spend 90\% of their time indoors, the built environment can have immense effects on human health (Hancock. Built Environment, 2002). For this reason, opportunities for encounter should be present in the build environment. Research by Shaftoe, in his book "Convivial Urban Spaces" suggests that limited opportunities for encounter could be the reason why "people go mad when held in solitary confinement and why this is used as the cruelest form of punishment," (Shaftoe, 2008, p. 12). And as such, inadequate opportunities to engage with one another can negatively affect ones health.

To exemplify, with the increasing popularity of high - rise residential towers that rose out of the modernist movement, studies began to investigate the affects of the typology on individual's health and wellbeing, Firstly, in London in 1937, the "baby cage" was distributed as a solution for families who were short on space, and as an acknowledgment to difficulties for raising and housing babies and small children in crowded cities. The baby cage was intended to provide space for kids to play with access to fresh air. This response however increased the level of isolation, and reduced opportunities for encounter between mothers and children.

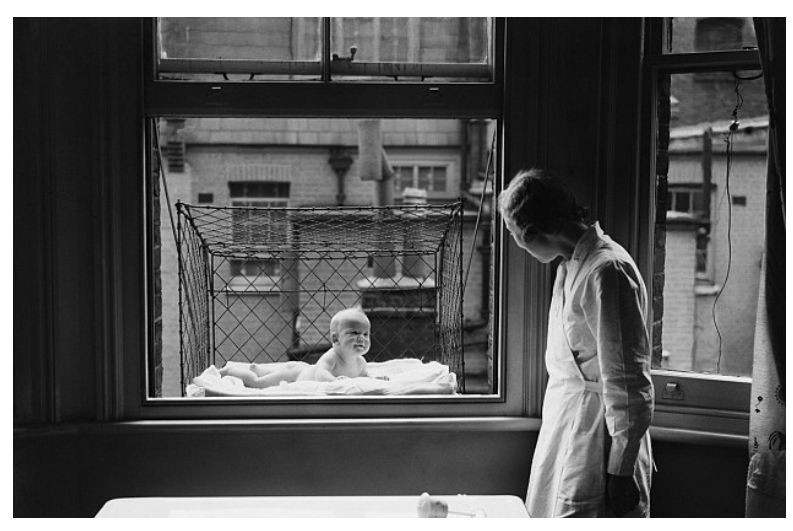

Figure 4: The "Baby Cage"
Later in the 70s, Christopher Alexander and Henry and Margaret Harlow conducted a study. which found that high-rises were associated with mental illness among adults and children. The study suggested the one of the factors to play a role in the cause of mental illness was associated with the large displacement of people from the ground plane that reduced access and contact between people. The second factor that was identified was that going out of ones residential unit became a formal experience rather than a casual informal one. This is because there were no opportunities for people to engage with one another right outside of their unit. In addition this research found that mental illness was greater among women and children. This was because it was more common for women to be stay at home moms and as such experienced greater isolation from human contact (Alexander, 1977, 342). In addition, the study also found that children who didn't play enough with other children during the first five years of their life. experienced some kind of mental illness later in their lives, or were "incapable of normal social, sexual, or play relations," (Alexander, 1977, 342). This study played a significant role because it highlighted the significance of interaction in relationship to mental health and wellbeing and its associated effect as a result of the built environment.

As such, this supports that human health and wellbeing is dependent on whether people have adequate possibilities to satisfy their fundamental human needs The concern with both of these situations is that people need access to other people, as they require contact whether direct or just being in the presence of others. Maslow indicated that, the "healthiest, happiest people tend to be more involved in their communities," and the "lack of interaction, human relationships, and a sense 

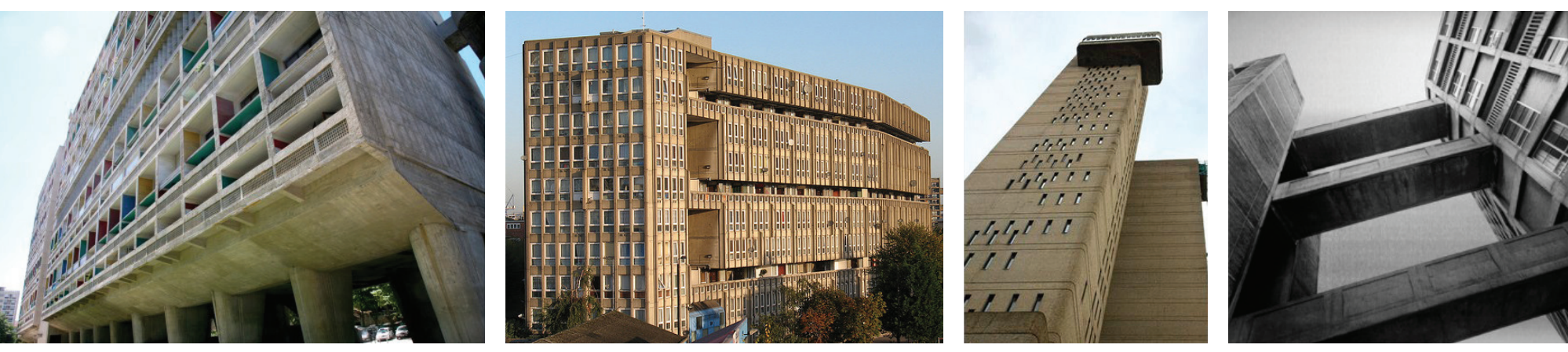

Figure 5: High-rise residential towers from the Modernist Movement - | Unite d'Habitation | Robin Hood Gardens | Trellick Tower | Park Hill |

of belonging may result in depression or loneliness" (1987. pp. 20-21). And although these situations were a concern in the past, scholars have also recognized it recently: "the lack of interaction and ability to engage in a community can be a serious determinant on a person's well-being" Bradley, 2008, pg. 20).

For this reason, it is presumably important that the built environment provide adequate opportunities for people to actively live out their human needs. Thus, it is important that architecture is realized as both a physical and social environment. Bradley supports that buildings should assist people to achieve their basic human need for interaction by providing individuals with opportunities to meet and converse (2008, pg. 28). This is important because the health of the individual can affect the overall health of a city. MaxNeef described that communities can be wealthier and happier if residents living within them were able to achieve their own needs, and were able to attain a level of well-being and happiness. An article published in Time News Feeds supports that "the more connected we are to family and community, the less likely we are to experience heart attacks, strokes, cancer, and depression. Connected people sleep better at night. They live longer. They consistently report being happier" (Pell, 2013). Thus, people's ability to live out their needs to interact and be connected can contribute to their health, and in turn the overall health of a city.

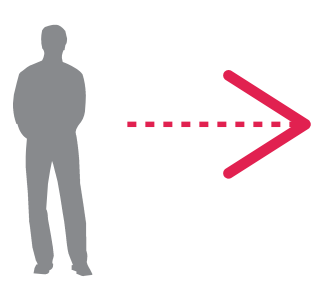

INDIVIDUAL

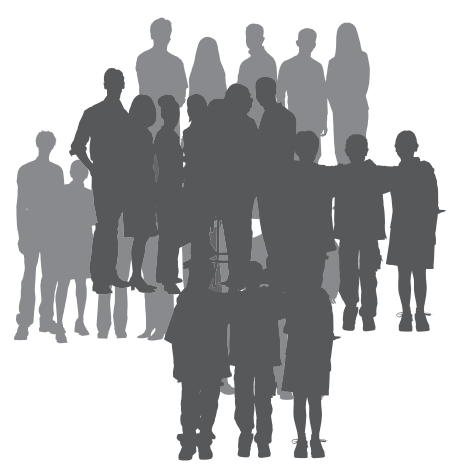

COMMUNITY
Figure 6: Health of individuals Impacts the health of communities and cities

Yet, despite the significance of social interaction that has been identified, many architectural responses do not start with people in mind or with a response to their need for social contact (Wallraff, 2012, 123). This is evident with the current approach to high-density development in cities. 



\section{| 3 | PAST \& PRESENT TRENDS}

\section{MIGRATION AT THE UNIVERSAL SCALE}

Around the world, cities are shifting their focus from low-density suburban developments towards high-density urban developments with the intention of growing sustainably. Over the years this has become a common trend; In 1990, 10\% of the world's population lived in urban cities, today this figure has grown dramatically to 50\%, and it is anticipated to grow further to $75 \%$ in the year 2050 (Burdett \& Rode, 2007. pg. 9).

This move to urban centers is partly due to the recognized sustainable benefits of densification, which include, increased walkability, and the preservation and efficient use of land. Firstly, densification can encourage residents to use public transportation by minimizing distances between locations of day-to-day activities and therefore increasing walkability in cities. In addition, densification also aids in the preservation of land needed for farming. As an increasing population also demands for an increase in the production of food. Maas, supports that, "the growth of the world population will lead to a tremendous demand for space, not only for buildings but also for farmland and areas reserved for nature" (2003. pg. 14). In addition densification can also help in the preservation of natural parks for recreation and activities. Lastly, it can also help to reduce costs for energy and infrastructure that would otherwise be needed to build new cities, as Robert Stern suggests "we don't need new cities; we need to reuse and make better use of our existing urban areas" (2003, pg. 21).

As such, many cities worldwide, including Moscow, Tel Aviv, Rotterdam, New York, and London have recognized the benefits of densification in their city centers. It has also become the focus in various areas and regions across the world from Asia to Europe and throughout North and South America as well as Africa.

\section{MIGRATION AT THE LOCAL SCALE}

Similarly, the migration to urban centers that has been recognized around the world have also been identified as an opportunity in Toronto. City planners and policy officials have recognized the potential for densification as a suitable option for growth through the construction of high-density developments (Scallan, 2012). This push is intended to enable people to benefit from the existing infrastructure and nearby amenities already in place (Greenberg, 2012). As such, Toronto has experienced a dramatic construction boom to accommodate increases in population growth naming it "North America's New- High Rise Metropolis" (Tencer. 2012). 
These high - density developments however, are changing the face of Toronto and also shaping the demographics across the GTA. This is because these developments are not affordable or attractive to the needs of families with children. This is because the condominium market has a narrow focus and they are mainly appealing to the demands of young professionals (the eco-boomers) who are moving into the city core as they desire close proximity to transit, amenities, and entertainment (O' Toole, 2013). As such, this influx of young professionals has resulted in 50,000 condominium units, which have been sold and built south of Bloor Street in 2000 and an additional 90,000 units, which were approved in 2011 (O' Toole, 2013). Yet, among these units only 518 of them have been designed as 3 bedroom units. This figures support that condominium developments are not built to support families with children

In addition, condominiums also do not meeting the demands of families. A articles published in the rises, these developments are unattractive to families with children "who see the lack of social-communal spaces and the distance between the flat and the street as a physical and psychological barrier" (Oldfield, 2013).

Thus, despite planner's efforts to intensify the core and mitigate sprawl, the development of condominiums across Toronto have contributed to the expansion of suburban cities. This is because once young professionals have families, condominiums no longer satisfy their needs. Some families still dream of the two-story house and garden and this "fuels the exodus of couples from apartment living to the suburbs when children arrive on the scene" (Oldfield, 2013).

Therefore, condominium developments are only appealing to a small demographic rather than contributing to long-term housing and densification of Toronto (Carras, 2013). And as such, these development patterns have created a monoculture in the city core. where young professionals and empty nester's occupy the city while families with children predominately reside in the suburbs.

Guardian indicated that despite the popularity of high-

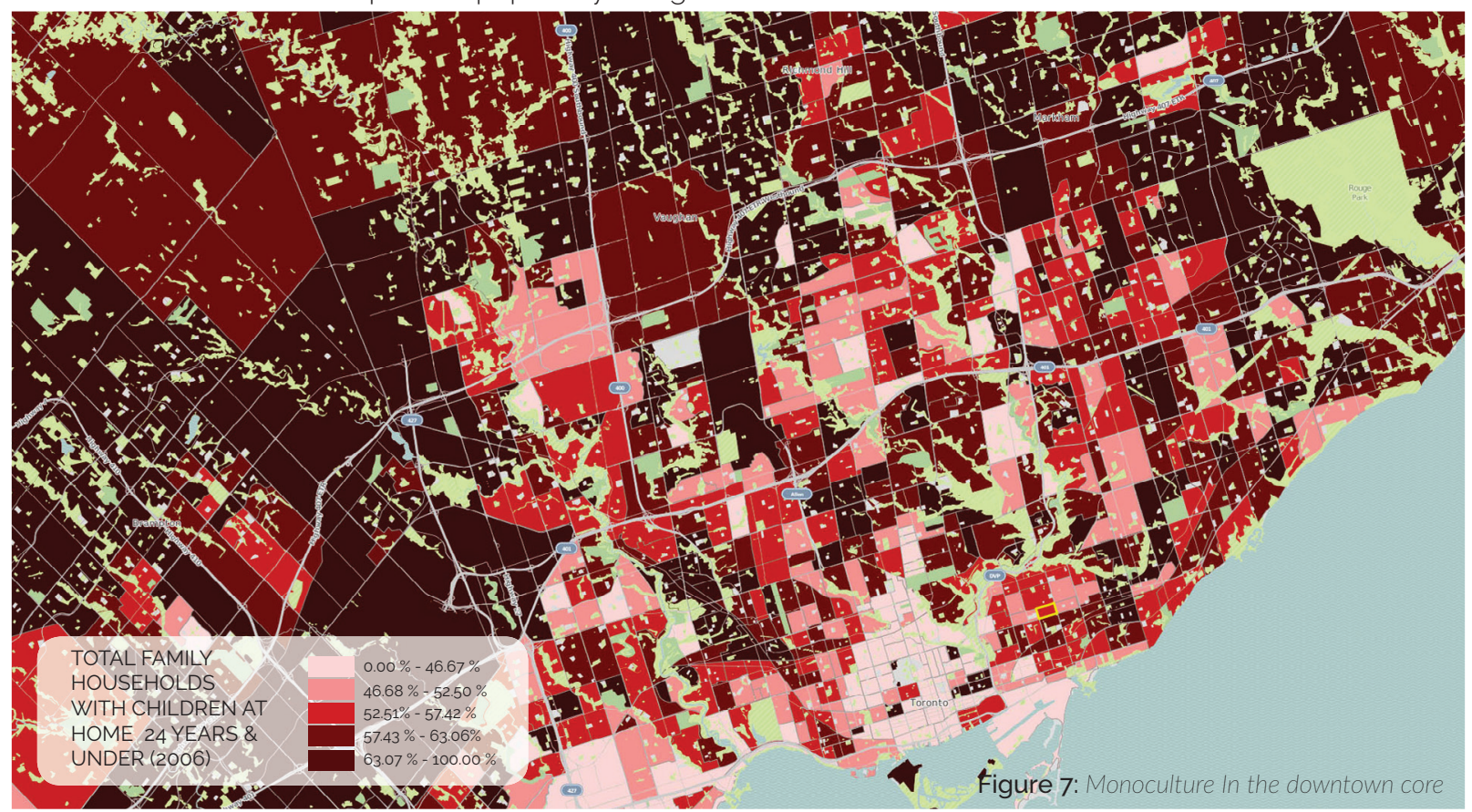




\section{DENSIFICATION TO ACCOMMODATE A DIVERSE DEMOGRAPHIC}

The current isolation of different segments of the population that have created a monoculture is troublesome because "no age in life is self- sufficient" as individuals require support from people at a different stage in life while at the same time, require the support of individuals of a similar age (Alexander 1977. p. 189). Yet, the problem is that there is a lack of variety in accommodation types in the city to allow for the integration of people of various ages. The lack of accommodations for a diverse family pushes families out to the suburbs,

Further to this, single family housing in the city has decreased significantly, families with children have limited options to remain in the city. This is because homes in the city are sold at a high value and are generating bidding wars. Census studies indicate that in recent years, the vast majority of new low-rise houses were constructed outside of the city, particularity in the Vaughan area ("Encouraging New and," 2007). In addition, few three-bedroom units are constructed in condominiums because the downtown market is driven by the demands of singles, young couples and empty nester's. Thus, accommodations to meet the needs of families in Toronto's downtown core are greatly limited.

In addition, between 2002-2007, an average of $3 \%$ of all condominium units were built with three bedroom units to accommodate families and only a fraction of that percentage, 1/5 were actually sold. The reason that many units with three bedrooms go unsold is because families with children give great consideration to community recreations, community participation, degree of access to amenity space in addition to cost, unit type, size, the number of bedrooms. Therefore, families have limited options for remaining in the Toronto's downtown core. Yet, the move to suburban cities increases commute time which takes time away from families as well as time from community engagement, "with less time spent commuting, more time is freed for socializing and the family - activities which are enjoyable in themselves but can also increase happiness through reinforcing community ties" (Blake \& Desai, 2008, p. 46).

In summary, it is important to provide for a variety of family types in the city core, as this increases the potential of interaction and community engagement, as people need the support of others. Furthermore, it is also important to provide for a variety of family types in the city to break the monotony in the downtown core and provide families with children the option to remain in the city

\section{DEVELOPERS EFFECT}

One of the reasons for this monoculture is a result of developers who are trying to maximize profit. This has been the case in a number of cities, throughout the years where economics triumph the needs of Individuals, and overlook the significance of social interaction. Currently, the race to accommodate the demands for a growing population has enabled developers control over the built environment. Yet, how will these affect the overall quality and livability of the city? In an essay written for "The State of Architecture at the Beginning of the 21st Century" Greg Pascarelli describes,

"today, many architects who are interested in shaping cities as well as buildings face a contradiction: on one hand, planned urbanism simply materializes the existing political apparatus, while on the other, architecture tends toward the 
market-driven production of fashion objects, removed from wider urban and social concerns" (Pasquarelli, 2003, p. 24).

In the past both Sweden and New York City lost valuable land and developments negatively contributed to the quality of life of residents due to developers control. And this is similarly occurring in Toronto today.

After WW2 there was a shortage of housing stock "in about the 1970s, when housing became decisive in Swedish politics, the country was building more housing per capita than any other country, and by the end of 1974, the government had fulfilled an earlier election promise, to build one million dwellings within ten years this successfully got rid of the housing shortage that was being experienced at the time (Egelius, 1990, p. 103). Yet, due to the rapid pace of these developments, many areas were poorly built and the social surroundings of these were insufficient and failed to reach the intended vision, (Egelius, 1990 , p. 103) Thus, rapid development, and lack of attention to social spaces lead to unsuccessful design, as many of the homes expressed poor living qualities and had to later be demolished.

Similarly, in New York in the 1960s, the city gave incentives for developers to add an additional 10 square feet of commercial space (an unprecedented amount) for each square foot of plaza that was provided at the base of the building for the publics use. By the 1970's, New York City ended up with 20 acres of plaza space, however, most of them went unused, as a result of poor design decisions which had little design consideration of peoples' needs. According to William Whyte, the city was taken advantage of by developers and should have demanded a greater design response to ensure that the public spaces provided be used and function for people and their needs (Whyte, 2000, pg. 249-250).

Currently, in Toronto, developers are taking advantage of the call for intensification by city officials (Carras, 2013). They are disregarding city plans for development, and do not follow height restrictions, and they are building condominiums too close together. causing shadows, and limiting views (Round 1 Public Consultation, 2013). These responses have simply been a way for developers to maximize profit, and as such, they are not contributing to residents well-being or the sustainability of the city.

Thus, the built environment should not exclusively be about generating a profit rather, it should be about the needs of people. The significance of well-being to the quality of life in a city can in turn affect economic success. Neef describes, "development is best when it is where the quality of life increases the most." (Neef, Human Needs Matrix, 2013). The way to improve wellbeing is to ensure that people have the "possibilities to adequately satisfy their fundamental human needs" (Neef, Human Needs Matrix, 2013) and this can be done by providing adequate spaces for congregation, where a sense of community can grow among neighbours. Similarly, Shaftoe agrees, "the success of good social policy should not be measured by economic gains but by improvements in wellbeing and happiness of citizens" (Shaftoe, 2008).

Although, the current approach to sustainable development in Toronto is not fulfilling its intended purpose to preserve land, densification should continue to be a focus for development, because it offers many sustainable benefits. However, to ensure that the City of Toronto grows sustainability, it is important that developments respond to people's needs for social interaction, and focus on providing 
variety in accommodations to sustain different family types. This response not only has the potential to respond to peoples need for social interaction but also has the potential to attract a greater variety of people such as families, who value opportunities for social engagement.

\section{ANALYSIS OF THE TYPOLOGIES}
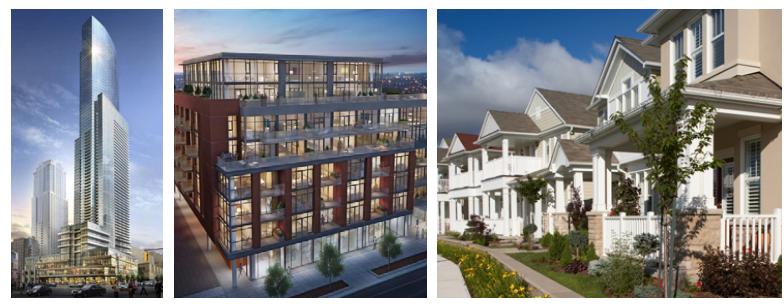

Figure 8: | High Rise | Mid-Rise | Low - Rise |

"On an exponentially urbanizing planet, the construction of new and sustainable cities is an urgent necessity, and we haven't risen to the challenge" (Sorkin, 2003, p. 23)

For the growth of sustainable cities, opportunities for social interaction should be provided as well as a response to the needs of people at different stages of life. Across the GTA the three typologies that are occupying the built environment include high-rise, mid-rise and the low-rise. These typologies have not only defined were various family types reside across the GTA creating the previously discussed monoculture, but in addition neither of them are providing sufficient opportunities for social interaction, and community engagement. Yet it is important to note that it was not the height of buildings or the housing typology that had a significant factor in determining the level of happiness on peoples experience that was the cause of isolation, but rather it was the quality of the physical environment, and lack of access to open space, and places to stop and chat that resulted in feelings of isolation (Toy \& Guite, 2008, p. 102). As such, despite the difference in appearances among the three typologies, they share many commonalities and lack sufficient opportunities for social interaction. These will be identified and discussed below.

\section{| A | LARGE NUMBERS OF PEOPLE}

Firstly, from high-rise to low-rise suburban homes, each typology is designed to hold an overwhelming number of people that are not organized together in any particular way. However, too many people can be intimidating and can result in withdrawal from social situations.

The new Aura condominium will accommodate 985 units distributed throughout 78 stories (Aura at College Park). These figures are not uncommon for high-rise condominiums in Toronto, for example the $L$ Tower accommodates 600 units in 58 stories ( $L$ Tower), while 101 Erskine a 35-story condominium houses 421 units (101 Erskine Condos). This is similarly the case with mid-rise developments, for examples a development; Victory Condos will house 179 units (Victory Condo). These figures are strikingly high, decreasing opportunities for conversations to occur between residents.

As a result of these figures many residents in high-density developments do not know who their neighbors are because people have limited opportunities to encounter the same people. This reduces the possibility of a relationship to be formed and as such encounters become formal. These are often minimal and limited to elevators, mail-rooms. and corridors; people do not see each other often enough to develop a relationship. This is similarly the case in suburban developments. At times people know their adjacent neighbours, but because there 
are limited places to stop and talk community ties are not formed. Furthermore, because these communities are car bound, people rarely walk in them. However, despite these common characteristics among these typologies it is important to reduce the impact of large numbers of people in design.

\section{B | SEPARATION OF USES/FAR DISTANCES TO COMMUNAL SPACES}

Secondly, communal spaces are placed far away from units and as such lack immediate access and more importantly visibility to these spaces. This reduces the possibility of informal and spontaneous use, "in high rises with social spaces, the connection to these spaces is not visible, so people hardly use them" (Cheng, 2012, p. 274). This is because the distance can be bothersome to many, and can limit people from using communal amenity spaces. The ability to see people can increase the use of a space, because what attracts people most is other people (Whyte, 2000, p. 256).

Similarly, this is the case with low-rise typologies where parks and communal spaces are far away from houses. Only houses that are adjacent to these parks and open spaces benefit from this proximity, while people who are further away have a disadvantage.

Thus, to encourage contact and provide all
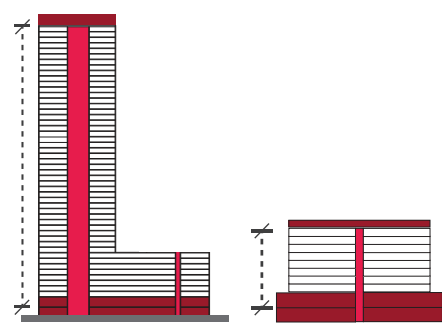

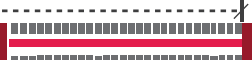

Figure 9: | High-Rise | Mid-Rise | Low - Rise | Large separation between housing units and communal spaces residents with equal opportunities for community engagement it is important that amenity spaces are integrated with residential units to allow for equal access and visibility.

\section{C | HIGH SPEED CIRCULATION SYSTEMS}

Third, opportunities for interaction in circulation systems are limited, brief and infrequent. Circulation systems are designed to minimum code requirements, and are simply pass through spaces. These spaces do not provide opportunities to converse with neighbours, and as such conversations are brief and happen only in passing.

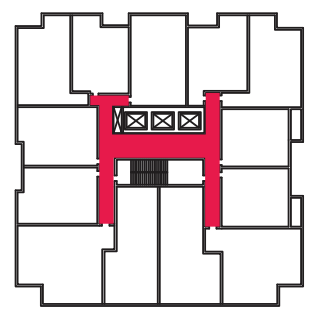

Figure 10: High - Rise condominium floor plan highlights corridor space

This is similarly the case with mid-rise developments, the difference rather is that units are organized along an elongated corridor.

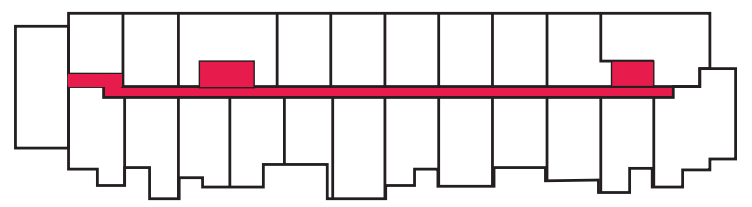

Figure 11: Mid - Rise condominium floor plan highlights corridor space

In addition, elevators are used to transport people to amenity spaces. Yet, conversations in these spaces are forced, and infrequent. As such, it is difficult for people to develop relationships and know who their neighbours are, in the span of short elevator ride. 


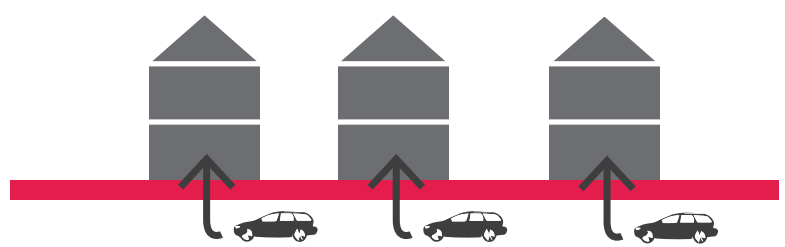

Figure 12: Low-Rise Suburban Homes - Private car - Private house

Similarly, in the case of the low-rise developments where people get into their private car, in their private garage and drive off, opportunities for encounter are greatly reduced.

\section{| D | LACK OF RESPONSE TO CONTEXT}

Lastly, all three typologies lack a response to context and greatly reduce opportunities for interaction between building residents and members of the greater community.

Condominiums either house big box stores, or private amenities for condo residents. These approaches to not respond to the context or the needs of the surrounding community.
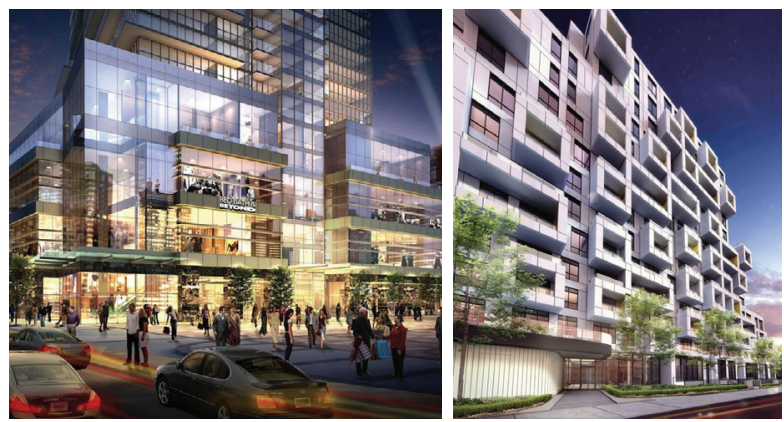

Figure 13: Images depict the lack of response to context, as the podium either houses big box stores, or private amenities.

In summary, through an analysis of these typologies it is evident that many of their characteristics inhibit the opportunity for interaction, and are not providing people with adequate opportunities for encounter. Thus, it is evident that these typologies are not contributing to the health and sustainable growth of cities. However, densification should become a viable option for the sustainable growth. In order to accomplish this goal, densification should focus on accommodating people in various stages of their life and in particular families with children as the predominate typologies in the city do not respond to their needs.

As such, this thesis will focus on designing to create the opportunity for increased informal encounters, which are limited by the characteristics of the typologies previously discussed. Therefore, the design of this thesis project challenges the current development of condominiums and poses the question for how a multistory residential building can be designed to foster social interactions to generate a neighbourhood by providing variety in housing accommodations to allow for a diverse demographic to reside in the city 



\section{| 4 | PROPOSING A SOLUTION}

\section{A VERTICAL NEIGHBOURHOOD TO FOSTER SOCIAL INTERACTION}

The absence of a variety of accommodations as well insufficient opportunities for community engagement and congregation have created a monoculture in Toronto's downtown core. However, for the sustainable growth and development of the city, densification should become a viable option for a greater number of people. For this to happen it requires both: greater variety among units as well as spaces that promote social interaction among neighbours.

This thesis will demonstrate how a multi-story residential building can be designed to foster social interaction to generate a neighborhood that provides variety in housing to enable for a diverse demographic to reside in the city while creating opportunities for social interaction. This will be done by applying principles and strategies that have been derived from both past and present precedents, which have made attempts to create encounters between neighbours as well as theories and observations of human behaviour that were derived from scholars and architects on how to successfully create social spaces for interaction.

Further to this, Alejandro Zaera-Polo, in an essay entitled, "Breeding Architecture" states that architects should step away from the typology with which they are designing and just design so that people benefit from the architecture,

"avoid resorting to typology as a device or tool to produce architecture, but rather a catalyst for architectural experimentation and development of new urban models, especially if we conceive of types as objects for manipulation and adjustment rather than for imitation" - (2003, pg. 56).

Thus, the design for this thesis project challenges the current development of condominiums in the city and as such, uses the mid-rise typology as a point of departure for the experimentation and insertion of social spaces. The design of this thesis project focuses on creating a vertical neighbourhood within the City of Toronto that is defined by a composition of parts which include: the generation of clusters, the integration of communal spaces, circulation to provide choice and generate encounters and a response to context. Furthermore, this thesis uses the above principles in combination with strategies for visibility, response to human behavior, response to demographics, and designing spaces to create a vertical neighbourhood for fostering social interactions. 


\section{PRINCIPLES}

Four principles were identified to demonstrate how to make densification a valid option for a greater number of people. These include: the generation of clusters, the integration of communal spaces, circulation to provide choice and generate encounters and lastly a response to context. Furthermore, this study seeks to improve opportunities for interaction at three distinct scales. These include: interaction between immediate neighours, interaction between all residents in the neighbourhood, and lastly, interaction between residents and members of the greater community.

\section{| 1| GENERATING CLUSTER}

\section{angan 口n⿴囗十 口n⿴囗十 घanna}

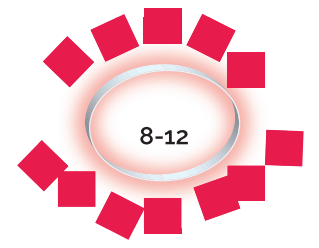

Figure 14: Current Condition vs. Proposed Condition

The first scale of interaction, the generation of clusters seeks to create opportunities for interaction between immediate neighbours. This response is intended to alleviate the intimidating affects of large numbers of people in high-density developments.

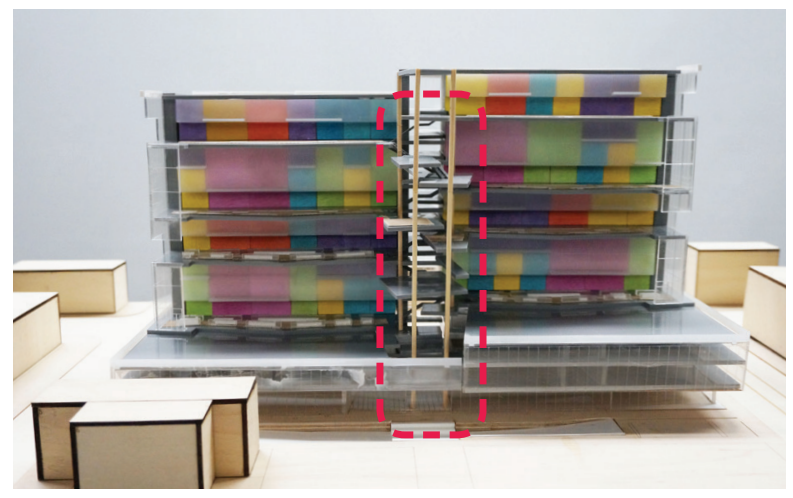

Figure 15: First Scale of Interaction - Clusters
| 2 | INTEGRATION OF COMMUNAL SPACES

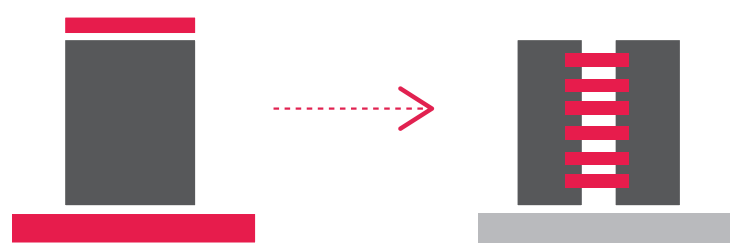

Figure 16: Current Condition vs. Proposed Condition

The second principle responds to the segregation of units and communal spaces. These spaces are typically programmed to the roof or podium of a building. This approach decreases visibility and as a result, the use of these spaces. This principle seeks to integrate communal spaces with housing units in an attempt to increase their use and create opportunities for all building residents to interact.

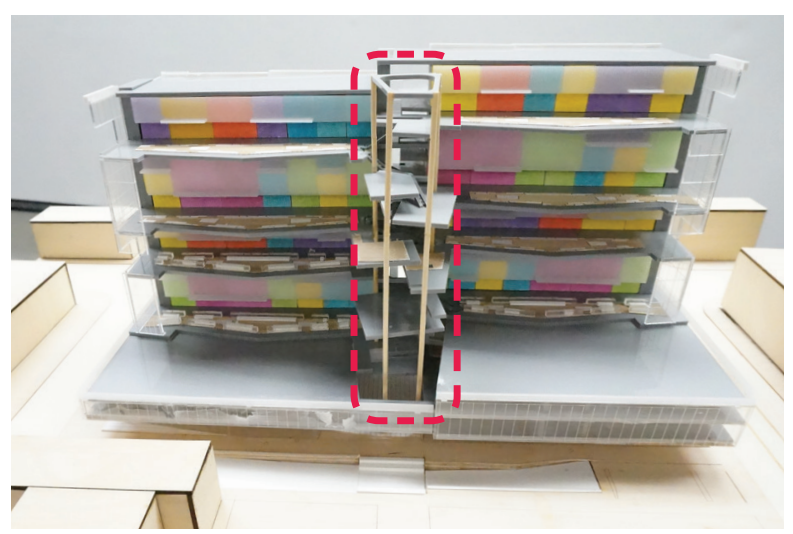

Figure 17: Second Scale of Interaction - Communal Spaces

\section{| 3 | CIRCULATION TO PROVIDE CHOICE \&}

\section{GENERATE ENCOUNTERS}
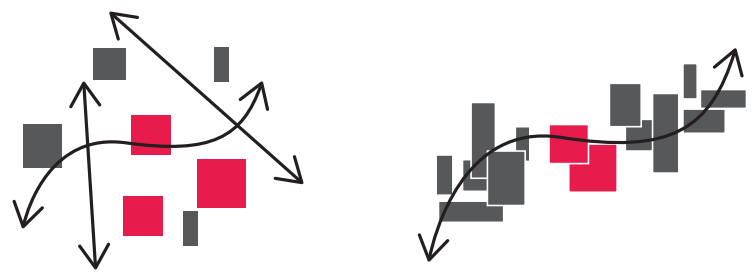

Figure 18: Current Condition vs. Proposed Condition 
Interaction in current circulation systems is limited, brief and infrequent. However, circulation systems can encourage interaction between residents by linking different functions and groups of people. Furthermore, it can provide people with the choice to avoid unwanted situations. This principle works to connect the various programming in the building to respond to human behaviour and generate opportunities for social interaction.

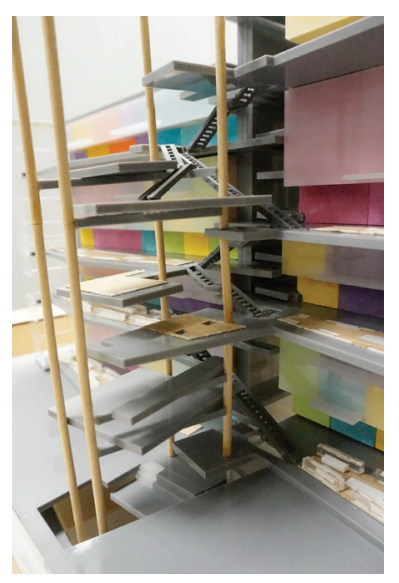

Figure 19: Circulation system linking clusters \& communal spaces

\section{| 4 | RESPONSE TO CONTEXT}
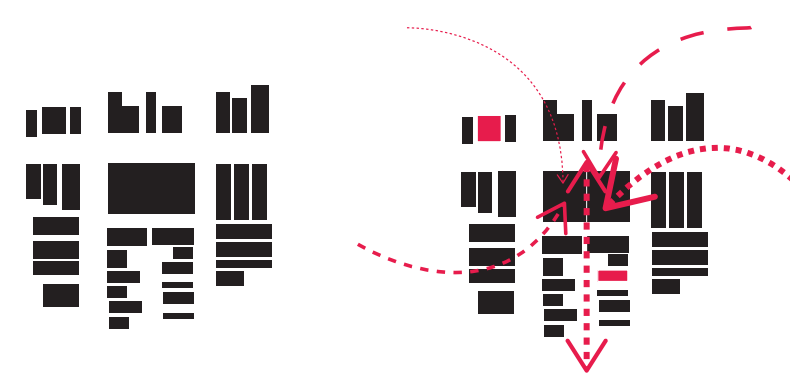

Figure 20: Current Condition vs. Proposed Condition

Lastly, the fourth principle responds to the insufficient consideration to context in current condominium designs, which greatly reduces opportunities for interaction between building residents and members of the community. As such, this principle aims to create a public podium that supports both the needs of residents and the community. It will do so by integrating different functions to work together and by creating opportunities for interaction between building residents and city residents, while also maintaining the role of the site within the community.

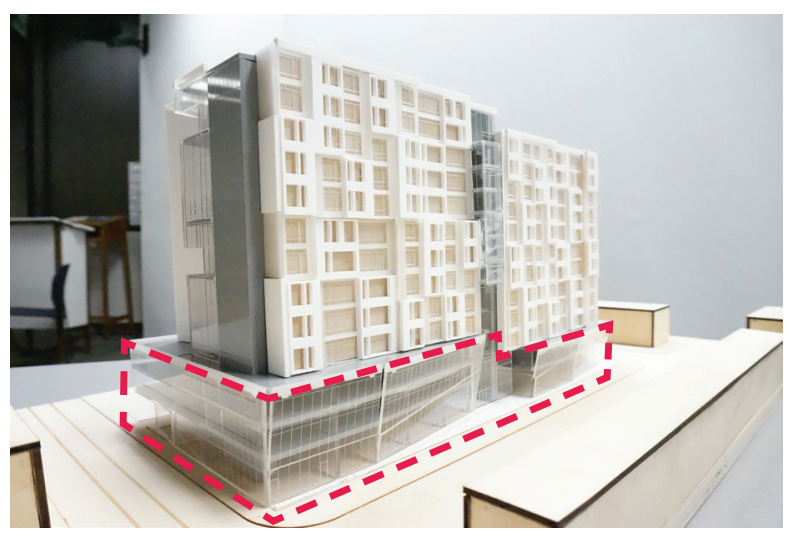

Figure 21: Third scale of interaction - Podium

\section{STRATEGIES AND TACTICS FOR ENCOURAGING SOCIAL INTERACTION}

William Whyte stated, "what attracts people most, it would appear, is other people" (Whyte, 2000. p. 256). Whyte stressed this point as he felt that urban spaces were designed as though people did not enjoy being in the company of others. Although, people did claim in questionnaires that they enjoyed getting away from busy zones and preferred to "escape" and find an "oasis" (Whyte, 2000, p. 256), when they were in social situations people gravitated toward one another. Further to this, Whyte observed that people in social settings did not move out of pedestrian flows when they had conversations, rather at times they even gravitated into them, "a great bulk of conversations were smack in the center of the flow" (Whyte, 2000, p. 256). Similarly people also enjoyed sitting, and picnicking in close proximity to other individuals. 
Similar to the findings of William Whyte, Jan Gehl in his famous transformation of the Stroget in Copenhagen made incremental changes and observed how people behaved to those changes.

"When the city added new benches, Gehl counted the people who came and sat down. Those benches told a story. A bench facing the passing crowds got 10 times as much use as a bench that faced a flowerbed. More people gathered on the edges of construction sites than in front of department store display windows. As soon as the construction crews went home, the audience dispersed " (Montgomery, 2013).

Analysis in the way that people use space is critical to design. This is because physical qualities can promote contact or cause isolation, and more importantly these considerations to design ensure that the spaces respond and contribute to peoples' preferences and behavior patterns. Strategies that promote contact between people can be applied to a number of typologies, and in a variety of contexts. These strategies are common throughout this thesis and are applicable to the principles that are identified and used to create a multi-story residential building. These are used to foster social interaction and generate a neighborhood that provides variety in housing and enables for a diverse demographic to reside in the city. The strategies identified to promote interaction for the purposes of this thesis will be discussed below.

\section{| A | VISIBILITY}

People's ability to see other people as discussed above from the observations of Jan Gehl and William Whyte can attract other individuals to a space and invite them to partake in a particular situation. This has been proven in an experiment that was conducted in the 1960 s by Richard Held and Alan Hein. They proved that people could only do (preform) an action based on what the see (perceive) - as such, if people don't see, they won't do; this is because the two are inseparable. The experiment that they conducted involved two kittens that were raised in a carousel. One was able to walk while pulling the other, which was suspended in a gondola. The free cat was able to link the act of walking to its own perceptions, because the development of the brain tissues connected the actions and perceptions as they are "integrated into a coherent neurological system" (Spuybroek, 2003, p 102). For the other cat however, action and vision were separate and after it was removed from the gondola. the suspended kitten was unable to behave normally it stumbled and bumped into objects, as it could not co-ordinate its movements with what it saw. This was because its "experience, action and perception had never existed in the same continuum" (Spuybroek. 2003. p. 103). This experiment proved that the two faculties were inseparable, "perception relied on action and action was only possible through perception" (Spuybroek, 2003, p. 103).

Thus, the relationship between being able to see and the desire to participate are closely linked

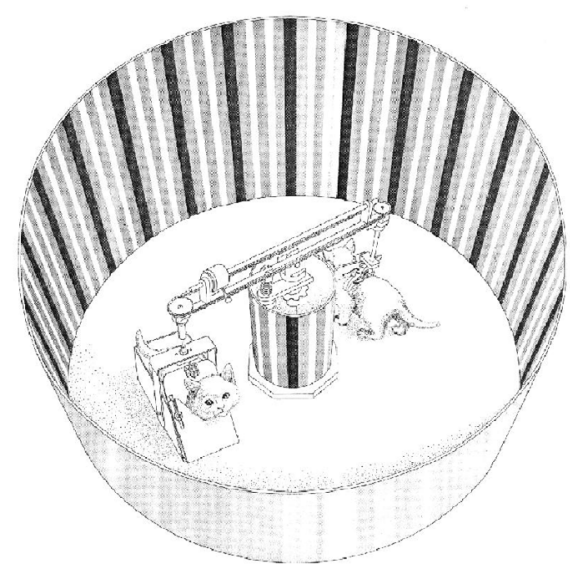

Figure 22: Held \& Hein Experiment 
as previously identified with the kitten experiment. Gehl also supported this notion in that. "being able to see what is going on in a public space can also be an element of invitation" children who can see the street or playground from their homes are often more motivated to go out and play while children who cannot see because they are either too far away or live too high up are less inclined to participate (Gehl, 2011, p. 113).

In response to the aforementioned findings, a number of tactics have been identified to allow for full visibility, these include: face-to-face orientation, designing to enable short distances, creating spaces that encourage people to travel at low speeds, and creating seating along edges to enable people a full range of vision (Gehl, 2011, p. 62).

\section{| A.1 | FACE TO FACE ORIENTATION}

People's senses are predominantly frontally oriented, and see best when things are directly in front of them "the sense of sight, is distinctly horizontal" (Gehl, 2011, p. 63). As such, spaces should be designed and oriented to face each other to encourage interaction and activate spaces.

\section{| A.2 | SHORT DISTANCES}

People in closer proximity to one another are more likely to interact and furthermore, use spaces that are closer to them than ones that are located further away
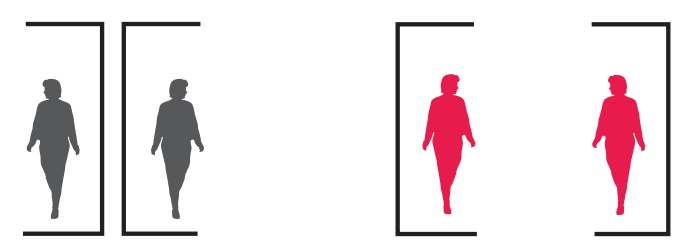

Figure 23.a: Back-to-back orientation vs. Face-to -face orientation

\section{| A.3 | LOW SPEEDS}

The integration of stairs can slow people down and enable them to take in details and see and process the spaces and people around them. If people are moving too fast there is no time for them to process meaningful information. Gehl asserts that it is only when people slow down, and analyze details, that meaningful contact has the opportunity to take place (Gehl, 2011, p. 72).

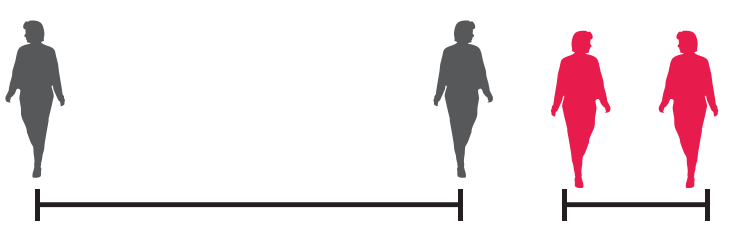

Figure 23.b: Long distances vs. Short distances

\section{| A.3 | LOW SPEEDS}

The integration of stairs can slow people down and enable them to take in details and see and process the spaces and people around them. If people are moving too fast there is no time for them to process meaningful information. Gehl asserts that it is only when people slow down, and analyze details, that meaningful contact has the opportunity to take place (2011, p. 72).
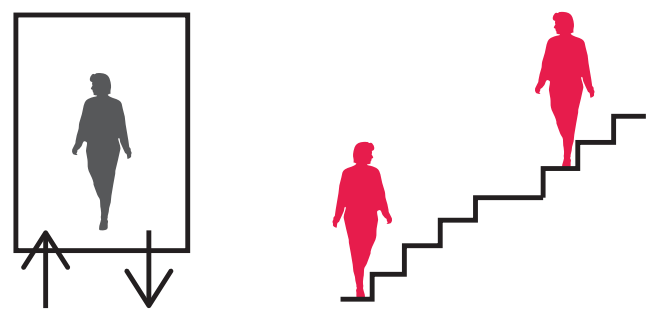

Figure 23.c: Elevator vs. stairs

\section{| A.4 | OCCUPYING EDGES \& SITTING NEXT TO} OBJECTS

People often choose to sit at the edge of space where they have access to see a full range of activities. In addition, they also have an inclination to station 
themselves near objects as they often prefer welldefined places and rarely prefer to stop in the middle of an open space (Whyte, 2000, p. 256). As such, to better ensure that people use spaces allocated to them it is important that they are designed in response to these parameters.
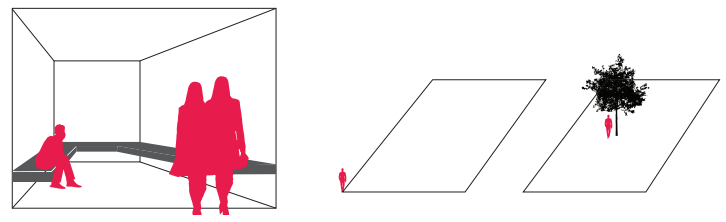

Figure 23.d: Seating at edges \& Standing next to objects

\section{| B | RESPONSE TO HUMAN BEHAVIOUR}

People's decisions and behavior are influenced by social, biological and environmental factors. Social factors influencing behavior derive from peoples "unique cultural, religious, social, and personal experiences" while biological factors derive from peoples "brains and bodies as part of the natural process of moving from one environment to another" (Kopec, 2006. p. 9). However, architects often design with the presumption that the physical is all that affects behavior, although this may be the case with some developments such as casinos, cruise ships, or churches; it is not the case with all designs (Kopec, 2006. p. 9).

\section{| B.1 | PROVIDING CHOICES}

The role of the architect should be to provide people with choice and enable them to avoid undesirable situations. This can be achieved by

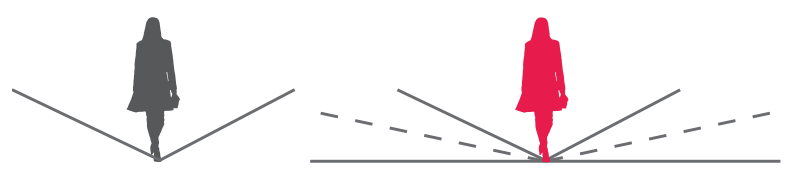

Figure 24: No choice vs. Choice designing to enable easy flows in and out of spaces, and designing to allow for moments of pause so that people have the option to observe a situation and consciously decide if they want to engage in a particular activity or not

\section{| B.2 | SCALES OF INTERACTION}

People do not always like to partake in large group activities -- at times they prefer imitate ones. Therefore, it is important that communal spaces are designed to allow for different scales of interaction. These can be achieved by using distances as a means to control and regulate intimacy and intensity in social situations (Gehl, 2011, p. 67). Gehl specifies that there are distances that define intimate relationships (o to 45 centimeters), personal distances (45 to 130 centimeters) for conversations between close friends. social distances (1.3 to 3.75 meters) for ordinary conversations and lastly public distances (3.75 meters) which are used for more formal situations (Gehl, 2011. p. 69). A such, design can use these parameters to create for varying scales of interaction.
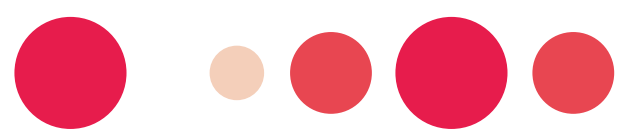

Figure 25: One large space vs. Scales of interaction

\section{| B.3 | PROVIDING TRANSITIONAL SPACES}

Currently, in high-density developments there is an absence of transition between private units and public corridors. At high densities, people often feel a lack of control over their social environment and they are likely to withdraw from social spaces (Williams, 2005. p. 198). The absence of transition spaces also reduces the opportunity for informal encounters and activities. However, by introducing a buffer space such 
as a semi-private space, it can "increase the threshold between neighbours", as it can create a "protective layer and provide a degree of privacy and territorial control with options for active contact into adjacent public space" (Williams, 2005, p. 198).
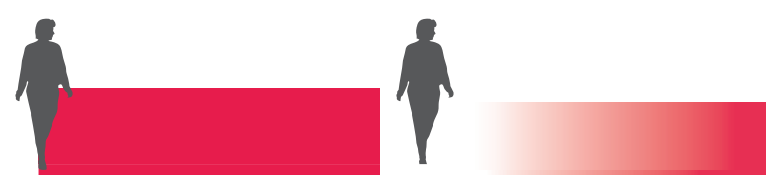

Figure 26: No transition vs. Transition through space

\section{C | RESPONSE TO DEMOGRAPHICS}

An understanding of people at different ages can provide a design response suitable for a greater number of people. Children up to the age of two enjoy playing and spending time with their parents. Whereas children ages 3 to 7, are much more interested in playing with kids their age (Scott, 2010, p. 23). They also enjoy running, playing, hiding and engaging in cognitive activities. Ages 8-14 and 15-18 require that spaces are easily accessible and easy to move into. Furthermore. ages of 15-18 at times enjoy being separate from adults. They also enjoying engaging in cognitive study and discussion.

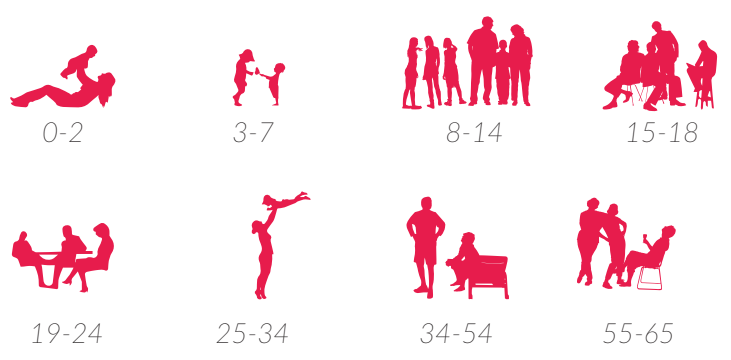

Figure 27: Response to demographics

People at the age of 19 - 24, enjoy spending time with people their own age as well as older adults. They enjoy playing games and engaging in cognitive study. In addition ages 25-34 enjoy spending time with their children. And the later ages, of 34 to 65 prefer time with other adults. It is important to have an understanding of the types of activities that people at different ages enjoy to take part in and the ages with which they like to engage as this analysis can help to define the organization of spaces in relationship to one another.

\section{| D | DESIGNING LIVABLE SPACES}

Green spaces have the ability to promote social relationships, which are key to personal and communal well-being. Groupings of trees planted in and around high density residential spaces can attract more people and can encourage social interaction. The reason that people prefer to have vegetation around them is because they offer a visual stimuli and relief from heat, glare and noise. Lastly, greenery has been shown to reduce stress levels and to facilitate attention restoration (Kopec, 2006, p. 5).
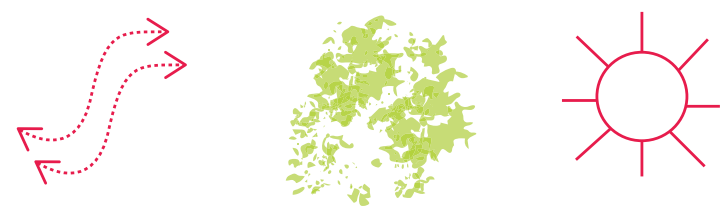

Figure 28: Cross ventilation, vegetation and daylight

In summary, these strategies for creating visibility, responding to human behavior, responding to demographics, and designing livable spaces and the subsequent tactics can facilitate opportunities for social interaction. Throughout this thesis, these strategies will be used to identify the shortcomings of precedents both past and present which similarly attempted to generate social relationships between neighbours. Furthermore, these strategies will be used in combination with the aforementioned principles in the design of this thesis project for creating a vertical neighborhood for fostering social interactions. 



\section{| 5 | GENERATING CLUSTERS}

This chapter begins by identifying the theoretical issues with current forms of development that impinge on opportunities for social interaction in highdensity developments. It will proceed to discuss the opportunity for and significance of managing large population numbers through the generation of housing clusters. It will do this by analyzing past and present precedents that focused on creating encounters between neighbours. These precedents will be compared to the strategies and tactics that have been identified for encouraging social interaction (in chapter 5). as well as additional theoretical research for how to successfully contribute to creating opportunities for social encounters. Finally, from the lessons learned through this analysis, the design of this thesis project will demonstrate how each theoretical issue was addressed in order to create clusters to encourage interaction.

\section{THEORETICAL ANALYSIS \& DESIGN RESPONSE}

This section argues that high densities can greatly reduce opportunities for interaction among residents. Despite the fact that people are physically closer than they have ever been, they have never been further apart socially (Cheng, 2012, p. 274). People in high-rises do not talk to each other, they don't communicate There are multiple reasons for this. Firstly, there are too many people living in these developments and this decreases the frequency of opportunities for encounter. Encounter is limited to mailrooms and elevators. Yet conversations in these spaces are brief and formal and do not allow people to develop meaningful relationships with their neighbours. In addition, the presence of too many people has been proven to contribute to people's withdrawal from social situations. William notes that, "at extremely high densities residents feel that they have less control over their social environment and are inclined to withdraw from the communal which they feel is invasive and beyond their control" (2005. p. 198). To enable relationships between residents, opportunities for encounter should be frequent and the impact of large densities should be managed to allow people to feel that they have control over their environment to enable them to interact

\section{| 5.1 | MANGING DENSITY THROUGH CLUSTER DESIGN}

Throughout the years, there have been architects interested in designing spaces to encourage interaction and to create social spaces for congregation at height. 
These came out of Modernist Movement, in particular with two design concepts "City Within a City" and "Streets in the Sky." Le Corbusier's "City Within a City" concept was conceived in his 1952 design of the Unite D' Habitation. The project was designed to accommodate an unpredicted demand for housing following World War II (Sherwood, 1981, p. 120). The building featured double-orientation open-ended units, organized along a double loaded corridor system, every third floor. These corridors were lined with approximately 29 units on each side. This created a harsh condition, as there was no access to fresh air or day-light. The condition in the corridor was unwelcoming and is believed to have contributed to isolation among the buildings inhabitants to their individual units. As such, amenities spaces in the building weren't necessarily used and eventually had to close.

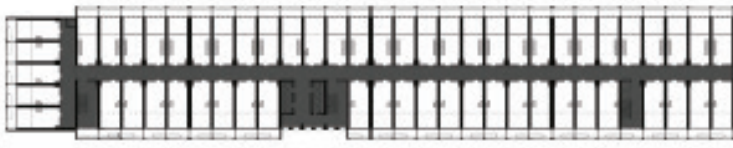

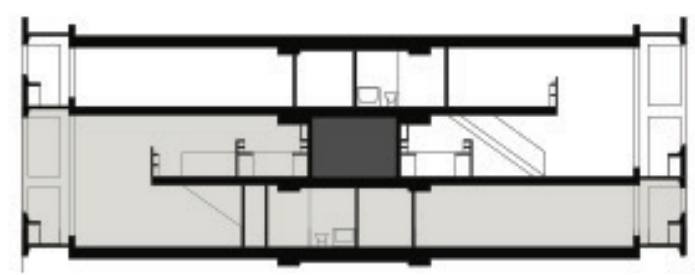

Figure 29: Unite D'Habitation - double loaded corridor system

Following Le Corbusier idea for "City Within a City", Peter and Alison Smithson conceptualized the concept of "Streets in the Sky". This concept was realized in the design of Robin Hood Gardens, a social housing complex. The Smithson's intended to design a building, which would "encourage residents to feel a sense of belonging and neighborliness" (Alison + Peter Smithson). This was done by introducing a "Street in the Sky" every third storey, and unlike Le Corbusier's design, the Smithson's opened their corridor to the outside. However, despite this attempt to create an inviting environment and encourage neighbours to interact, the design of the "Street in the Sky" was simply a single loaded corridor with no places to stop; it too was just a place to pass through.

The management and organization of units into manageable groupings is essential to high-density developments. Le Corbusier's, Unite d'Habitation contained a total of 337 units and the Smithson' s Robin Hood Gardens, held 213; yet in both designs, units were distributed along elongated corridors. This design feature resulted in decreased visibility, which further reduced opportunities for contact due to the long distances created by the corridor spaces.

To put it simply, high densities could be managed through the design of clusters, consisting of small organizations of units. This would create the opportunity for frequency of encounters. The organization of people into smaller groups can increase the potential for interaction and decrease the possibility of withdrawal from social situations.

Christopher Alexander identified the opportunity for generating clusters. His study suggested that an organization of $8-12$ units would allow for one representative from each family to sit comfortably face to face and talk with one another directly. Alexander determined that 8-12 units was an appropriate number of people to allow residents to make decisions as a community (Alexander. A Pattern Language, 1977. p. 200). He also determined that more than 12 homes forming a cluster would make communication more difficult. Although the work of Alexander is dated, having been published in 1977, his concept for the organization of smaller groups of people offers great 
potential to make social interaction manageable. which could lessen the impact of density that often lead to social withdrawal.

Suburban developments exemplify this concept that occurs naturally as a result of proximity where people know their immediate neighbours surrounding them. When asked who they most visited, "91\% said they visited the people immediately across the street or next door," Alexander stated "the beauty of this finding is its indication of the strength of the spatial cluster to draw people together into neighbourly contact" (1977. p. 199). Although, in the case of current suburban developments, neighbours may not interact, people do know their neighbours, which are in closest proximity to them. The use of clustering is also used in co-housing design, where houses are organized into smaller groupings to allow for the informal interactions between neighbours in close proximity, (Williams, 2005, p. 215)

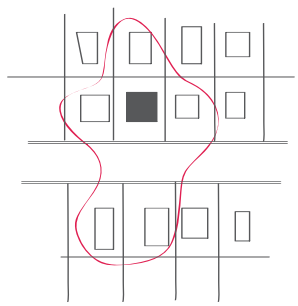

Figure 30: Christopher Alexander natural clustering

\section{| 5.1.2 | DESIGN RESPONSE - Manging Density} Through Cluster Design

The design of this thesis project began with the clustering of units to manage densities. Clusters were designed to hold 12 units, which is the upper limit defined by Christopher Alexander as previously discussed. The design began by creating clusters with a typical mid-rise typology as a point of departure. Units were renumbered to create two distinct clusters side by side.

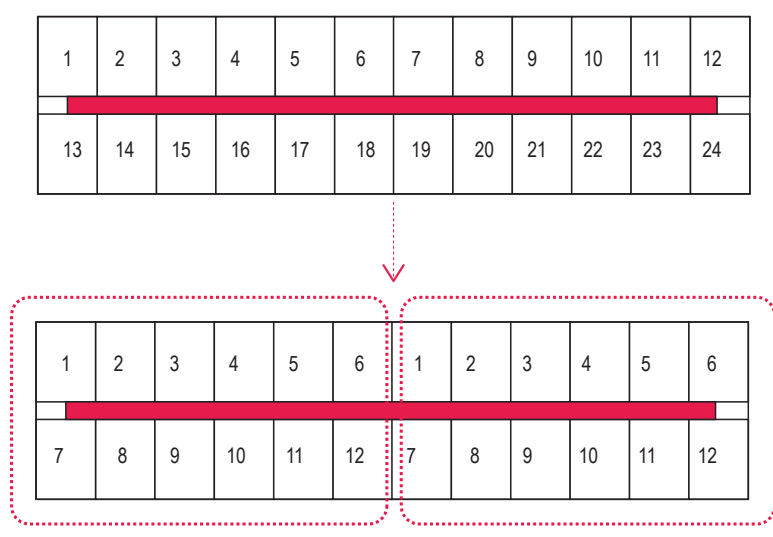

Figure 31: Reorganizing a typical mid-rise to create clusters

\section{| 5.2 | DIVERSITY AMONG UNITS FOR INCREASED INTERACTION}

Furthermore, to create opportunity for interaction between neighbours, high-density developments need to accommodate a wider demographic. Creating diversity among units can make densification a suitable option for a larger demographic while also increasing the potential for social interaction. Research describes that in co-housing communities, where there was a variety of people living within clusters, there was an increase in communication and connection between residents. This is because no one group is selfsufficient, people need support and confirmation from other people (Alexander, A Pattern Language, 1977. p. 197). Therefore, creating housing clusters with a mix of people can promote social interaction.

\section{| 5.2.2 | DESIGN RESPONSE - Diversity Among Units}

In response to the theoretical issues discussed above in regards to a need for diversity among residents, 14 different housing types were designed to create diversity among demographics to further increase the potential for interaction among residents. Units have between 1 to 4 bedrooms and 1 to 3 stories 


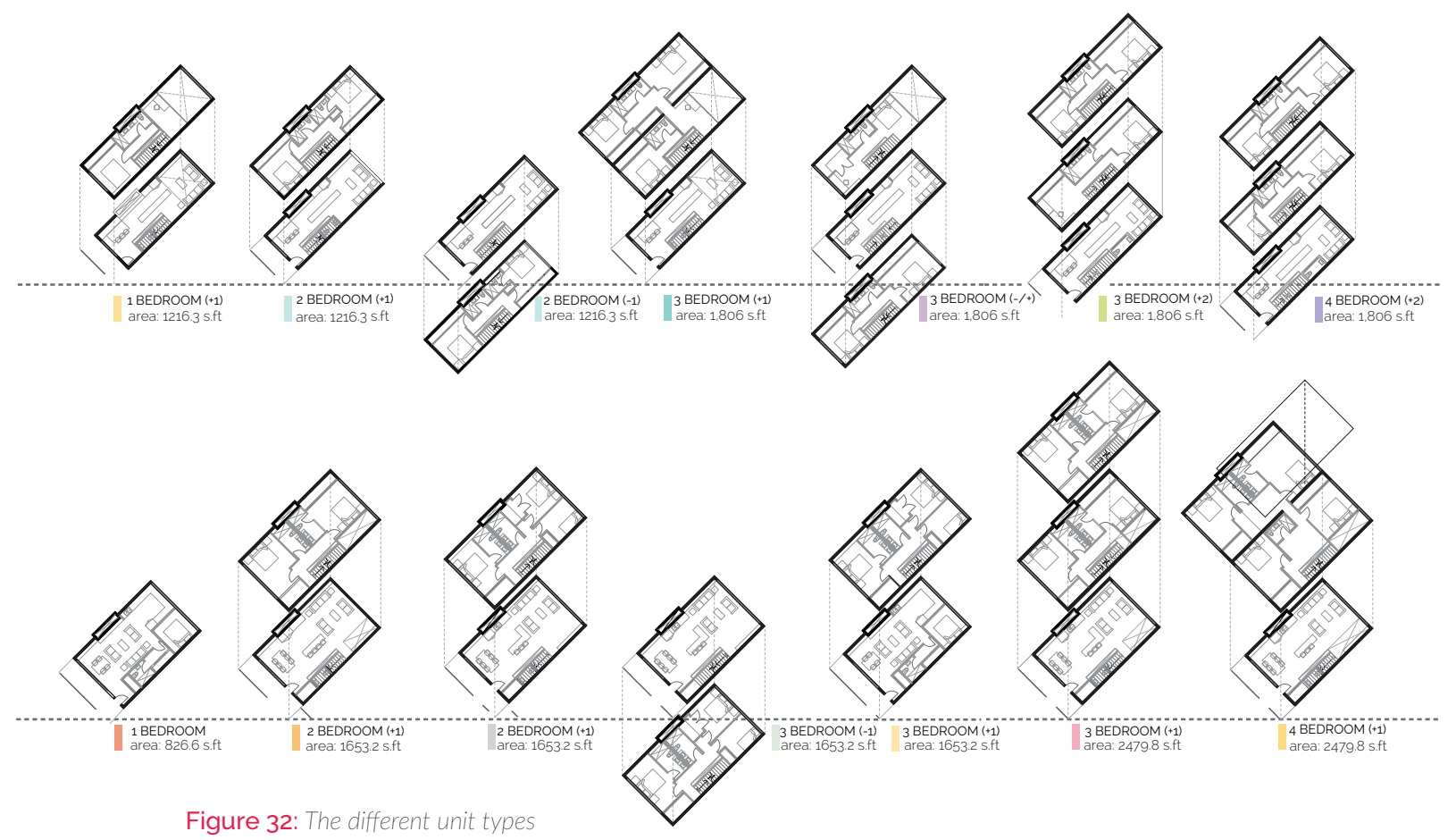

These units were combined to create diversity in clusters. As such, all the clusters are unique in that they each hold different variations and combinations of unit types. However, each cluster carries the same number of one, two, three and four bedroom units to enable a diversity of people to belong to each cluster.

In some studies, particularly in the case of cohousing, clusters created conflicts as people became

too territorial and did not engage with people from other spaces. In response to this situation, units were designed to come down from one cluster into another. This allowed for the integration of people between different clusters. In addition an interior balcony was incorporated to give residents the opportunity to see what was happening below, and engage with residents belonging to an area other than their own.

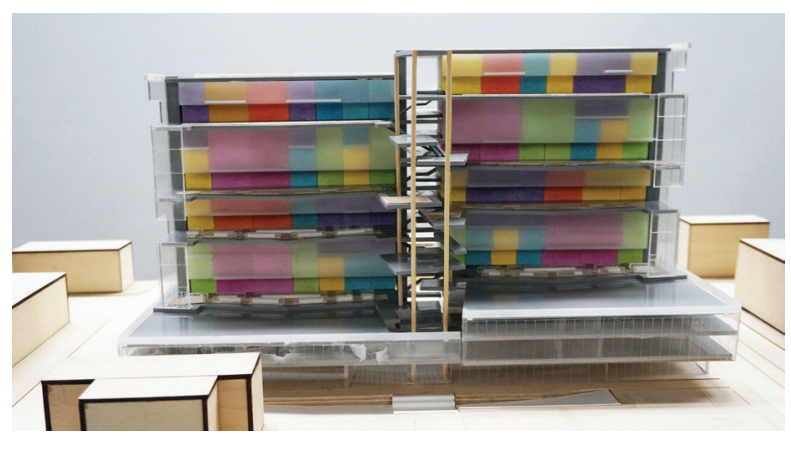

Figure 33: Physical Model - Showcasing diversity among units

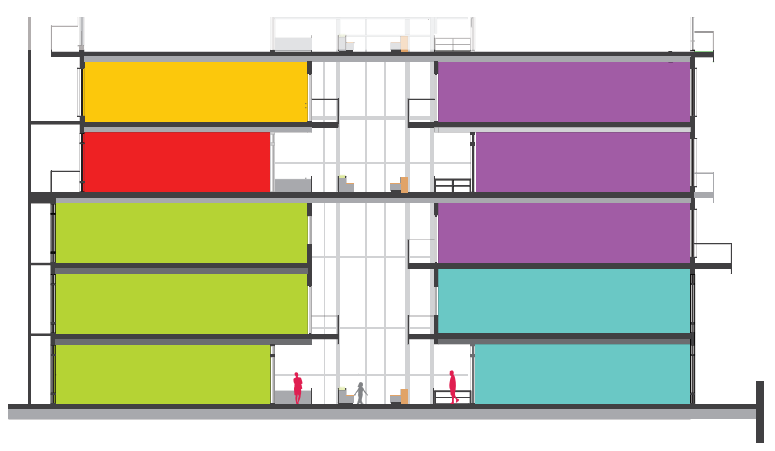

Figure 34: Partial transverse section through two clustersAllowing units to cross into clusters below 


\section{| 5.3 | COMMON SPACE FOR CLUSTERS}

In addition, residents require spaces where they can meet, spaces that allow for frequent encounters and conversation. These spaces should belong to residents of a particular cluster, which would enable them to meet casually and informally. This idea is similar to the pattern created by Alexander "Common Land", which he describes as a space that would belong to the residents of a particular cluster. (Alexander, A Pattern Language, 1977. p. 198; Alexander, A Pattern Language, 1977).

It has been argued, both in the past with Christopher Alexander, and recently in The Vertical Village by MVRDV, that social interaction is limited in high-density developments due to the "loss of ground" (Brillembourg \& Klumner, 2012, p. 267). As buildings get taller they are further distanced from opportunities for encounter. However, the design of clusters enables similar interactions that occur on the "ground" in high-density developments. Thus, it's not necessarily the distance away from the ground that prohibits interaction, rather is the absence of a common space at height that can enable residents to congregate in close proximity to their units, and at a manageable scale.

"Streets in the Sky" did not yield the anticipated success that the Smithson's had hoped it would have. despite the access to daylight and fresh air in the corridor access spaces. This was due to the large span of the development, which resulted in large distances between neighbours. Because of this, the "street in the sky' became nothing more than a pass through space. Although, the Smithson's envisioned that the space would allow kids to play and adults to talk, the space was not designed to respond to various ages, rather it was designed minimally, with no opportunities for
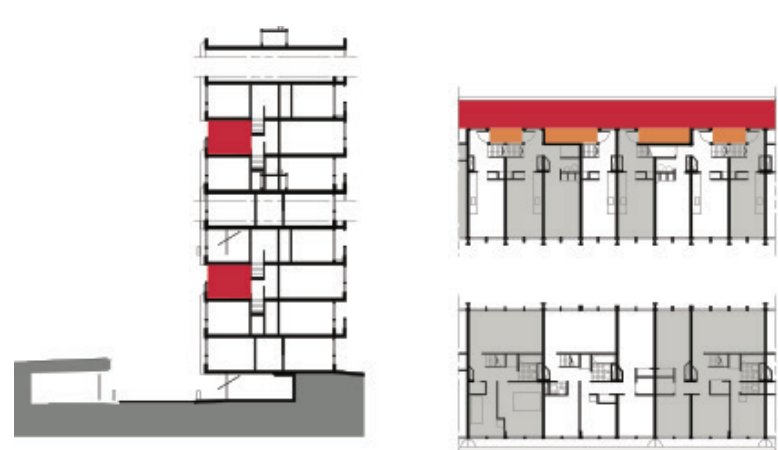

Figure 35: Smithson's Robin Hood Gardens - "Streets in the Sky"

residents to meet, thus further limiting opportunities for encounter.

Residents need proximity to one another, a space for neighbours to meet, a space for staying. and consequently, things for people of all ages to do. This would create opportunities for encounter through proximity between residents belonging to a particular cluster. In the Unite D'Habitation as well as the Smithson's Robin Hood Gardens, opportunities for encounter were limited in part because of the distribution of people in a linear fashion along the corridor. This horizontal distribution of units did not provide the same opportunities for all residents. This can be demonstrated in the case of row houses where residents that live in the middle of a row of houses are more likely to communicate with adjacent neighbours. while those living at the edge of the community have limited opportunities for contact. Williams describes that "immediate neighbours tend to communicate more with each other than residents living further apart" (Williams, 2005, p. 197). People at the edge have decreased access to social contact and as such are isolated from the greater community. Therefore, it is important that the form of the cluster enables easy and equal access for all residents. 


\section{I}

Figure 36: Illustration of WIlliam's description for row houses at the ends have less access to social interaction

Furthermore, research by Williams describes that "the number of residents that could potentially use communal spaces will also influence actual use. Residents are more inclined to use communal spaces where they are shared between smaller groups" (Williams, 2005, p. 220). Therefore, the layout of the development is essential to aid in or discourage impromptu social interactions.

Further to this, units need to be designed to allow for face-to-face orientation. In the case of the Smithson's Robin Hood Gardens, the complex was

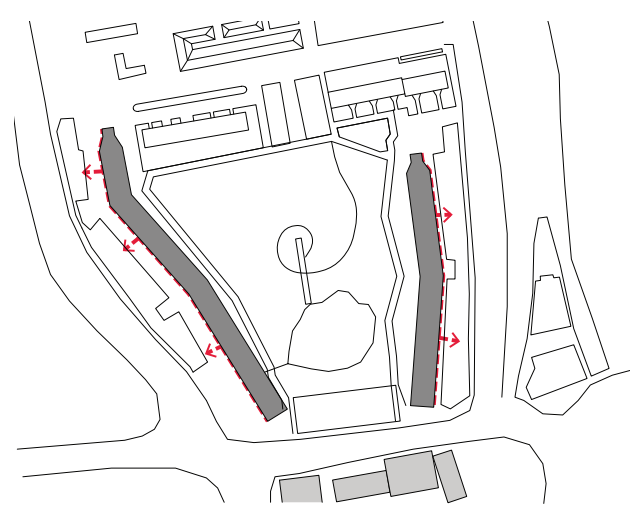

Figure 37: Robin Hood Gardens Site Plan - "Streets in the Sky" ordinated to face away from one another

designed with two residential strips, and a green space in between them. Yet, the two complexes faced away from one another and looked out onto vehicular streets. This lack of visibility into communal spaces is believed to have caused a high crime rate (Alison and Peter Smithson). Although, the Smithson's argued that the crime was a result of the types of residents living there, it was presumably due to the lack of visibility between the two complexes which removed eyes on the street, not only reducing possibilities for formal contact in the green open space below but further encouraging poor conduct. This is because visibility can encourage contact, as William Whyte has stressed. "people go where people are" (Whyte, 2000, p. 250) Further, research in the study of co-housing supports this notion, "access and visibility of communal facilities were highlighted as being the key design factors influencing social interactions. Residents said they had poor surveillance opportunities due to the layout of the development, which greatly reduced informal social interactions (Williams, 2005. p. 220). Therefore, in the design of housing clusters, visibility is important to promote contact between neighbours and as such, it is important that units are designed and laid out to feature a face-to-face orientation to one another. Furthermore they should all be designed to face into the communal cluster space to ensure that all the units have equal access and visibility to the communal spaces.

One project that took a different design approach to that of Le Corbusier and the Smithson's, and which has stood the test of time. was the Keeling House, by Architect Denys Lasdun. For Lasdun, the intention was similar to those of projects previously discussed in this chapter: he hoped for social exchange in the tower to occur as freely and vibrantly as the activity on streets. The striking difference between Lasdun's design and previous example of 'streets in the sky' and 'city within a city', was his design of a concentrated floor plate, which featured 8 units. This project successfully integrated circulation and communal space in a concentrated and condensed area featuring a central lift. From the central lift residents have to pass communal spaces programmed for laundry and storage to access their units. Unlike the other projects, the Keeling House is still thriving and was newly renovated in 2001. The 
success of the project is presumably due to the management of population with the clustering of units, (8 units sharing a common floor plate), and common facilities for laundry that promoted interaction between neighbours.
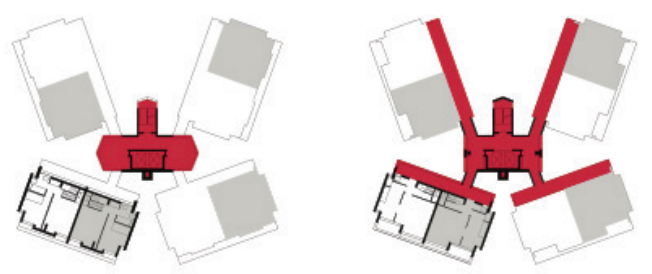

Figure 38: Keeling House - Highlighting the Communal Spaces \& circulation system to units

\section{| 5.3.2 | DESIGN RESPONSE - Creating Common}

\section{Spaces For Clusters}

In response to creating a common space for interaction between residents belonging to a cluster, it was important to create a form that encouraged people to stay, and one which was not simply a pass through space. As such the form was broken up to create a space where residents would have the opportunity to meet casually and informally outside of their units. This condition was created through the separation and angling of the form. The separation of form was done

1

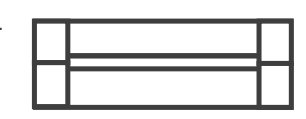

2

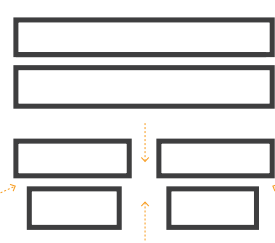

4

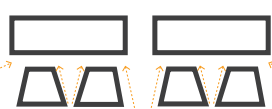

5

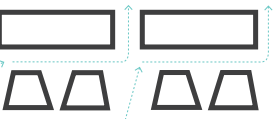

Figure 39: Separation \& Angeling of Form to allow light and air to enter into the building space. Further to this, greater separation of the form was done on the south side to further allow light to enter.

The angling of the form was created the common space for clusters previously discussed. This space was introduced immediately outside of residential units. Here the units were designed to have a face-toface orientation into the communal space. The angling in the volume was created to design a space that can encourage people to stay and not simply for them to pass through. This design feature also provides equal visual and physical access to the common cluster spaces for all residents.

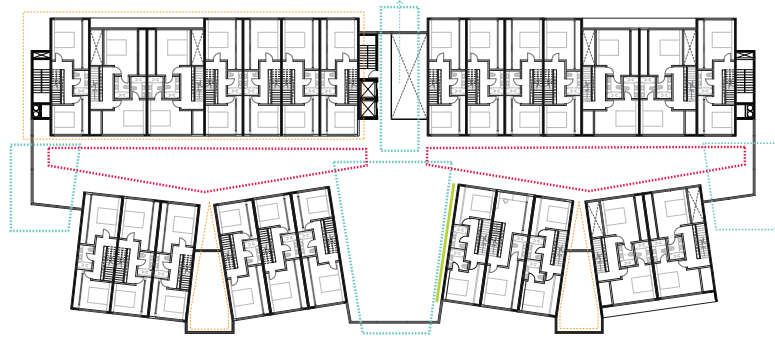

Figure 40: Communal space for cluster indicated by the pink. Angeling of the form creates a space for "staying"

\section{| 5.4 | UNIT DESIGN FOR FLOW}

To further encourage the use of communal spaces, it is important to allow for easy flow through units. This could be accomplished by the layout of and organization of the units program where people are able to flow easy in and out, from private to public spaces. In addition, communal spaces belonging to the whole cluster can be activated through the placment of communal spaces in units (such as the dinning room) in adjacency to the cluster communal spaces.

For example, in the design of the Elementa Complex, Otto Steidle structured his building around a central area located on the first floor, which penetrated through the core of the building to the top. This 
central space also held the circulation system and the ramps and lifts that gave access to the units above. Furthermore, Steidle designed his units with the "kitchen, dining rooms and terraces oriented toward the active, communal area in the center of the building" (Steidle, 1994, p. 50). His reason for doing this was to bring people in close proximity to the communal space. This was because the act of seeing others in the their units, still enables for a sense of community and engagement as the presence of people can activate a space.

\section{| 5.4.1 | DESIGN RESPONSE - Unit Design For Flow}

The design response for flow is two parted. Firstly.

Figure 41: Building section demonstrating that all front doors open on the same level (Scale 1:600) (Below) it requires that all residents have equal opportunities for encounter, thus all doors were designed to open on the same level with direct access to the communal spaces

Secondly, it is important that the unit design allows for easy flow in and out. This was done through

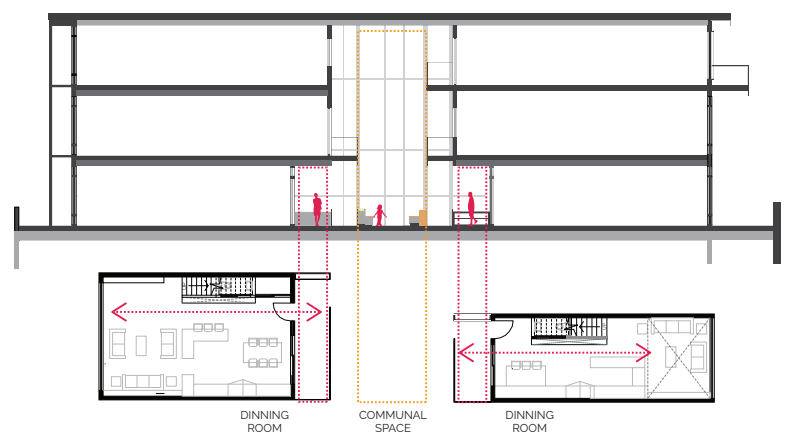

Figure 42: Flow enabled through unit design Dinning room adjacent to communal space (Above)

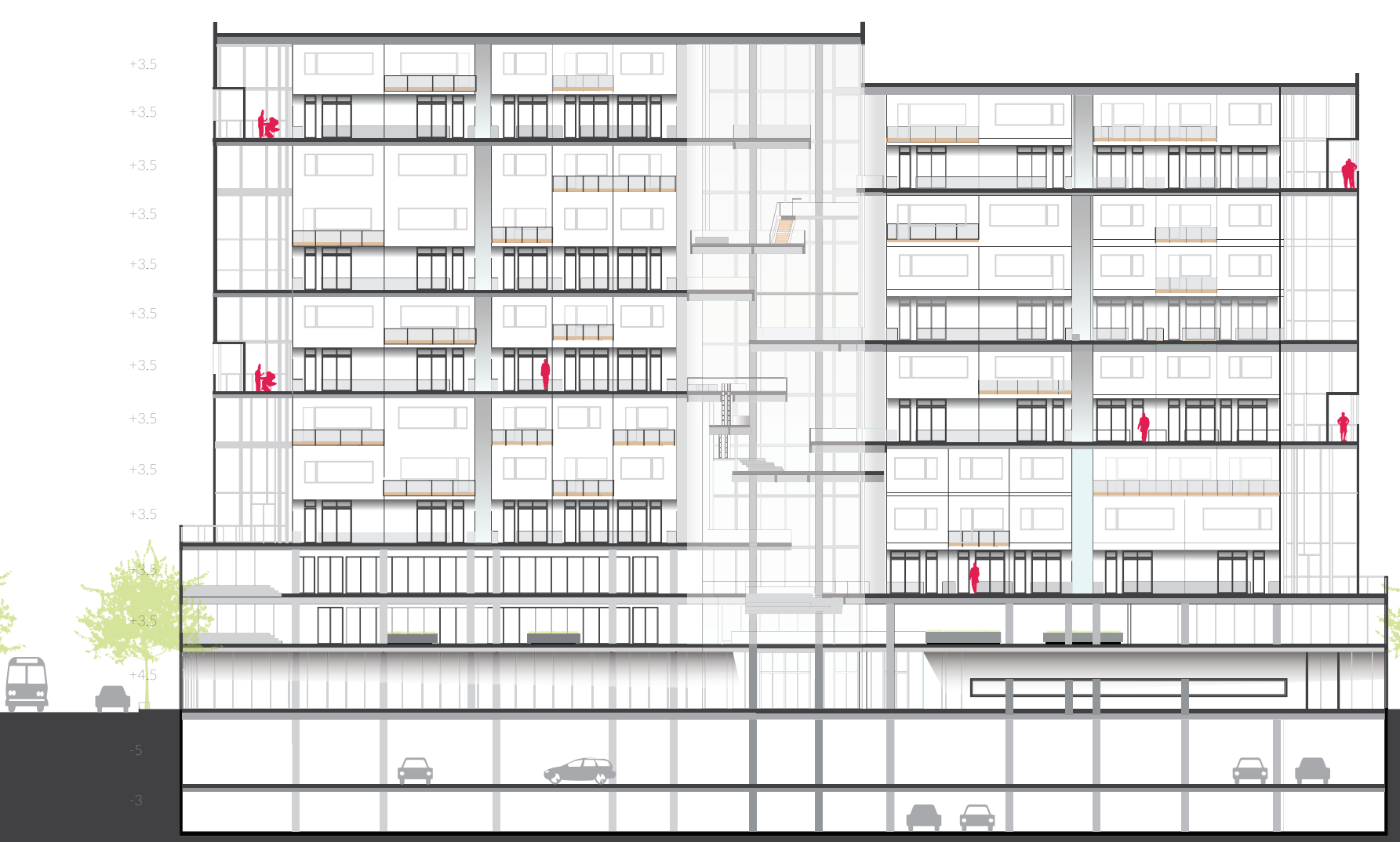


the layout of programming to allow people to easily flow through space. The inspiration for the unit design came from the Steidle's Elementa Complex that demonstrated the activation of communal spaces even when they were not in use.

\section{| 5.5 | PROVIDING TRANSITIONAL SPACES}

This section discusses the significance of incorporating a semi-private space to transition people from their private units into the communal space. In current developments, people move from their private units into the public corridor, and for this reason people only leave their units for formal encounters, and rarely converse with their adjacent neighbours. The purpose of a transition space is to invite people out of their units, into an open "semi-private space", from where they can view and see what is happening in common spaces, who is in it, and with whom they would like to engage with.

In the design of co-housing developments, the semi-private space would allow for a gentle transition from private units to private spaces, (Williams, 2005. p. 198). The role of this space. William states is to create a protective barrier "providing a degree of privacy and territorial control with options for active contact into adjacent public spaces" (Williams, 2005, p. 198). At most it invites people out of their private units, and makes them visible and accessible to other residents, therefore increasing the potential for social interaction.

In co-housing developments, the space functions to "protect residents from overexposure to the community, which may lead to withdrawal and a reduction in social interaction" (Williams, 2005, p. 198). This space can help to greatly influence residents sense of community, because it increases the potential for frequent encounters.

\section{| 5.5.1 | DESIGN RESPONSE - PROVIDING}

\section{TRANSITIONAL SPACES}

The introduction of a "semi-private space" was important because it invites people to come out of their private units and in doing so it creates the opportunity for engagement with their neighbours, and creates the opportunity for informal interaction.

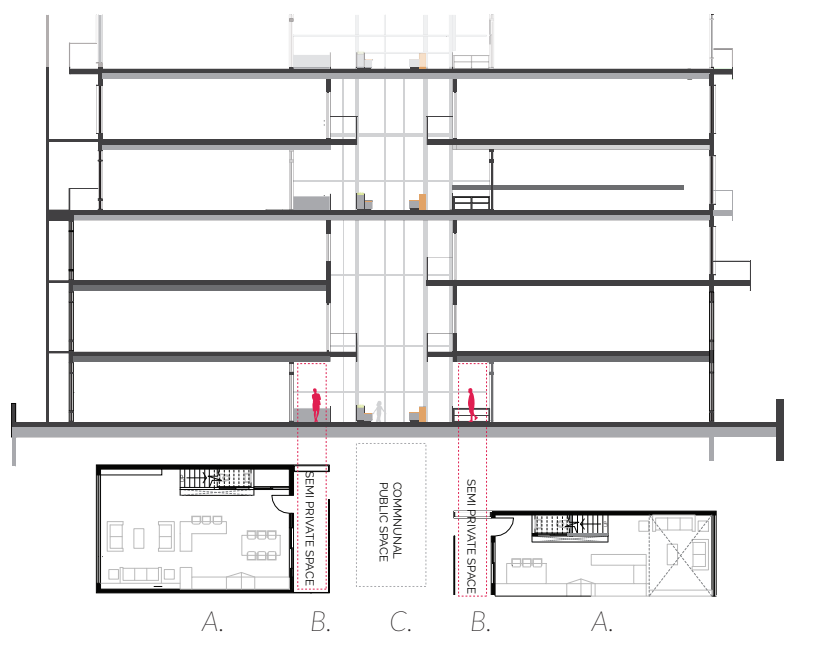

Figure 43: Transitional spaces

$\mid$ A. - Private Units $|B|$ Semi-Private Space |C | Communal

\section{| 5.6 | RESPONSE TO DEMOGRAPHICS; ENABLING FOR SCALES OF INTERACTION}

As discussed previously, no age group is selfsufficient; people require the presence of others to support and guide them. However, different age groups prefer to engage in different kinds of activities With the design of "Streets in the Sky" the Smithson's hoped that these streets would allow children to play and neighbors to chat-similar to the workings of a traditional street (Balters, 2011). Yet, there was nowhere to sit, nothing to lean on, nothing for children to do in that space, it was simply a wider corridor. Therefore to ensure that people use the spaces provided they need to be designed to allow people to stop, sit observe, and play. And as such, the common space belonging to each cluster should be designed to ensure that 


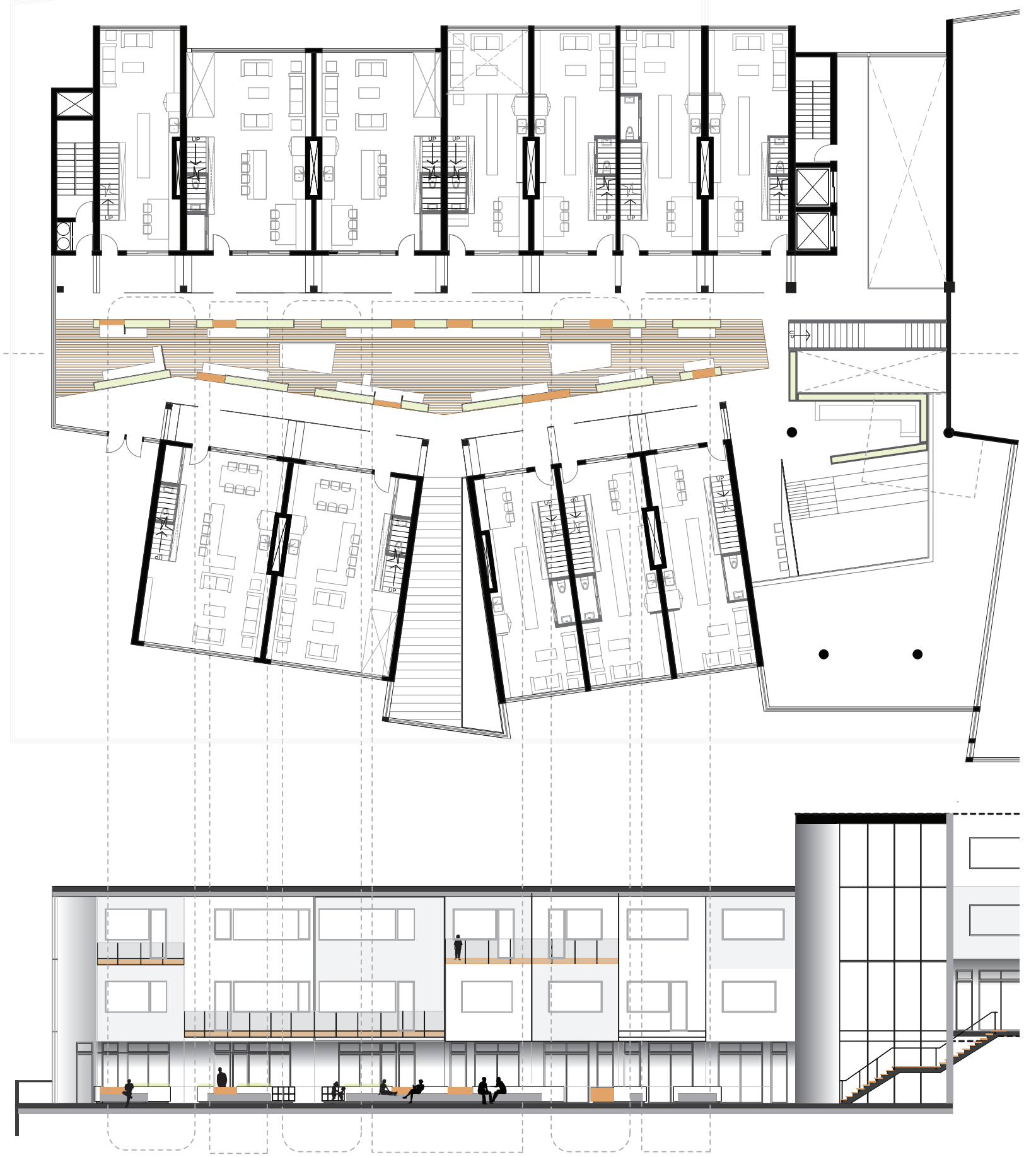

Figure 44: Scales of interaction within a cluster (Scale 1:300) 
there are opportunities for people to sit and converse at various scales of interaction. For example, teenagers enjoy being with other people their age, adults should be able to have opportunities to play with their children, as well as opportunities to converse with other adults, and lastly, the whole cluster should have a space that can accommodate all of the residents belonging to a cluster

Furthermore, Gehl supports, "it is important that places for resting as well as opportunities for being engaged in an activity are present in front of the house. In this way small, improvised events have reasonable chances for development" (2011, p. 193).

\section{| 5.6.1 | DESIGN RESPONSE - Response To}

\section{Demographics; Enabling For Scales Of Interaction}

The common spaces for clusters were designed to provide for various scales of interaction, which were enabled through the build form. A bigger space at the center with a distance for 3.5 meters (a public distance - discussed in chapter 4) between seating spaces can accommodate interaction between all members of a cluster. From the center of the cluster outwards, the angling of the form reduces the distance between seating in the common space, creating opportunities for intimate conversations. As such, the cluster design allows for a universality of uses, for adults to sit, teenagers to lounge, and smaller children and babies to play.

Vast differences were not created between clusters for this thesis, because it was more important that the common cluster spaces in front of the units allow for encounter and engagement of residents belonging to that cluster, thus they did not need to be vastly different. As such, the clusters were designed with slight variations between them, some were designed with the option to step outside onto terraces,

while others were designed with edge seating.

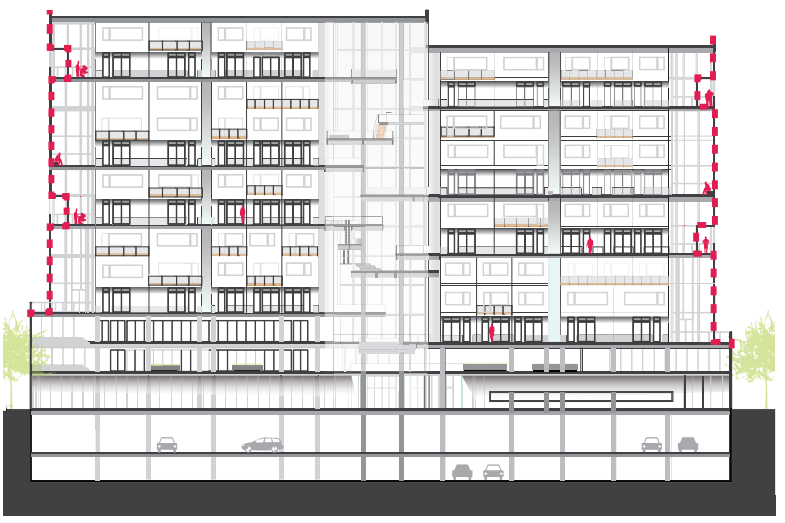

Figure 45: Clusters with opportunities to step outside and sit along edges

\section{CONCERNS/ INQUIRES / RESPONSE}

The integration of these communal spaces raises concerns for how they will be sustained and maintained. Currently, in condominium developments residents pay high rates in maintenance fees However, it is anticipated that the residents belonging to each cluster would maintain these spaces, This is anticipated because residents have the opportunity to develop close relationships with their neighbours and as such it is believed that they would want to maintain them for their continued enjoyment and use. Literature on co-housing supports this notion where "residents maintain and manage indoor and outdoor communal spaces" (Williams, 2005, p. 201). In co-housing this is accomplished by "advocating a ownership where the deed to one home carries with it part ownership in the cluster. so everyone has part ownership of the public space to which their house belongs", and are responsible for its repair (Williams, 2005, p. 201). It is important to note however that poor maintenance of communal spaces proved to reduce use and social interaction between residents in co-housing. Thus, 
this is an important issue that has been considered but requires a greater degree of consideration into the logistics and ownership of the space.

Furthermore, the integration of communal spaces in this manner may also raise a concern in regards to the degree of privacy. What is the appropriate distance? what is the right threshold? With a common space in front of one's home, do greater measures for privacy need to be considered? These spaces however, where designed with consideration and a response to a typical porch condition in a house in the design of 1.82 meters. Furthermore, the pass through corridor space was designed larger than a typical corridor in a condo at 1.3 meters. More importantly, the communal spaces were purposely designed with degrees of transition to ensure that people do not feel overwhelmed or lack a sense of safety. These conditions are intended to allow people to feel comfortable, secure and develop a degree of trust with their neighbours. Thus, it is believed that a greater degree of privacy is not needed. However, until this project is actualized, the true workings of the space can only be speculated through the use of literature and case studies, which have been discussed previously in this chapter and have greatly shaped the design development of these spaces.

\section{CONCLUSION}

The generation of clusters creates the opportunity for residents to develop relationships at a manageable scale. In addition, the integration of communal spaces in front of housing units creates the possibility for informal and causal encounters to take place between neighbours. These interactions have the potential to create frequent encounters and in turn allow for residents to develop meaningful relationships. This first scale of interaction is intended to help residents feel comfortable as the scale is smaller and more manageable so that from here, they can feel comfortable to engage with residents from the whole building --the neighbouhood. Opportunities for interaction with people from other clusters at the neighbourhood scale are provided in communal spaces, which is the second scale of interaction created in this thesis design project and will be discussed in the following chapter. 


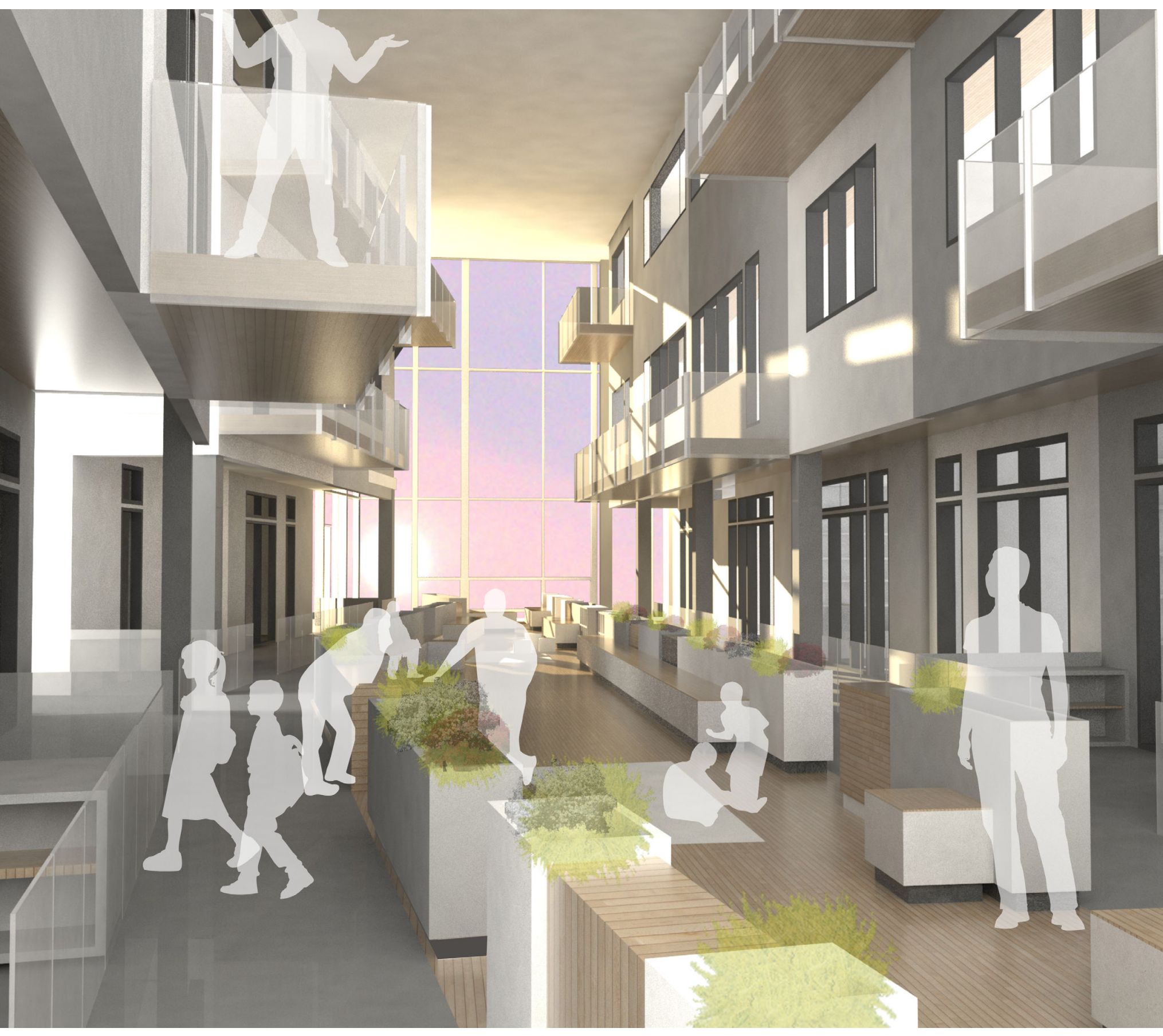

Figure 46: View inside of a cluster 



\section{| 6 | INTEGRATION OF COMMUNAL SPACES}

This chapter begins by identifying the significance of integrating communal spaces with housing units to facilitate social interaction. It will then go on to analyze methods used in both past and present precedents for integrating communal spaces. These methods will be compared to the strategies and tactics that have been identified for encouraging social interaction (chapter 5). Finally, this chapter will demonstrate how the design of this thesis project responded to the theoretical issues in order to successfully integrate communal spaces to promote use and informal interaction between all residents at the neighbourhood scale.

\section{THEORETICAL ANALYSIS \& DESIGN RESPONSE}

In the case of most condominiums, functions are segregated from one another, where amenity spaces are often programmed in the podium or on the roof of the building. In some cases, this has limited the use of amenity spaces and more importantly, reduced opportunities for encounter and interaction between residents. This is presumably because there is a lack of visibly to these spaces as a result of the separation from the residential units. The large distances created between units and amenity spaces requires that people use elevators to access communal spaces, and as such reduces possibilities for encounter. Furthermore, this lack of visibility and infrequent opportunities of encounter makes for informal and short interactions which are not enough to help people develop a sense of community. Williams suggests that "multi-storey buildings can also reduce social interaction in terms of short-term and spontaneous stationary activities" such as socializing, eating outside private units, and sporting activities, "this is because for residents living in upper floors it is too bothersome to come down and go out into public areas to join in" (2005, p. 199).

Consequently, due to a of lack of proximity and visibility from the residential units into communal spaces, and because these spaces are the only public spaces in the building where residents can all congregate, communal spaces in condominiums are only marginally supporting residents' needs and insignificantly contributing to residents' ability to grow as a community. As such, there is an opportunity to integrate communal spaces with housing units to enable residents to have easier access to communal spaces.

The other concern with the design of amenity spaces that are currently provided is that they are usually separated from one another other; walls separate and distinguish where various activities and 
age groups belong, thus further reducing the possibility for contact between a greater number of people.

In addition, the amenity spaces provided do not respond to the needs of people at different ages: spaces for different activities are separated from one another, which does not enable different ages of people and activities to engage with one another. Yet, people do not interact in these ways, people require spaces which can allow them to see other people and were they can communicate with one another. Jan Gehl suggests that "different categories of activities have a strong tendency to weave themselves together - if they are allowed to do so" (2011, p. 112).

\section{| 6.1. | VISIBILITY}

This section critically examines how communal (amenity) spaces have been integrating in past precedents in relationship to housing units. Further, it seeks to identify how communal spaces should be integrated in relationship to the units.

People seek out concentrations of other people. as such visual access into communal spaces are essential for occupant's engagement of a space. whenever they are available. Literature in co-housing design describes that "residents' ability to see and hear others using public spaces outside their home greatly influences their sense of community and enables them to observe others with whom they would like to interact" (Williams, 2005. p. 198). Thus, it is important that residents have visual access into communal spaces.

Subsequently, in the case of Le Corbusier's, Unite d'Habitation, the lack of visibility to communal spaces decreased the use of the amenities provided. Although, Corbusier's "City Within a City" was focused on communal living, where inhabitants could shop. play, live and come together many of the spaces went unused. The programming that was incorporated in the building included shops, restaurants, a medical facility, and a small hotel in the middle of the building, as well as a gym, areas for kids to play, a running track, and a shallow pool, (Sherwood, 1981, pg. 120). However. despite the density in the building (roughly 1600 residents), people rarely used these offered amenities, and eventually they had to close.

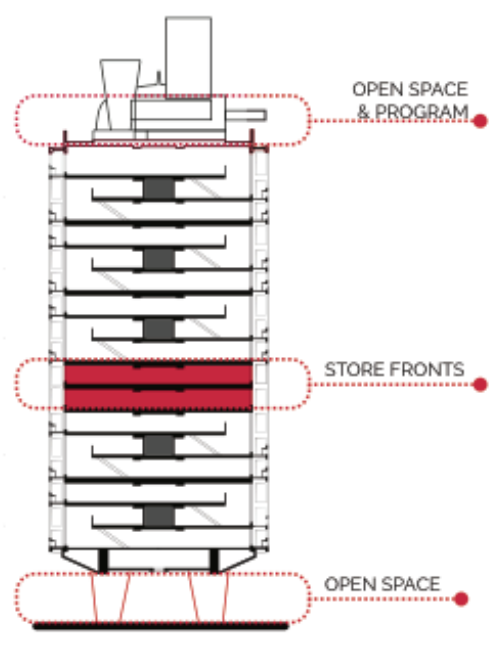

Figure 47: Unite d'Habitation - Separation of program

Le Corbusier programed the amenities in a similar fashion to what is being done today; distinctly programmed to their own individual level and separated from the residential units. In addition, the circulation spaces in the building were poor and simply functional. Approximately, 29 units lined double loaded corridors creating a harsh and unwelcoming condition, which did not have access to natural light. Such unwelcoming conditions made the process of leaving residential units unappealing, this further contributed to the isolation of individuals to their individual units. The Unite d'Habitation supports the notion that it is important to have visual access from the residential units to the amenity spaces in order to encourage the 
use of the amenities provided. This design initiative can encourage social interaction between residents to take place.

Recent precedents that focused on enabling visual access to amenity spaces include Bjacke Ingels 8 House, and De Architekten's "The Whale". Both of these developments focused on created spaces for interaction between residents at the base of the building with the design of courtyard spaces. The 8 House, featured balcony spaces facing into the communal spaces, while The Whale featured balconies on the outside of the development and access corridors overlooking into the courtyard at alternate levels. In this respect, the 8 House took a better approach because the balcony spaces belonging to the units provided residents the chance to step out of their units and observe activities and people below. While in the case of The Whale, it is rare that people would spend any amount of time in the access corridor and as such, this reduces the opportunity to see what is happening in the courtyard space below. Thus, a balcony condition overlooking communal spaces is more suitable as it gives people a longer time to look into spaces below.
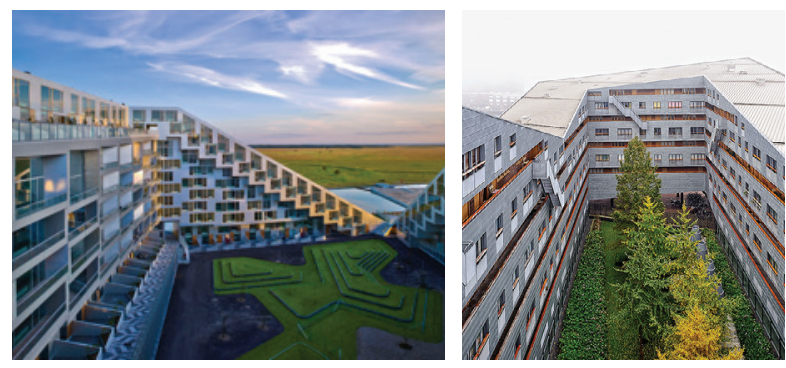

Figure 48: The 8 House \& The Whale

Yet, the concern with both of these developments is that the access to these courtyard spaces is not direct from individual units, and this can reduce the use of the communal spaces provided. This is because residents need to make their way through their private units, and into an access corridor before reaching the communal spaces. Jo William describes that " for residents living in upper floors" it is too bothersome to come down and go out into public areas to join in" (2005. pg. 199). However, by provided access directly from units, residents can proceed from their private unit, to a semi-private space to a corridor space, and then to the public communal (amenity) spaces. This not only provides for a gradual transition from ones unit to communal spaces, but it can also ensure that people have direct access to communal spaces. This can increase the use of the amenities provided and further increase the potential for interaction at the neighbourhood scale.

In addition, the concern with these designs is the fact that people do not like to occupy large spaces and some find it bothersome to go down to use these spaces. Although these developments allowed for visual access to communal spaces from the units, the integration of one large communal space is not inviting, and its distance from units, reduces both the possibility for informal conversations, and it also limits people from using the amenities provided due to the distance between the units and the courtyard space. Thus, amenity spaces need to be integrated in closer proximity to the units to allow for easy flows and spontaneous use

It is also important that all units have visibility and access to the integrated amenity spaces. In the case of Mirador Tower, by MVRVD, although the communal spaces are integrated with the units, many of the units do not have visual access to this communal space. This will create isolation among some of the units, and discourage people who are further away from using them. Thus, it is important that all residents are provided with the same opportunities. 

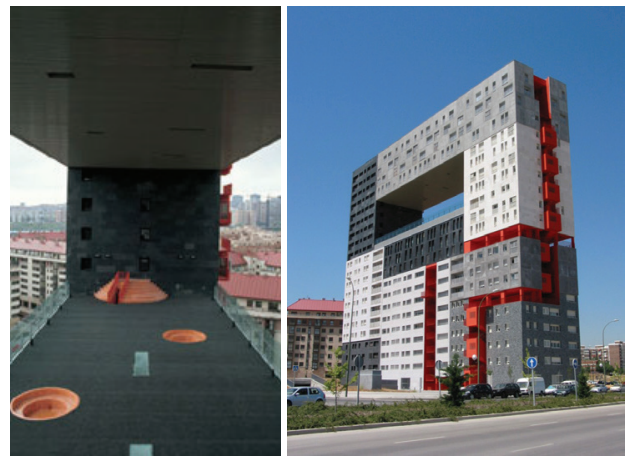

Figure 49: Mirador Apartments

Furthermore, the integration of amenity spaces with housing units can remove borders between different functions and groups of people as they would be integrated with the housing units. This would give people visual and physical access to the amenities provided. Furthermore, the ability to see and access these spaces more easily will encourage people to use them more frequently and in turn, this integration can greater facilitate increased opportunities for encounter and social interaction between residents.

\section{| 6.1.2 | DESIGN RESPONSE - Visibility}

As it has been discussed above, the ability to see into communal spaces increases the potential for use. Thus, communal spaces integrated with the housing units and they were designed to connect directly from the housing clusters.

\section{| 6.2 | RESPONSE TO DEMOGRAPHICS}

Although it is important for amenity spaces

Figure 50: Longitudinal building section illustrating the integration of communal spaces with housing units

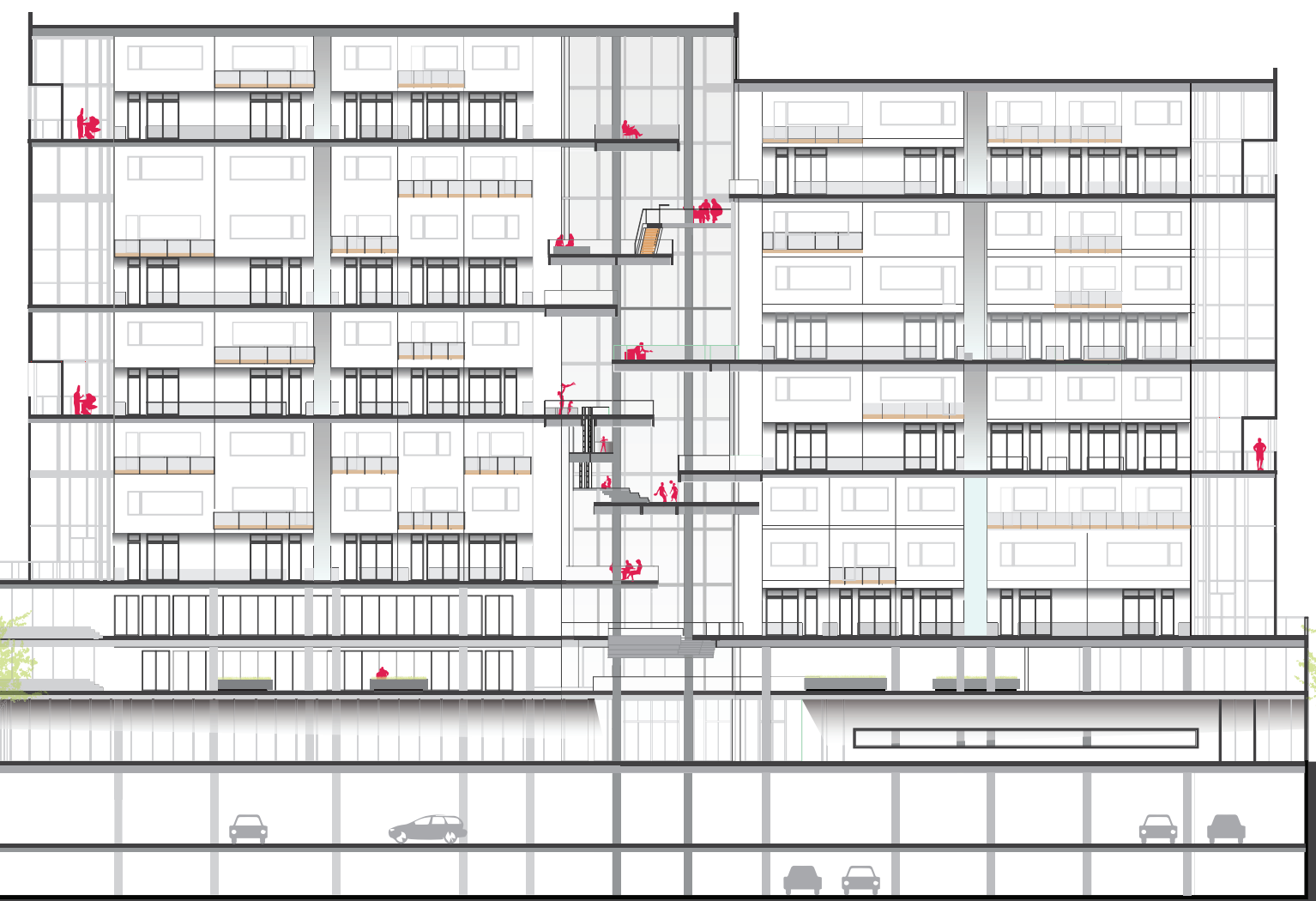


to be integrated with the housing units, it is also important that these spaces remain concentrated so that they can relate and support the functions of one another. Currently, in the design of condominium developments, the amenity spaces provided do not support each other. Although at times, amenities are offered for different activities and different users, they are often separated by walls. This limits people of different ages or people partaking in different activities to support and engage socially with one another.

For example, this is the case with the Newton Tower in City Place. The amenities provided include a dance studio, art studio, music studio, cardio, a photostudio and children's playground and an outdoor lounge and terrace. Yet, despite the variety provided among these programs there are walls separating each of the different uses. The concern with this layout is that, it discourages opportunities for people of different ages to interact, as there is no opportunity to engage with anyone else while partaking in various activities.

This division of space and alienation of functions are unappealing to families who value opportunities for community engagement. Thus, amenities spaces should have a better response and understanding

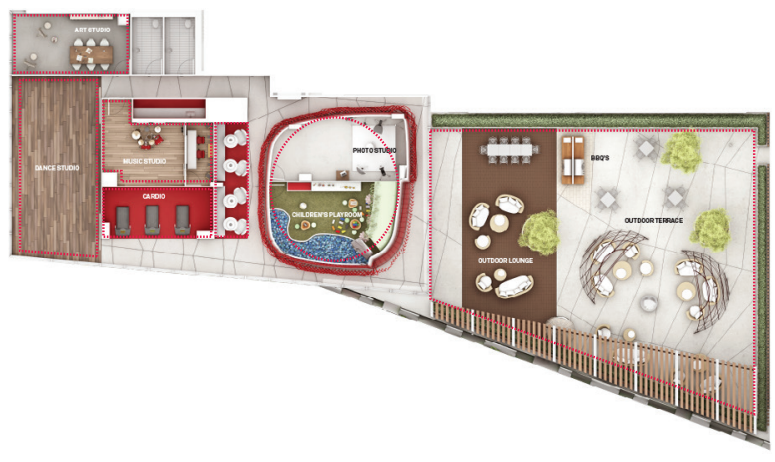

Figure 51: Newton Tower - City Place Condo Separation of spaces for how people interact and what activities individuals of different age groups enjoy to take part in. This is because as people undergo various stages, from youth to old age, there are different demands on spatial qualities and organization of space. The desire to accommodate families in the city, demands spaces for kids to play, teenagers to study and gather, and adults to meet and converse. Thus, it is important that amenity spaces provided in condominiums support the needs of people of all ages, with consideration to spatial proximity.

As discussed above, different age groups have different spatial requirements. Firstly, toddlers at an early age prefer to spend more time with their parents than other children. Thus, communal spaces should accommodate spaces for adults to play with their children. Yet as they grow, children ages $3-7$ enjoy spending more time with each other. They need spaces that can keep them active, by allowing them to run, play, climb and hide (Scott, 2010, p. 19). It is important to provide opportunities for children to play with one another because both positive and negative experiences can form sensibilities early in life, which can help children from an easily age learn to "manage their bodies, minds and emotions" (Bradley, 2008, p. 27). Designing spaces for children to play can also create opportunities for adults to interact, because it can bring parents together (Williams, 2005, p. 212).

The needs of children change, as they get older. Ages 8 -14 as well as ages 15 to 18 are more private and they enjoy spending more time with people in their age group. At this age spaces for study and discussion are valuable. In addition, due to the vulnerability of children at this age, spaces should be designed to enable easy accessibility and flow. This can help to encourage teenagers to easily join in activities with each other. 
Adults ages 19 - 24, enjoy spending time with individuals of a similar or older age. They prefer spaces that are causal, inviting and not too well defined (Alexander, 1977, pg. 348), where they can eat, drink, play games, socialize and engage in cognitive study. Furthermore, adult's ages 34 - 54 enjoy spending time with their kids. As such, some communal spaces, as discussed above, should allow for both adults and children to play together.

In addition, it is also important to consider and design for a level of separation between adults and children. Some condominium users, in the consultations held in Toronto in February of 2013, indicated that the local parks in Toronto are predominantly designed and occupied by kids and as such there are little spaces for adults to enjoy (City of Toronto, 2013). Thus, communal spaces should also be divided to allow for a degree of separation between different activities and age groups. Spaces for adults can be placed in the middle of circulatory paths so that adults can see these spaces on their way to and from their home.

Furthermore, the integration and organization of amenity spaces should also enable well-being by promoting active leisure as opposed to passive leisure.
The intention is to allow for a variety of activities to take place in close proximity to one another so that they can support each other. For example, there is an opportunity to allow adults to engage in physical activity while keeping an eye on their children. The integration of programming in this manner increases the opportunity for people to interact and further engage with one another all while living active life.

The organization of spaces in response to different age groups, is not intended to strictly distinguish where specific age groups must go, rather the intent is to provide a variety of opportunities for a variety of people. People can choose where they want to go, what they want to do and with whom they want to engage with. Furthermore, this response can help to create interaction at the neighbourhood scale.

A precedent study that integrated communal spaces with residential units, while also keeping communal spaces concentrated was Michael Wallraff's research project, Verti City. Wallraff and his firm aimed to improve the quality of life and spatial diversification in densely populated areas (VertiCity, 2012). As such, the research project looked at the districts in Asian cities that are developing rapidly and which have "reached
PASSIVE LEISURE

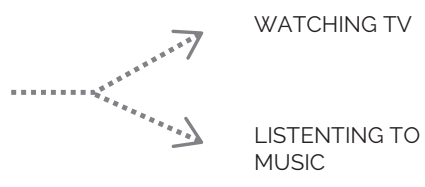

ACTIVE LEISURE

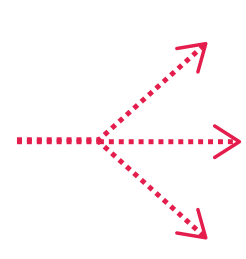

PHYSICAL EXERCISE

cognitive stimulation

SOCIAL CONNECTION

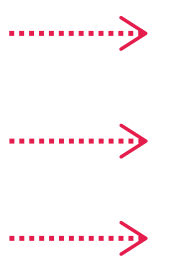

STAIRS

THE NEIGHBOURHOOD GYM AREA

READING/GAMES/STUI BOOK CLUB
TUTORING

SITTING

Figure 52: Passive \& active leisure 
shocking proportions and manifested into brutal urban conditions" (Wallraff, 2012, pg. 131). Thus, in response to densely populated areas. Wallraff was interested in creating spaces that would allow people to rest and relax, in close proximity to their homes. (Wallraff, 2012. pg. 131).

This particular study has been found to "impinge on the traditional horizontality of public spaces" (ThunHohenstein, 2012, pg. 9) because the project focuses on bringing the public up into the building. Although the goals outlined for Verti - City are not in tune with the goals of this thesis, it is important to note the way in which public spaces were introduced into the
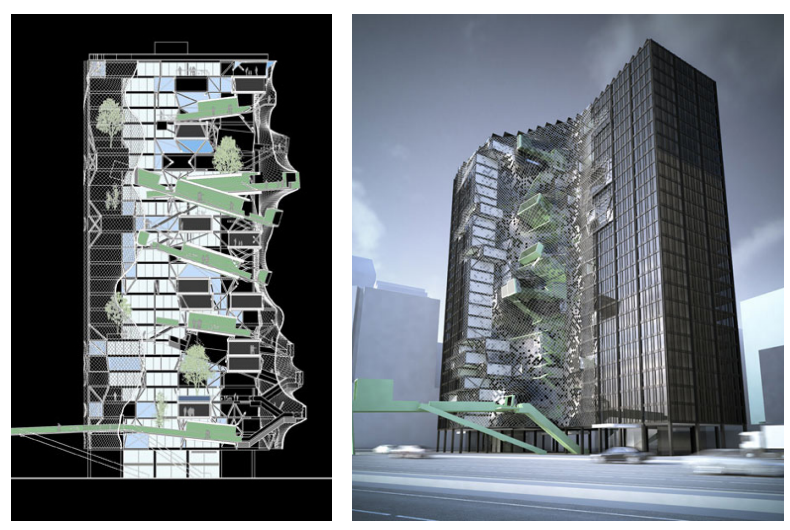

Figure 53: Verti City - Michael Wallraff

building. Wallraff's design envisions "social networks and neighbourly relations (that can) develop in spite of large structures and verticality," (Wallraff, 2012, pg. 127) for the firm, these include spaces of rest, relaxation, communication and social structures, and spaces where kids can gather and play on the 2oth floor. The communal spaces are integrated and concentrated to support one another throughout the section of the building, and the units come off of these spaces (Wallraff, 2012, pg. 127). In section, these social spaces are linked to one another allowing people to flow from one space to another. Thus project is believed to be an appropriate response for how communal spaces should be integrated with housing units.

\section{| 6.2.1 | DESIGN RESPONSE - Demographics}

The programming in the building was designed in response to the research previously discussed Spaces for children to play, run, climb and hide were incorporated in the middle of the building with the design of two levels to accommodate a court space jungle gym, and a movie screen. The upper level was designed to accommodate for adults and children to play. These spaces are not only for children but were also designed with the hopes to bring the neighbourhood together, and possibly participate in the viewing of a film.

Workout spaces for spinning and jogging were placed in relationship to the kids spaces to enable adults to engage in physical activity while also watching their children play. In addition, a games room for adults was integrated above the kids space. Here adults have the opportunity to partake in social activities while still being able to see into the kid's spaces below. In addition, gathering spaces were also incorporated to allow adults to congregate away from other programming, in response to adults preference for a separation from children at times Also, a games room was incorporated for teenagers on two floors, which were connected by a stair to enable easy flow between the two spaces. The integration of these spaces provides opportunities for engagement between different functions and groups of people.

\section{CONCERNS/INQUIRES / RESPONSE}

The integration of these communal spaces however, raise concerns for noise and fire control due to their interconnected nature through the 


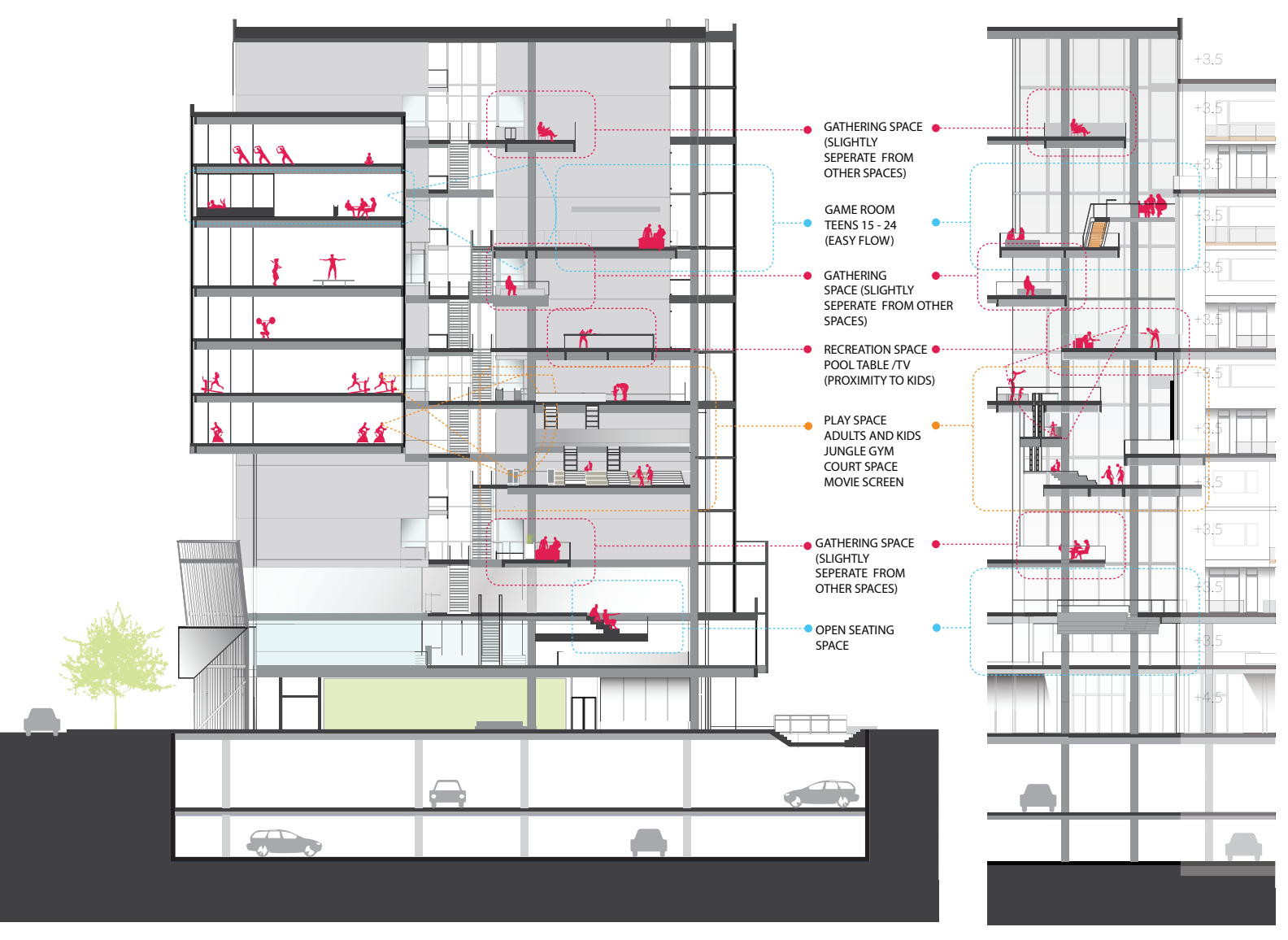

Figure 54: Transverse section \& partial longitudinal section (Scale 1:600)

verticality of the building. Although these two facets were recognized they were not addressed in the architecture. However, they have been considered; concerns for noise can be addressed through choice in material by incorporating industrial felt with wood or drywall paneling. While fire control can be addressed through the compartmentalization of spaces, or by responding to building code requirements for interconnected spaces.

\section{CONCLUSION}

Therefore, amenity spaces should be integrated with residential units to allow for direct visual and physical access from each housing cluster. In addition, it is important that communal spaces are not only integrated with residential units but also concentrated so that they can work and function together. The integration of spaces in this manner were intended to provide opportunities for various activities and for various age groups to engage informally and spontaneously with one another. Thus, by allowing for different spaces to function together it can create comfortable opportunities for engagement between residents from various clusters in the neighbourhood. 


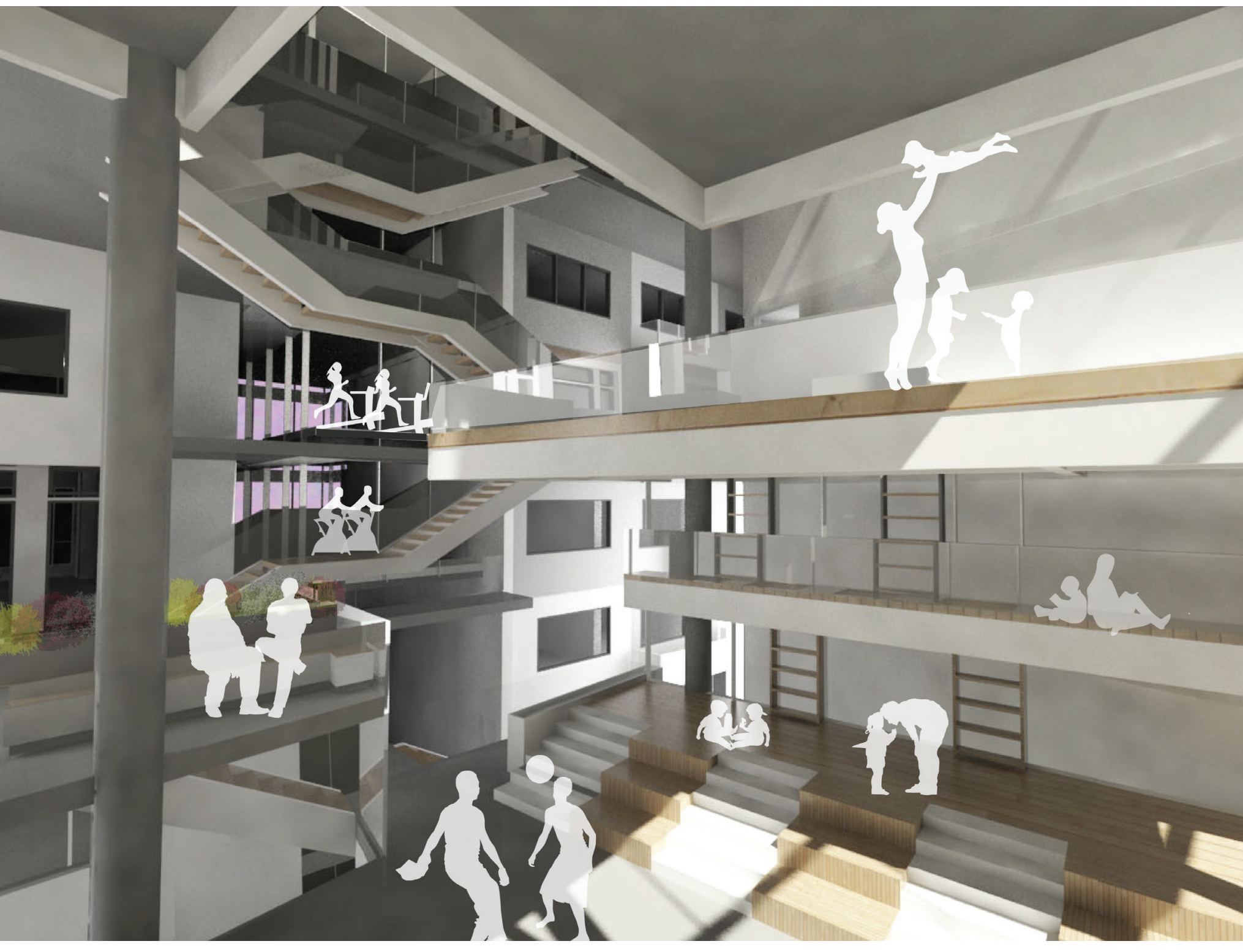

Figure 55: View of kids space \& workout spaces (spinning \& jogging) 



\section{| 7 | CIRCULATION TO PROVIDE CHOICE \& GENERATE ENCOUNTERS}

This chapter begins by identifying the significance of circulation as more than a functional link and a space for movement, but rather as a space that provides residents with choice, as well as an opportunity to generate encounters. This section will then go on to review literature for how circulation can be integrated and relate to other programs in the building. These methods will then be compared to the strategies and tactics that have been identified for encouraging social interaction. Finally, from the lessons learned through this analysis, the design of this thesis project will demonstrate how each theoretical issue was addressed to enable residents with choice and design a main circulation system to generate encounters.

\section{THEORETICAL ANALYSIS \& DESIGN RESPONSE}

"Spaces for movement, whether cloister, gallery or hallway, were planned for informal or ceremonial enjoyment," where "the routes from entrance to room, and from one space to another, had significance and value. Galleries of great houses were used for constitutional recreation, and the colonnades of colleges for interaction and debate" (Weston, 2011, pg. 34).
Today, however, circulatory spaces are undermined, in particularly in the design of condominiums where circulation is regarded simply as a functional system to provide access to units. Corridor systems are designed to minimum code requirements, they are narrow and provide no access to natural light or fresh air. Bradley supports, "in modern buildings the inbetween places are treated as a pragmatic necessity," and as such they are "left for minimum interpretation" (2008, pg. 21).

Nevertheless, circulation spaces can contribute greatly to encourage and enable social interactions between people. According to Gehl, "traffic to and from houses in nearly all instances is the most comprehensive of all outdoor activities in residential areas" (Gehl, 2011, p. 111). As such, it is important to seek to integrate activities with circulation systems, as this will increase the possibility for encounter between residents.

\section{| 7.1 | RESPONSE TO HUMAN BEHAVIOUR}

Human behavior is influenced by a number of factors, including social, biological, and environmental factors (Kopec, 2006, p. 9). Therefore, it is difficult to predict how people will respond to a particular situation, on a particular day. Therefore, for this reason 
it is important that circulation spaces allow people to by-pass spaces for group interaction if they do not wish to engage in conversation for any given reason. Thus, it is important that people are not forced into social situations, but rather are provided with the choice to partake in or bypass social situations.

\section{| 7.1.2 | DESIGN RESPONSE - Human Behaviour}

With the generation of communal cluster spaces that were integrated and designed to encourage opportunities for interaction between residents (previously discussed in chapter 5) it was important to design in response to human behavior. This was done by enabling people the choice to by pass communal spaces on their way to and from residential units. Thus, in design, a pass through space was integrated along the back of communal spaces in clusters to enable people to get to their units without having to interact, if they did not wish to do so.

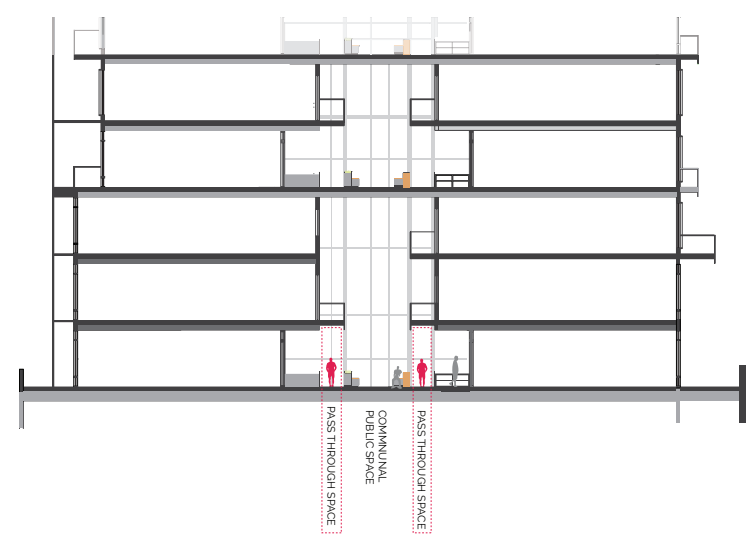

Figure 57: Partial Transverse Section - Pass through spaceresponse to human behaviour

This pass through space was separated from communal cluster spaces by a half wall. The space is not too defined to limit people but closed enough to allow people to move through it comfortably. Alexander describes, "you need a frame work that is not enough defined so that people naturally tend to stop there: and so that curiosity naturally takes people there, and invites them to stay," (Alexander, 1977, pg. 348). This,

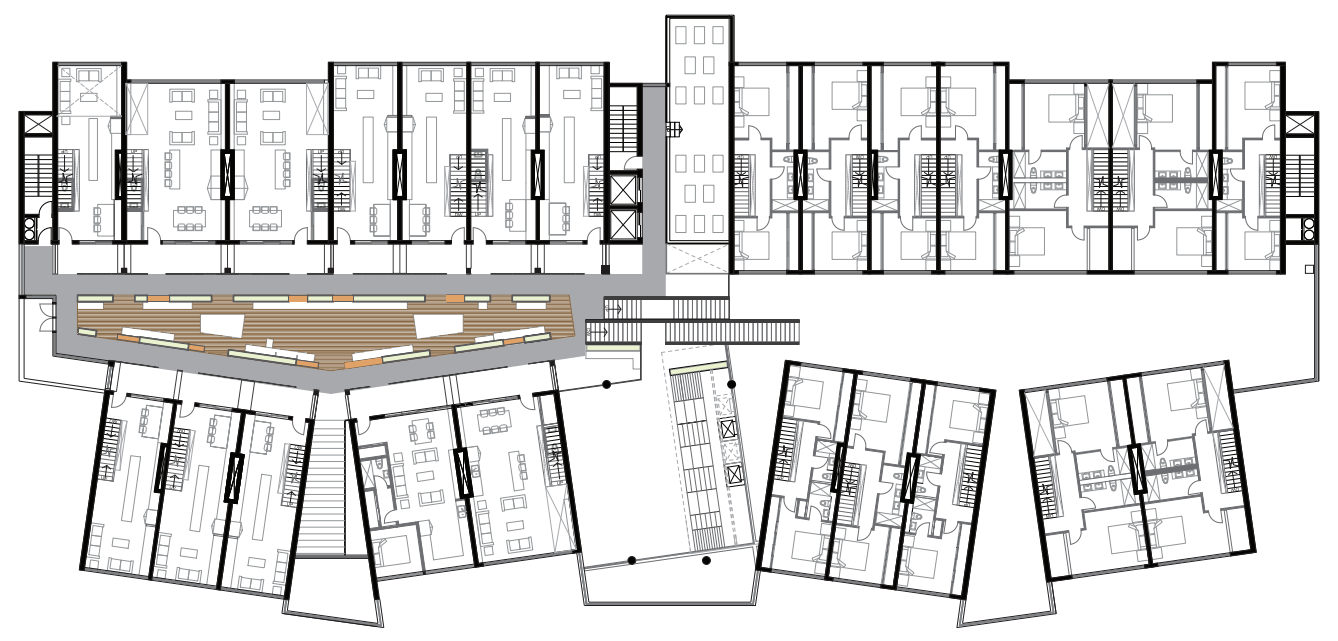

Figure 56: Pass through space highlighted in plan Level 6 
would allow people to pass through, but does not completely limit the possibility for interaction. People are able to see into the communal space, and this can allow residents to engage with their neighbours if they wish to do so. Thus, the circulation system that leads to and from units can promote contact and interaction, or it can enable people to bypass and get to their units.

\section{| 7.2 | GENERATING ENCOUNTERS}

"a key in the way we experience a town or town like structure is the communication routes and the form these take. Inside it is the stairs and corridors, the communication area, which are of particular importance. Their function is not merely to act as a physical link, but much more as a place for encounter, a place for many activities, just like in a town." (1994, p. 67).

Circulation can enable encounters at the neighbourhood scale by connecting residents from various clusters. However, in current condominium designs, elevators are used as the main circulation system, yet interactions in these spaces are formal and brief; discouraging the opportunity for meaningful

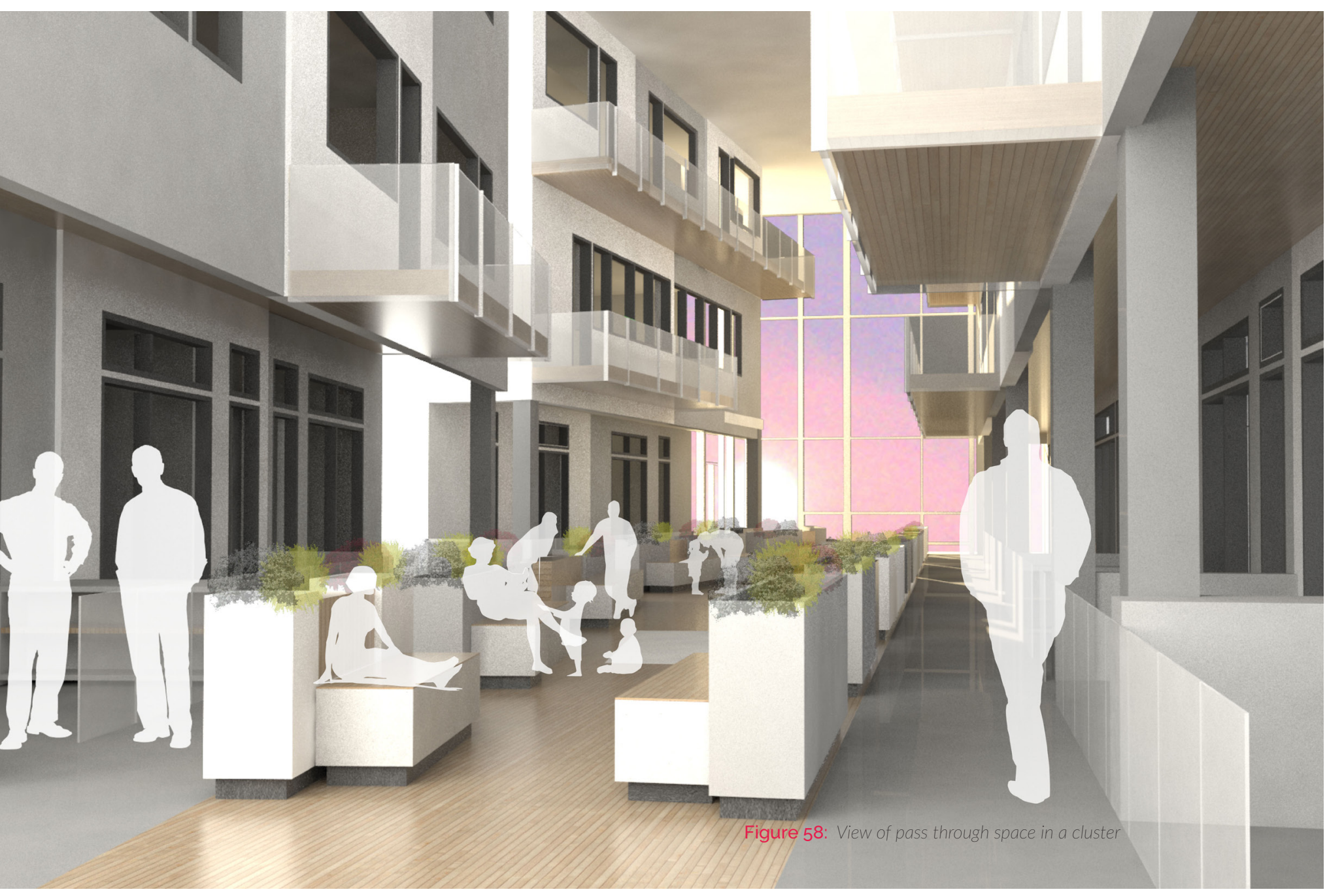


relationships to form. Thus, to improve opportunities for interaction in circulation systems, residents should be encouraged to travel at a lower speed. Gehl describes that "an important factor in experiencing others is that there must be a reasonable amount of time in which to see and process visual impressions" (2011, p. 69). As such, it is important that peoples' movement is reduced to a slower speed in order to perceive details and actively engage in "meaningful social activities" (Gehl, 2011, p. 72). Thus, to generate encounters, residents should be encouraged to travel using a stair system rather than an elevators.

\section{| 7.2.2 | DESIGN RESPONSE - Generating Encounters}

In response to generating encounters, stairs were integrated to connect all the clusters together and provide access to amenity spaces integrated through the vertically of the building. As such, it was important to encourage people to use stairs to move through the building to access communal spaces. Thus, stairs were designed to lead directly out of clusters to enable easy flow and encourage residents to use the stairs rather than using the elevator.

Furthermore it was important that the circulation system was highly visible from all communal spaces

Figure 59: View of circulation leading directly out of a cluster

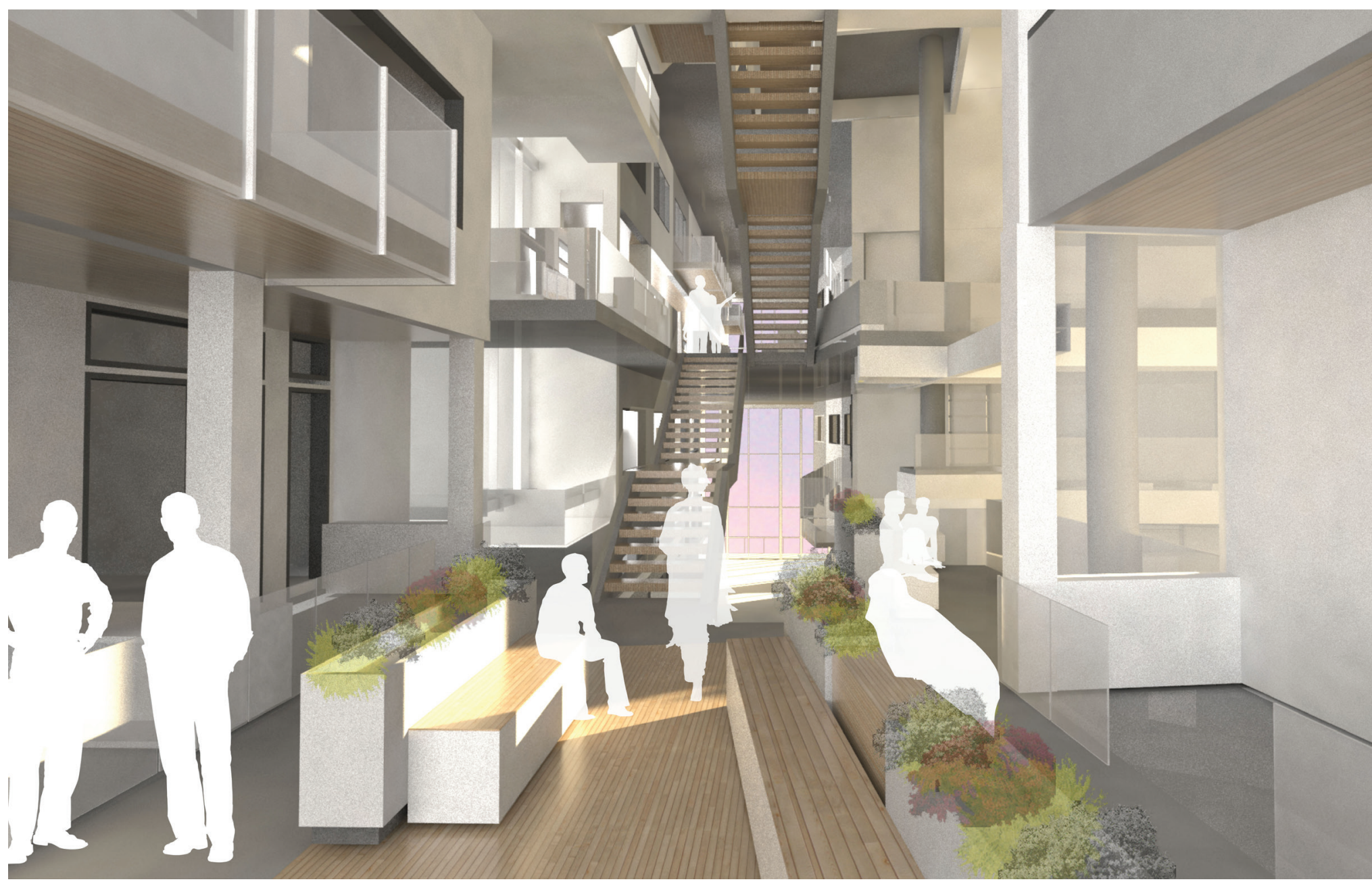




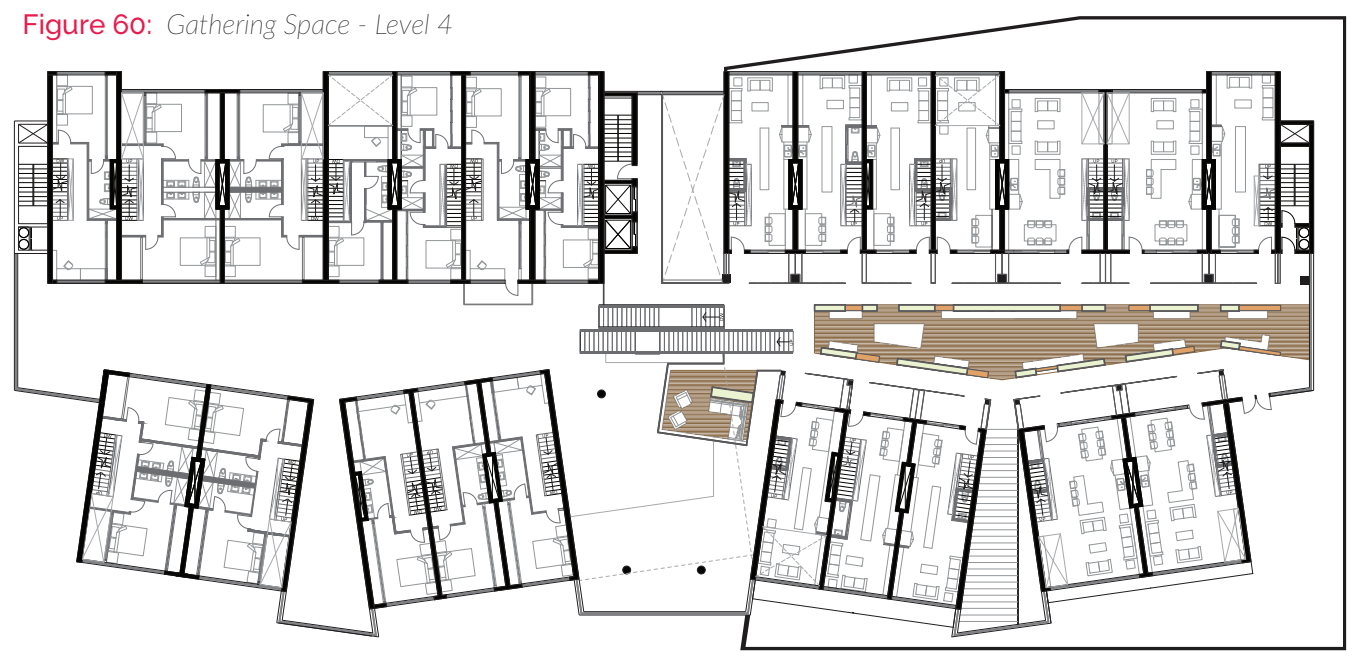

Figure 61: Play Space - Level 6

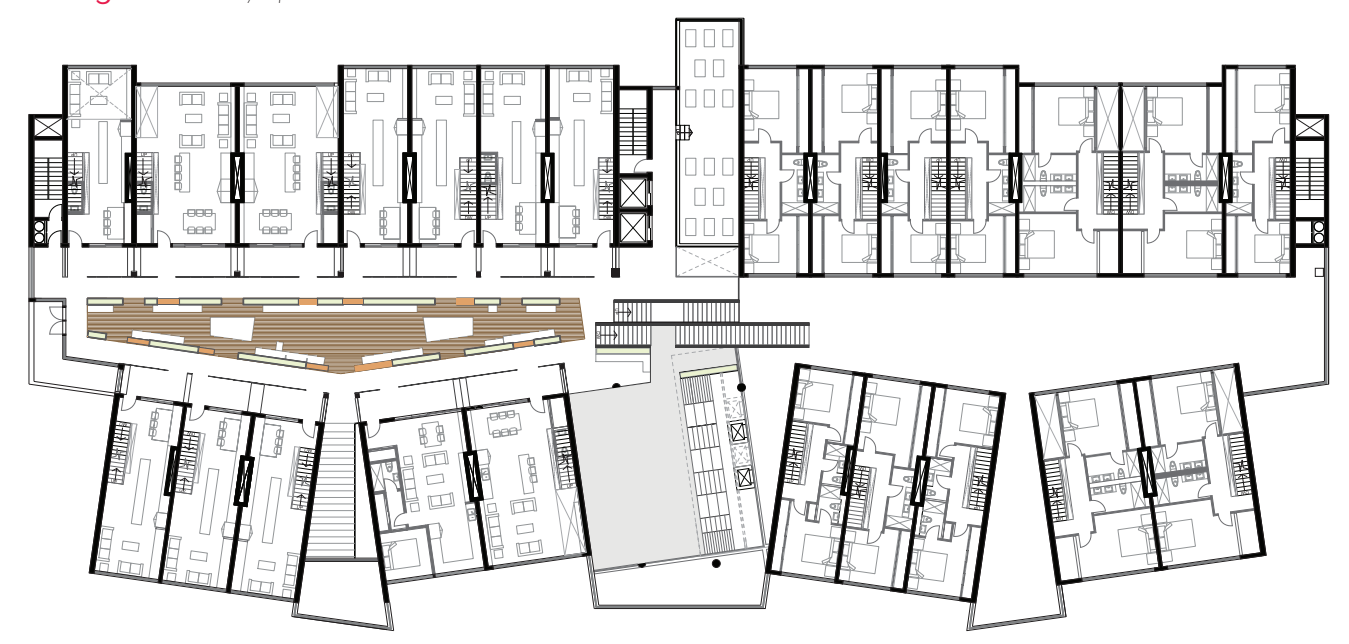

Figure 62: Play Space - Level 7

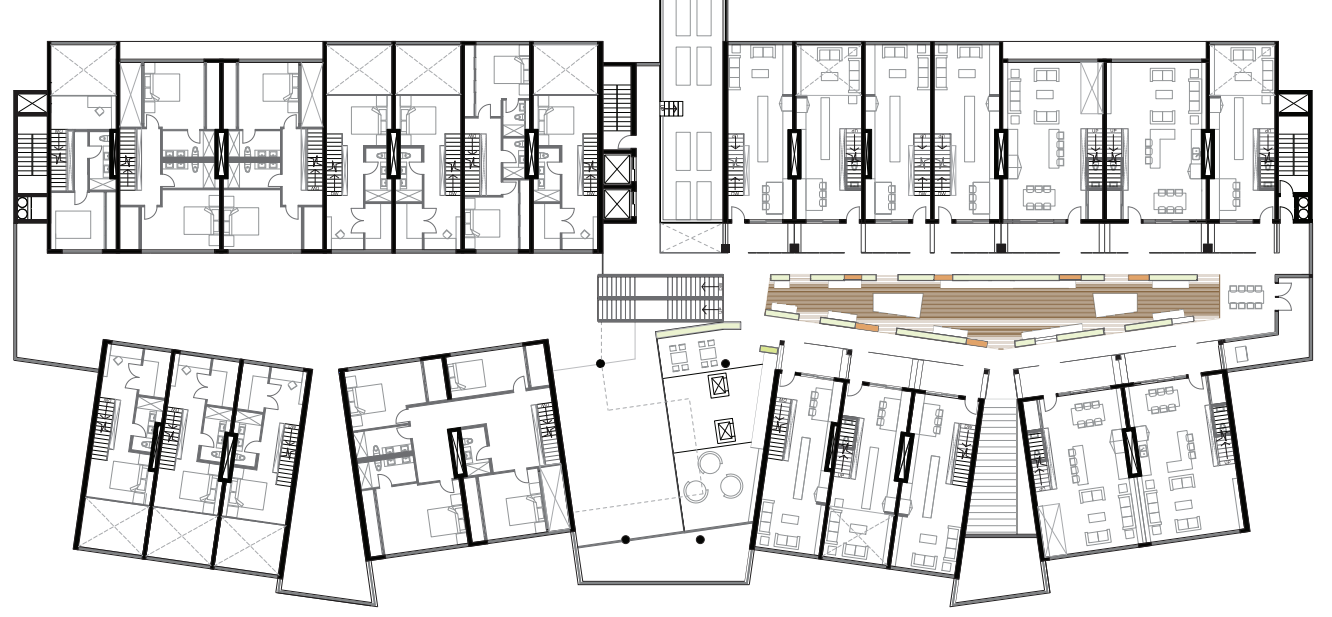


and housing clusters, as the ability to see and hear others using public spaces outside their home can greatly influence the sense of community and encourage others to participate. As such, the stairs were designed to connect all the programing in the building through a main circulation system. In addition, the stairs were designed to incorporate moments of pause. where people can look out onto the communal spaces, or stop to engage with other residents.

\section{CONCLUSION}

In conclusion, circulation systems can play two significant roles. Firstly, circulation can provide residents with choice to engage or bypass social situation on their way to and from their units. Secondly, it can promote social interaction by integrating a stair system that is highly visible and connects all clusters and communal spaces. These design responses can help residents within clusters to feel comfortable while also creating the opportunity for residents from the various clusters to interact with one another as this design response connects all the residential programming.

Figure 63: Longitudinal Building Section: Circulation connecting clusters \& communal spaces

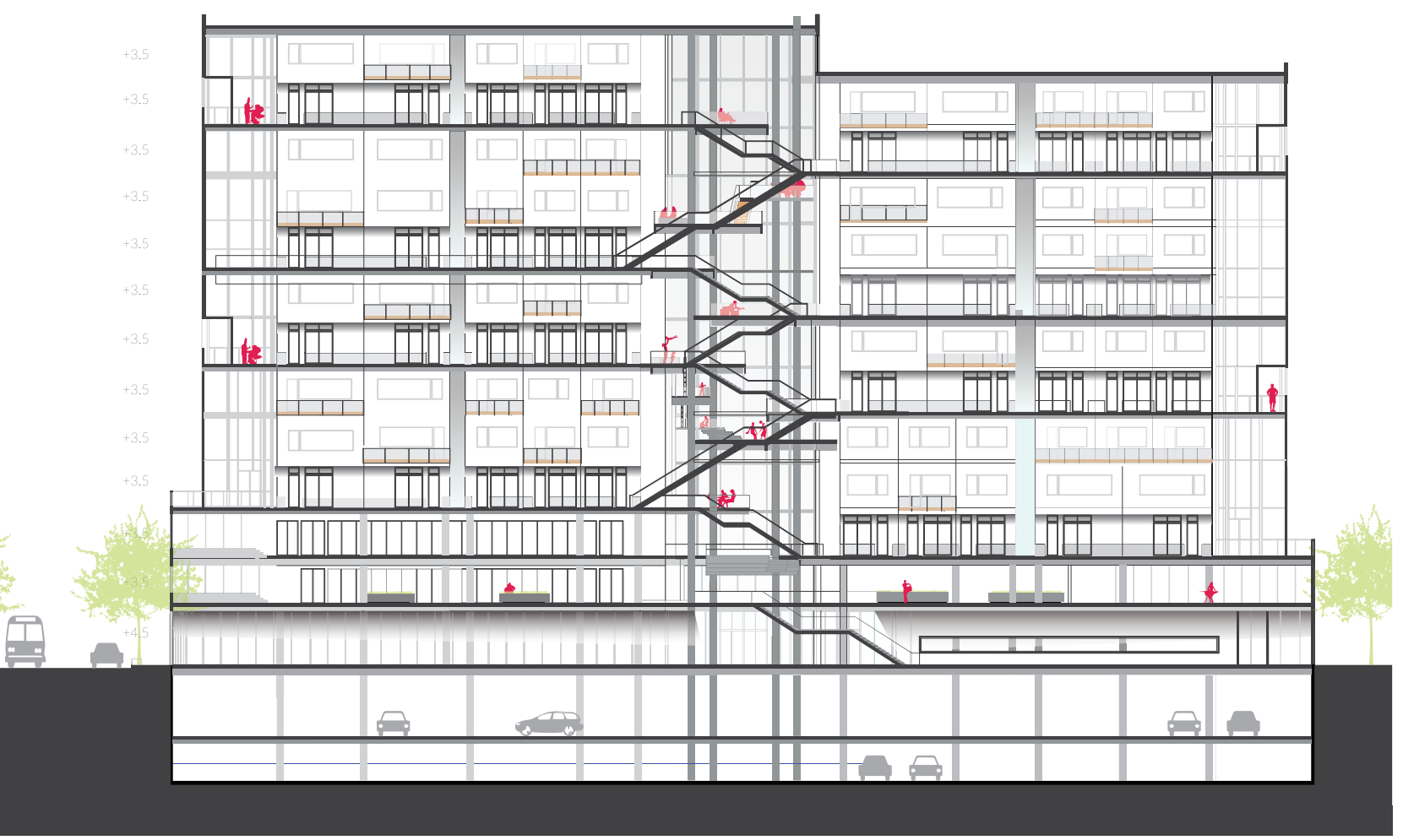




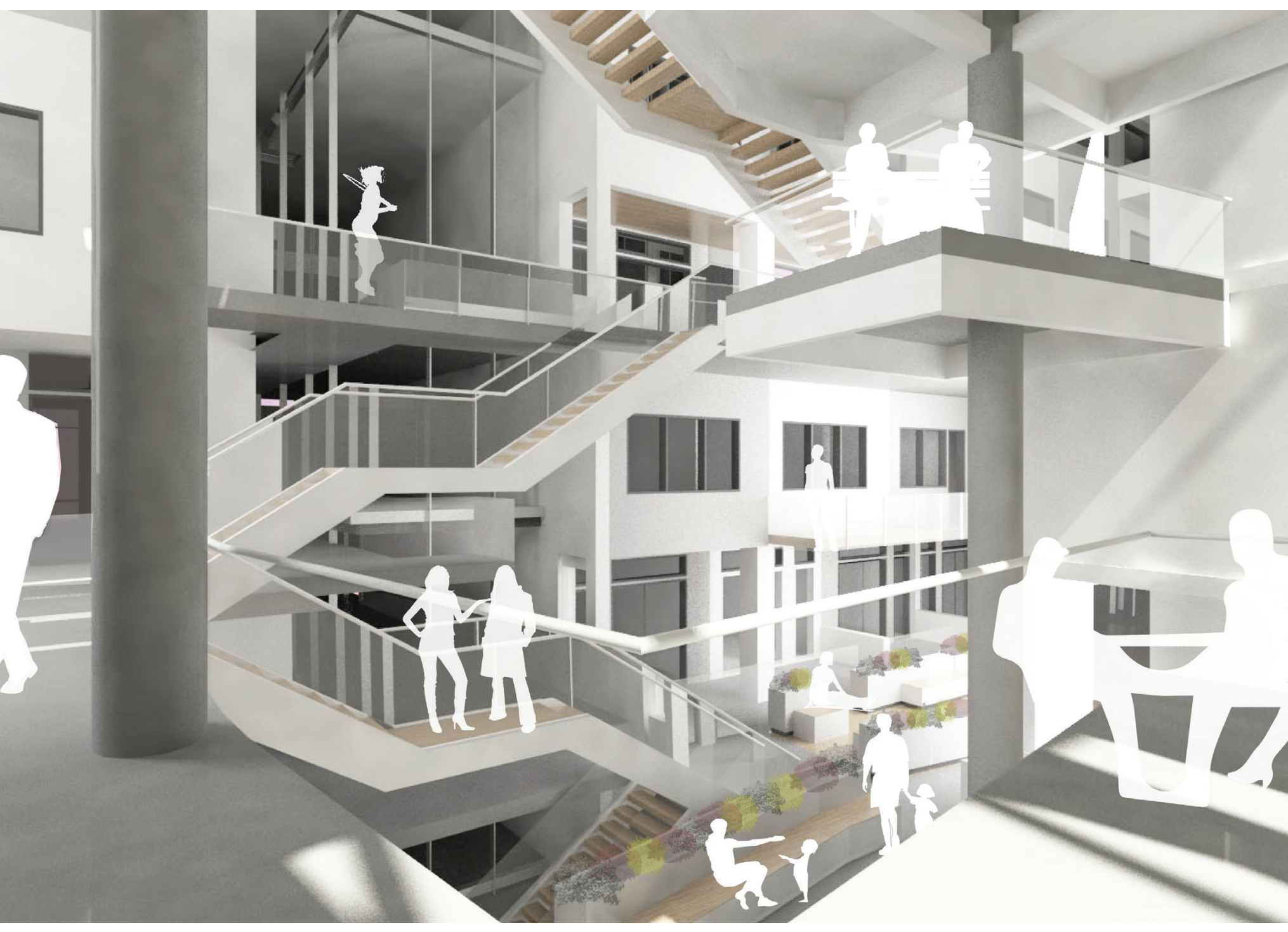

Figure 64: View of circulation connecting clusters \& communal spaces 



\section{| 8 | RESPONSE TO CONTEXT}

This chapter begins by identifying the theoretical principles associated with site design. It will then go on to analyze the current approaches to podium design in condominium developments and their impact on the city at large. The chapter will proceed to discuss the character of the selected site and demonstrate how the lessons and analysis learned through this study were addressed in this thesis project. The intent of this chapter is to provide opportunities for interaction between building residents and members of the greater community.

\section{THEORETICAL ISSUES}

Filip Balestra suggested, "you don't walk into a meeting late and start talking, you start listening" (Incremental Strategies for Vertical Neighbourhoods, 2014). For this reason, when addressing the design of a site, it is important to respond to the existing characteristics already in place. These may include, the history of a site, its existing role within the community, the characteristics and identity of the residents.

Further to this, it is important that the site's strengths and weaknesses are identified so that appropriate decisions can be made to subtly make poor conditions better and maintain the existing conditions that are working well. For example, Van Eyck focused on designing to develop a relationship with the urban environment, where his designs aimed at creating "interactions with the surrounding urban tissue," (Aldo van Eyckand the City as Playground, 2013). Furthermore. he focused on designing "incremental adaption, instead of the tabula rasa approach of modernism" (Aldo van Eyck and the City as Playground, 2013). By adapting these method for incremental strategies, it can help to generate an appropriate design response to the surrounding context, by maintaining and responding to the role that a site plays in its local context. This would further ensure that a building maintains its role within its community.

\section{| 8.1 | CURRENT RESPONSE}

Currently, condominium developments in the City of Toronto have responded to the migration of young professionals into the city core. As such, some businesses and retail developments have recognized that once families grow, the condominium market can no longer support their needs. Thus, local businesses and retail have simply responded to a limited demographic and as such, these have provided little support for families with older children.

Furthermore, many of the condominium developments lack a response to the existing character 
of the site at grade, as many have taken a tabula rasa approach where the podium is given to large franchises. In other cases, the condominium podiums house the private amenities for residential units. These approaches have undermined the significance of a site's history, its characteristics, its role in the community and the character of the people.

The podium design however, has the potential to provide opportunities for interaction between residents and members of the greater community. This can be done by responding to the role of the site within the community and providing public amenities that can invite and support their activities. Further to this, by incorporating program for residents as well, there will be opportunities for encounter between residents of the building and members of the community.
Thus, the podium belonging to condominiums can invite the greater community by integrating spaces in response to the characteristics and needs of the surrounding context. This involves an understanding of the sites history, role within the community and the characteristics of residents.

| 8.1.1 | DESIGN RESPONSE - To Site Characteristics \& Incremental Adaption

The site selected for this thesis project is 581 Bloor Street West, currently home to Honest Ed's. The site has played a significant role in the community since 1948, as the store provided low-priced merchandise and was a main destination for community members. Throughout the years, the Mirvish family maintained low rent fees, which allowed for small businesses

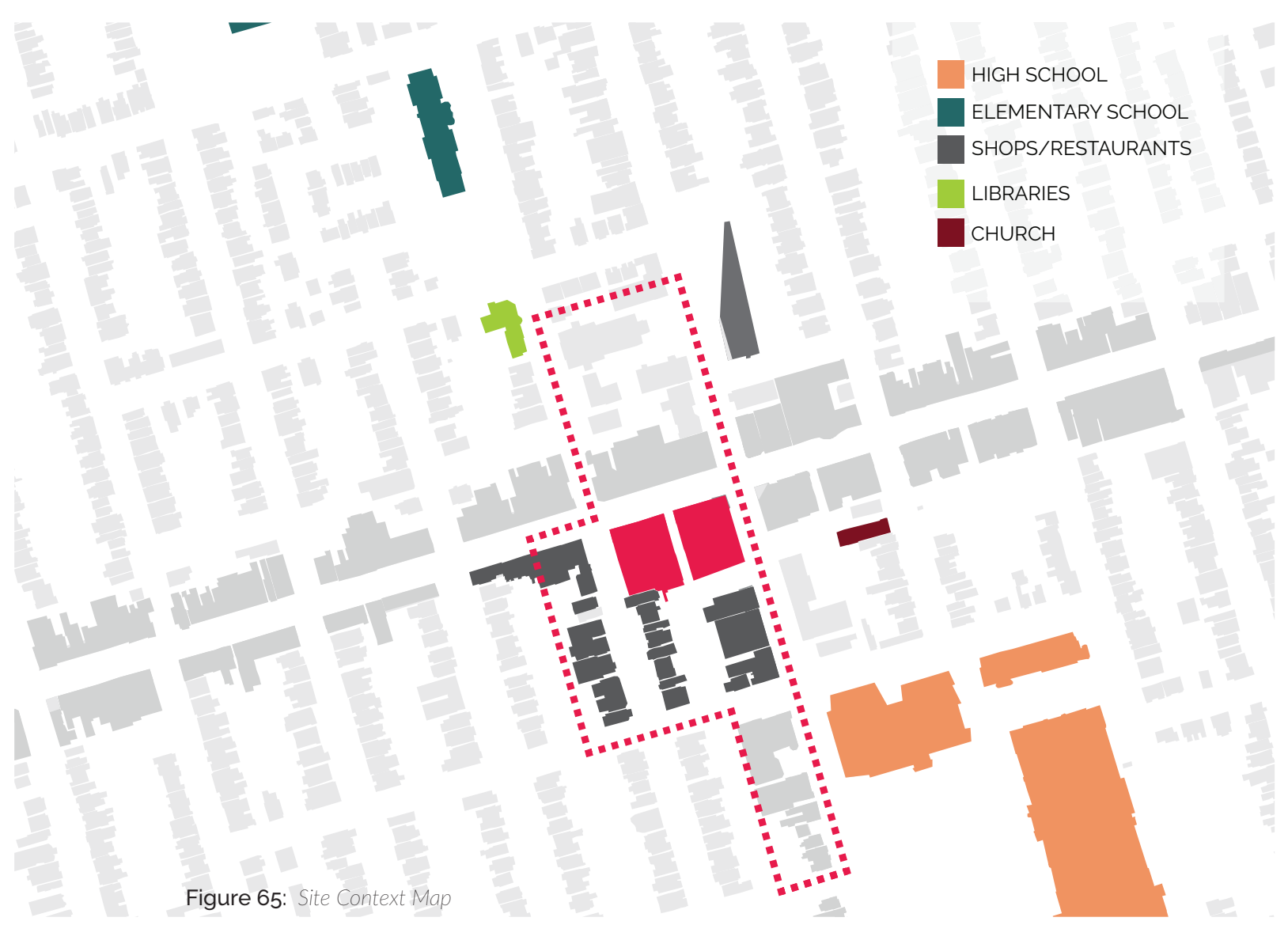


to flourish (Kuitenbrouwer, 2013). Furthermore, the surrounding area has been recognized for its art, culture, and cuisine, featuring; restaurants, art galleries, book shops, comic book store, movie theatre and a record store. There are also a number of high schools and elementary schools, namely Central Technical School that offers great technical programs as well a visual arts center. To the west of the site is Markham Street, a charming venue for retail and restaurants. The site is also an active place for community events.

The alleyway featured through the site is both a means of access as well as an event space. It has generated a sense of community by accommodating events that include: adult craft night, story telling, beer tents and a night market.

A response to site requires that important functions and characteristics are maintained. In the case of Honest Ed's this meant that the site should be able to continue to host community events. However, because all of Mirvish Village has been sold to West Bank Developers, the laneway at the back of the site
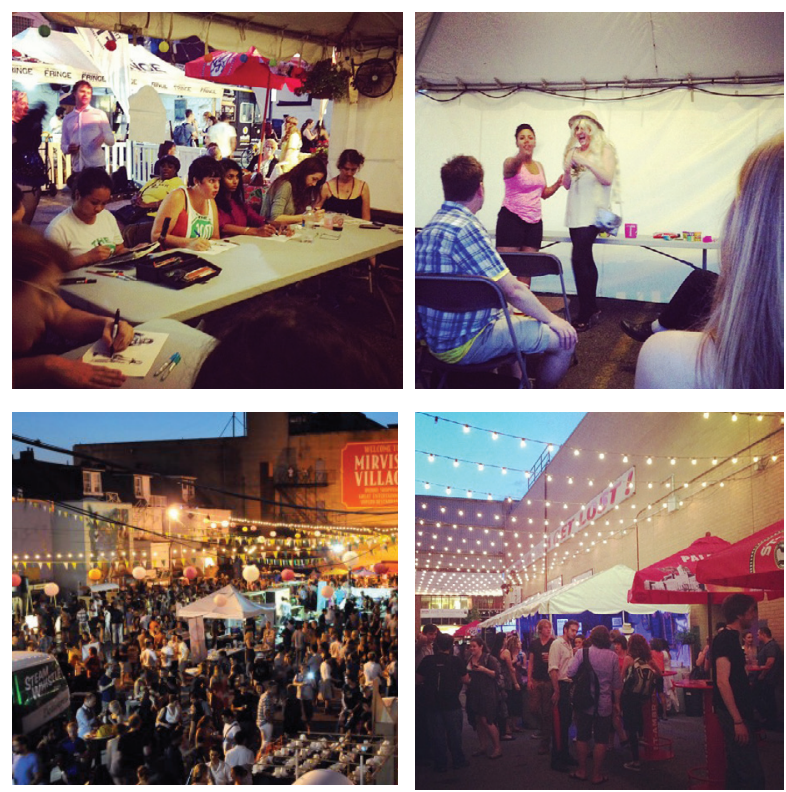

Figure 66: Adult craft night, story telling, night market \& beer tent may not be available in the future.

The laneway has two functions; it has allowed people to pass through, as well as hosting community events. The laneway however, presents the opportunity to accommodate people on a regular basis. As discussed above with Van Eyck's approach for incremental adaptation, there is an opportunity to identify the potential and address the disadvantages of the site. Currently, on a daily basis the laneway functions simply as a pass through space, and creates a wind tunnel effect. As such there was an opportunity to enclose a part of the laneway on site. while still maintaining its function as a pass through space. Next, because the site has been sold, and its unknown whether the laneway will be maintained from Bloor to Lennox, a new laneway was incorporated to link Bloor and Bathurst. The space is smaller, but can still accommodate outdoor events. Furthermore, it was important to increase the use of the laneway and improve opportunities for interaction on a daily basis To accomplish this, the space needed to provide opportunities for staying, and not simply passing. Thus, informal seating was provided into a sloped ground plane. In this way the site can continue to be a destination point. Furthermore, restaurants were programmed at the back of the site to continue the character on Markham Street, which were designed to spill into this space. This design move was intended to populate the back laneway and create a vibrant environment as it was important to provide programming that will not close early in order to keep the site active and safe. Shaftoe describes, that people are attracted to "rice, vibrant mixed-use environment, that does not die at night or on the weekends and is (are) visually stimulating and attractive to residents and visitors alike" (2008, p. 71). 
In addition, on the ground plane it was important to respond to the small-scale retail in Mirvish Village to enable small business to flourish, and as such, maintaining the character of the site. By creating smaller store frontages it can help contribute to creating a human scale and contribute to the life on the street, Gehl describes that the, "principles of good human scale must be a natural part of the urban fabric in order to invite people to walk and cycle" (Gehl, Cities for People, 2010, p. 59). Thus designing to allow for small business to occupy the ground plane, not only helps to maintain small businesses on site which have been important to the area, but it can also contribute to the city and create a comfortable pedestrian realm at grade.

The building form features a canopy to create a comfortable walking environment that elevates across the face of the building to draw the eye of pedestrians to the main building entrance. This design move was done in response to Gehl's literature. where he states that people predominately see in the horizontal direction, and as such the "challenge is to build splendid cities at the eye height with tall buildings rising above the beautiful lower stories" (Gehl, Cities for People, 2010, p. 59). Furthermore, the building form was pulled back from the street, to open up the space for pedestrian movement.

\section{| 8.2 | INVITING RESIDENTS \& THE PUBLIC TO INTERACT}

The integration of functions can create an environment that enables different individuals to function together in the same space while doing various activities at the same time (Gehl, 2011, p. 107).

Figure 67: Ground Floor Plan
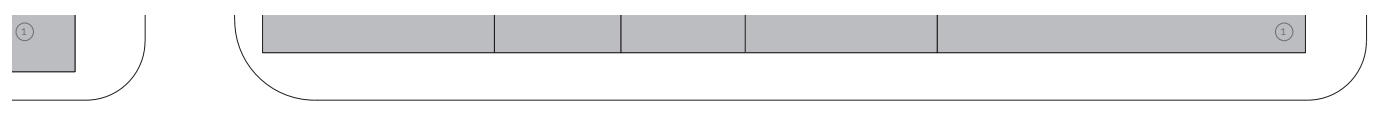

BLOOR STREET
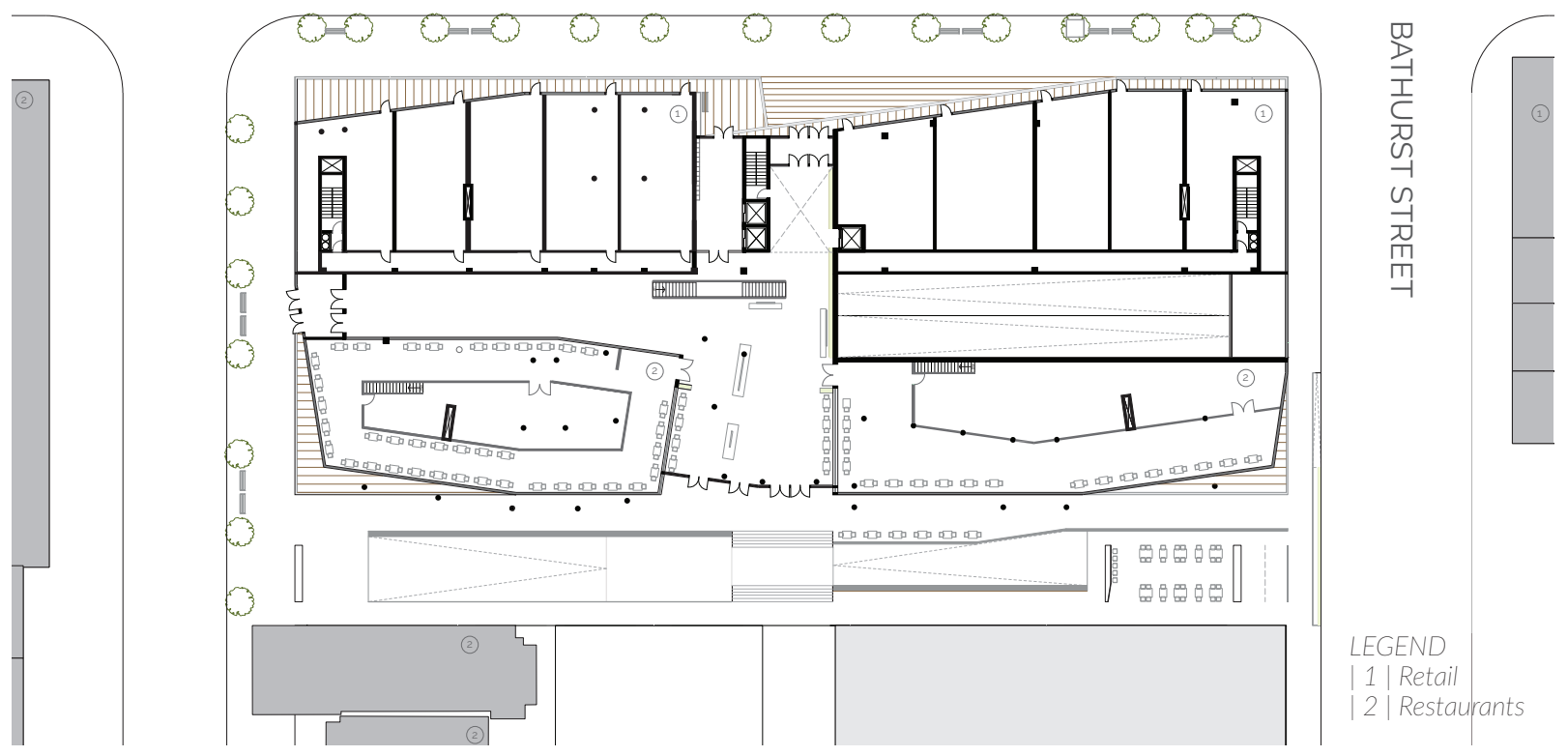


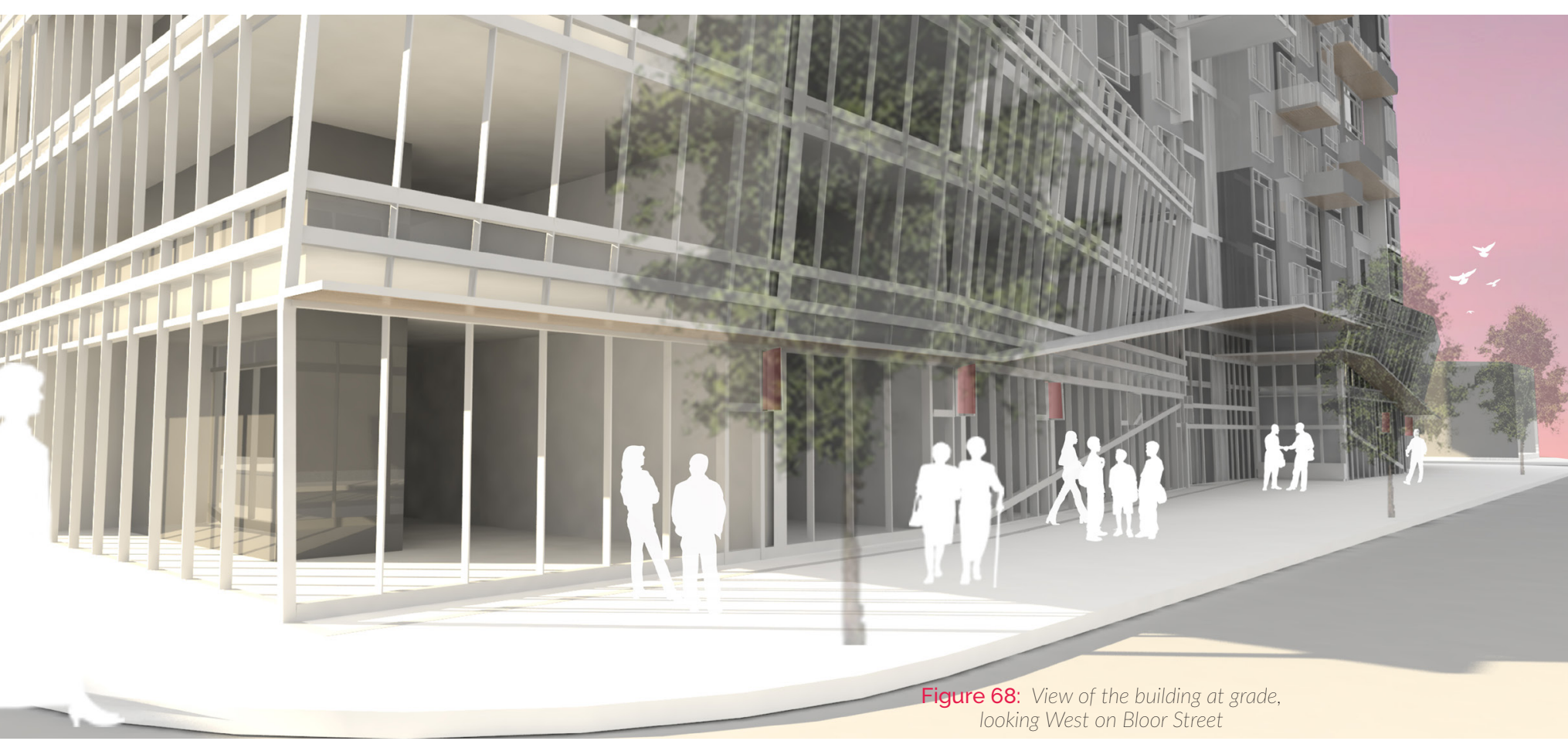

To enable interactions between different people to take place it is important that there is an understanding of the different activities that people partake in. These have been outlined by Gehl and include; necessary, optional, and social activities (2011, p. 11). Necessary activities involve people going to work, school, running errands; optional activities are ones which people do if they want to and if the opportunity to do so is there: and lastly, social spaces are "all activities that depend on the presence of others in the space" (Gehl, 2011, pp. 11-12). An understanding of these three activities can

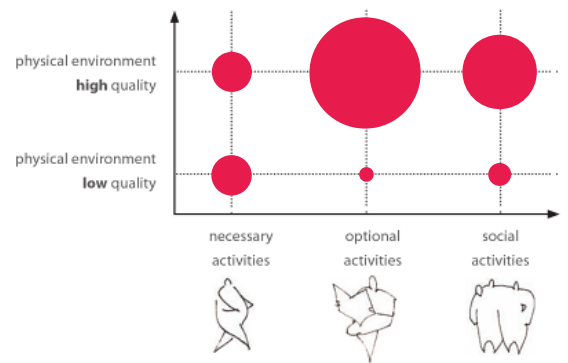

Figure 69: Jan Gehl's Necessary, Optional \& Social Activities help designers to integrate functions for different users to promote different people to cross paths. This would present the opportunity for different people to interact.

\section{| 8.2.1 | DESIGN RESPONSE - Residents \& Inviting The}

Public \& To Interact

These ideas presented for necessary, optional and social activities were used in conceptualizing and designing the podium and in particular, the second and third floor in order to create opportunities for interaction between residents and members of the greater community. Firstly, for the residents, laundry facilities were incorporated in the podiums second level. This would ensure residents' use of the podium. Doing laundry would be classified as a necessary activity. Also, spaces were allocated to support start up businesses (incubators) in response to Mirvish Village having been known to support small businesses. These would also be classified 
as necessary activities. Secondly, in order to attract people from the surrounding community to the site, spaces were allocated to accommodate community programs. These are anticipated to respond to the richness in arts and culture in the surrounding area, and as such were anticipated to include spaces for dance, music, painting, and possibly an education center for children, and adults. Such programming would also respond to the needs of families. These programs would be classified as optional activities. In addition, there are opportunities for social activities in the circulation spaces that link all of these programs together. These spaces were designed to be open to allow for easy flow, as well as incorporating moments of staying.

The integration of these programs would enable a diversity of people, both building residents and community members the opportunity to interact with one another or at the very least have the opportunity to cross paths and share the same space.

Figure 70: Second Floor (Scale 1:600)

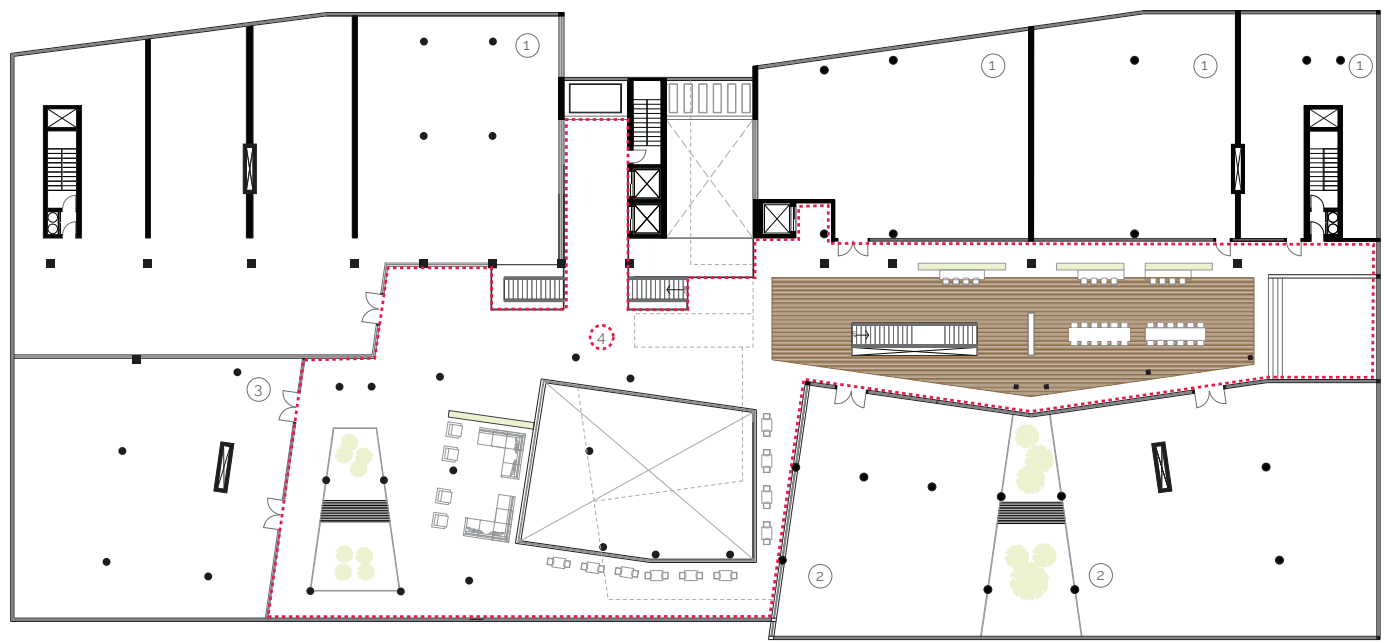

Figure 71: Third Floor (Scale 1:600)

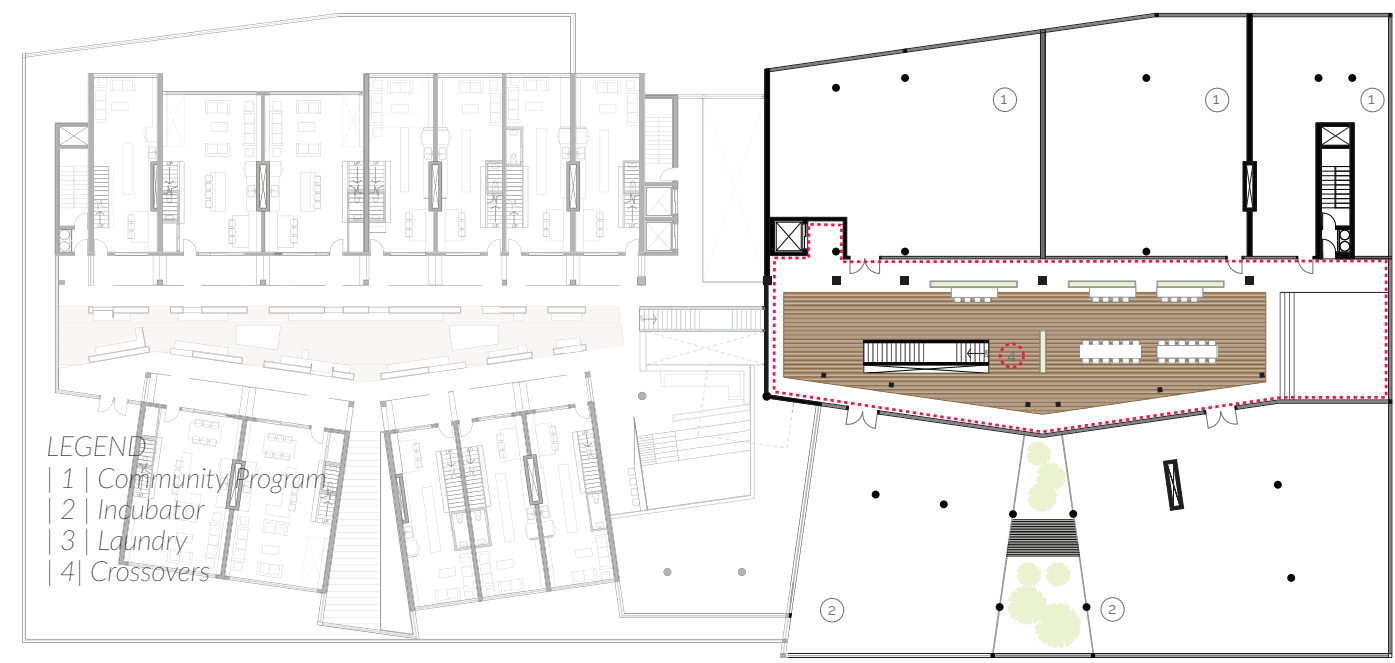


The benefits for designing for the integration of functions can also contribute to the health and well being of residents. Research supports that, "people grow only by the processes of encountering the unknown and the best places to encounter difference and the unfamiliar are public spaces, where all segments of society can cross paths, mingle and be observed" (Shaftoe, 2008, p. 19)

Furthermore, spaces were designed to allow for visibility in public spaces as this design response can further enable social interaction. "As a species we are sociable animals who like to gather in groups or packs. Thus, when we see people like us lingering in a space. we are attracted to it, over and above any physical or environmental attractions that the place may have" (Shaftoe, 2008, p. 66). Thus, designing to allow people to see one another can improve the use of a space, as it can attract other people to it. As such residential communal spaces were designed to come down into the podium. This would allow visitors to visually engage with the architecture in the building that supports social interaction between residents in the building above.

\section{| 8.2.2 | CONCERNS/ INQUIRES/RESPONSE}

Although the podium was not designed in great detail, the main concept for creating spaces that were inviting, open and accessible to the public was achieved The intent was to create spaces that allows residents and community members to interact -- a design move that is not enabled in current condominium designs which house big franchises or private amenities for residents.

Figure 72: Longitudinal Section - Crossovers between residents \& community members (Scale 1:600)

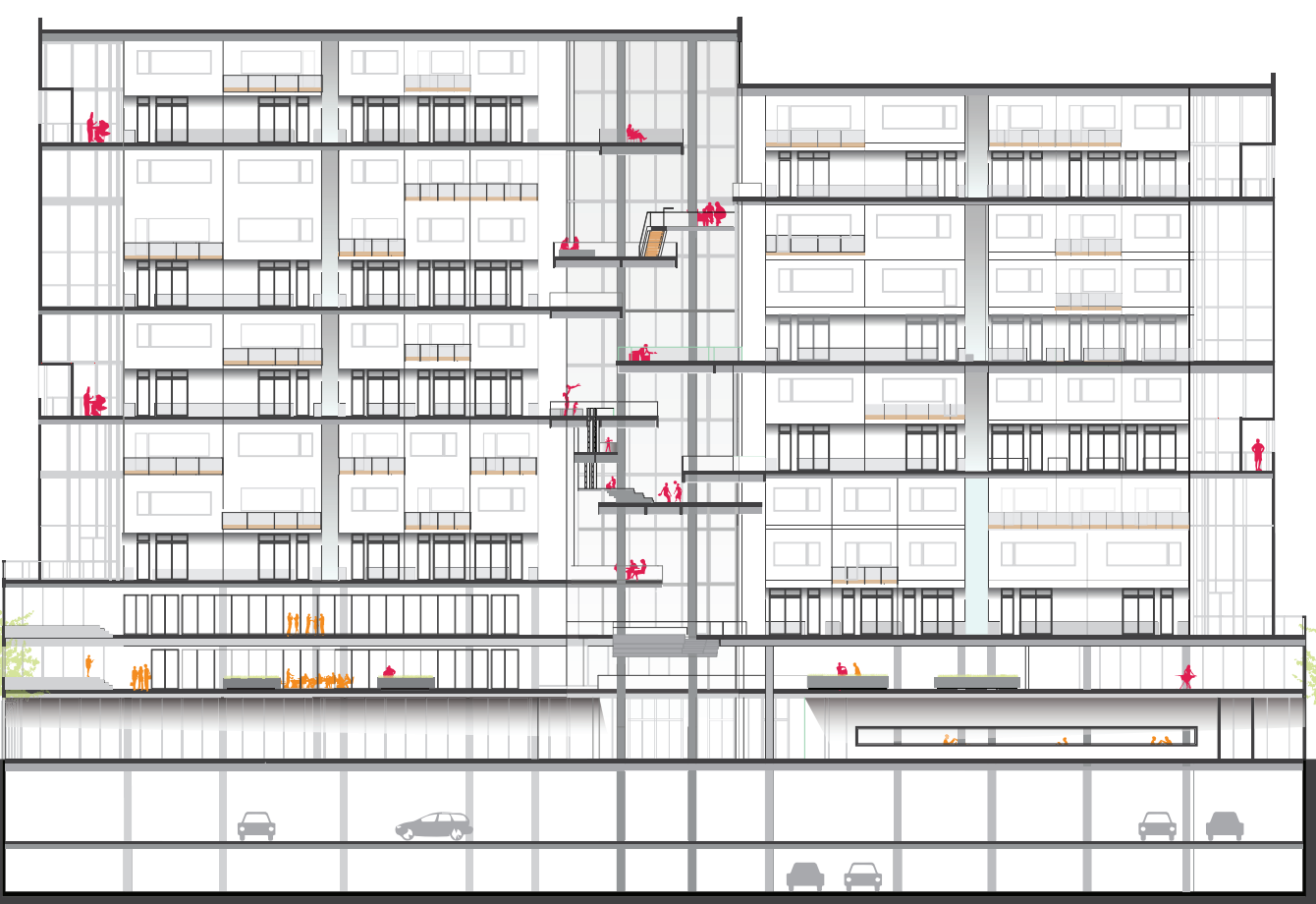




\section{| 8.3 | RESPONSE TO HUMAN BEHAVIOUR - ELEVATION DESIGN}

Building elevations should be designed with an understanding of what people see when they are walking and how many stories of a building influences pedestrians walking by. Research found that people see predominately in the horizontal direction, and this also enables them to see movement further out (Gehl, Cities for People, 2010, p. 39). Furthermore, because "the upper floors of tall buildings can only be seen at a distance and never close up." pedestrians walking by do not see beyond the fifth floor of the building (2010, p. 39). In addition to people mostly seeing in the horizontal direction, they also like intrigue. Shaftoe describes that "physiological attractors of a good public space is the promise to satisfy our innate curiosity...people like to
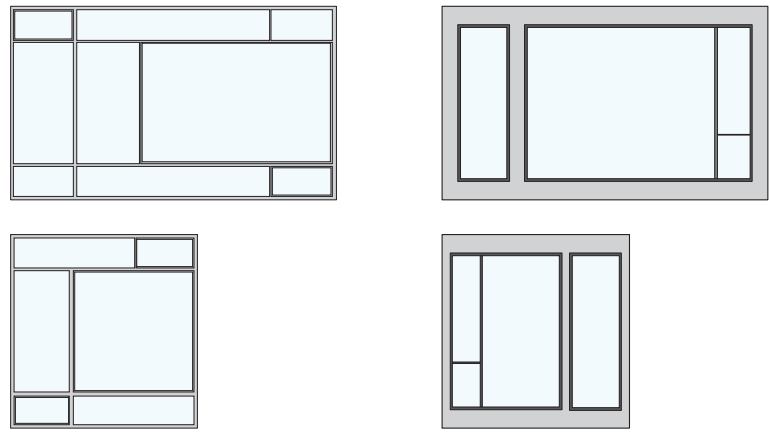

Figure 74: 4 Modules - 2xGlass Panels - 2xConcrete Panels

be intrigued that there is more to a space than initially meets the eye" (2008, p. 55).

\section{| 8.3.1 | DESIGN RESPONSE - Elevation Design}

The goal with the elevations was to express the richness inside the building. For this reason, residential

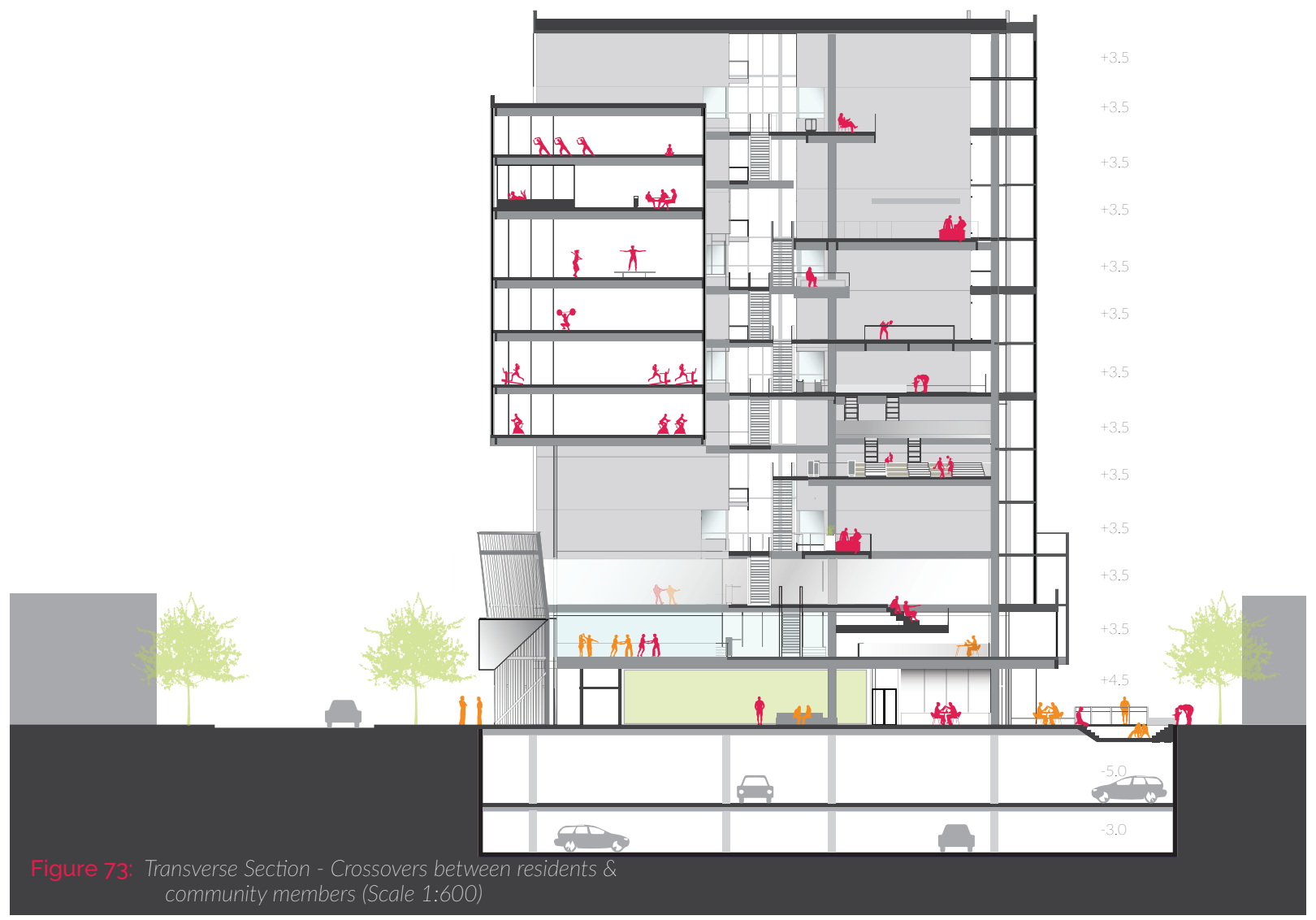




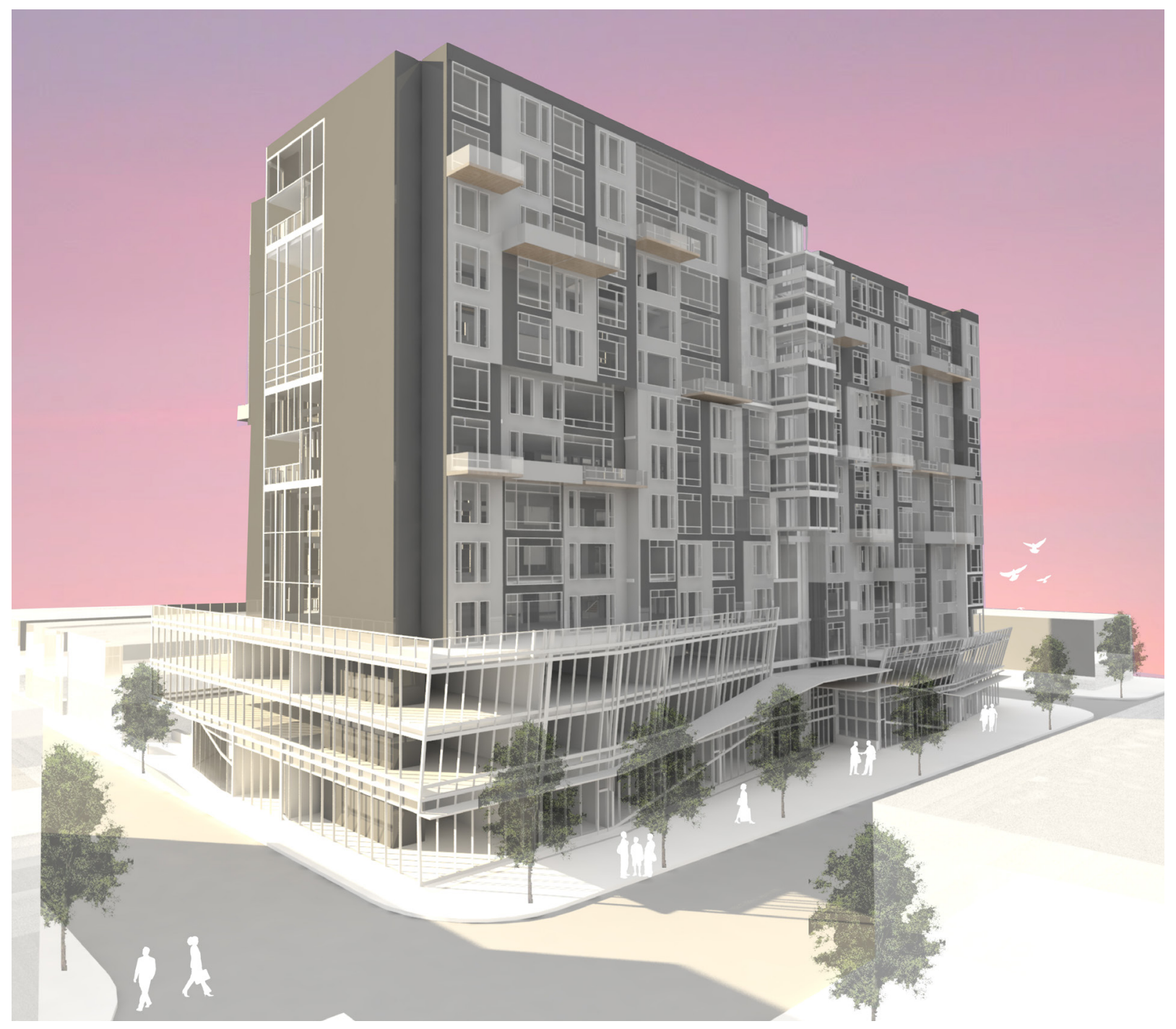

Figure 77: View of the front of the building at Bloor Street looking West to Markham Street 


\section{| 9 | CONCLUSION}

Architectural responses to sustainability should focus on generating human health and well - being by creating adequate opportunities for people to interact socially and by recognizing that people seek the presence of others (Gehl, 2010, p. 25). This response can contribute to the health and sustainability of both individuals and cities. Yet, the built form does not adequately provide sufficient opportunities for people to interact socially. This is especially evident with the design of current condominium developments in the City of Toronto, which are mainly controlled by developers whose intentions are to maximize profits.

Initially, city planners and policy officials recognized high-density condominium developments as a suitable option for the sustainable growth of the city. These were intended to allow a greater number of people to benefit from the existing infrastructure and nearby amenities already in place. while also helping to mitigate the development of suburban cities. However, these high-density developments have instead contributed to the growth of sprawl and have shaped the demographics across the GTA and created a monoculture in the downtown core. This is a result of small condominium units and a lack of communal spaces, which are not attractive to families who seek larger units, as well as opportunities for community engagement. Thus, once the needs of families with children evolve and exceed what condos can provide, they migrate to the suburbs and as a result, high-density condominium developments are simply appealing to young professionals. Therefore. the intention to grow sustainably by densifying the downtown core has created the opposite effect and contributed to the growth of suburban cities.

However, although specific typologies are attractive to a particular demographic, neither of the current built forms, from high to low-rise developments, are adequately providing opportunities for interaction. This is because they each carry large numbers of people and are designed with a separation of uses where communal spaces are distanced from units. They each function with the use of a high speed circulation system (either the car or the elevator) and lastly they each lack a response to context. Thus, neither of these typologies are contributing to the health and sustainable growth of the city. However, densification should become a viable option for sustainable growth by accommodating people in various states of their life, and in particular, families with children as the predominate typologies in the city have not responded to their needs. Thus, to accommodate families this can contribute to the health of individuals and the 
sustainable growth of the city, densification should focus on generating clusters to allow for interaction to take place at a smaller scale, integrate communal spaces with housing units, circulation for choice and encounters, and lastly, design a podium in response to context, Further to this, it is important that these principles are applied in combination with strategies and tactics for encouraging interaction. These include: designing to allow for visibility of people, responding to human behavior, responding to demographics, and designing livable spaces. These principles and strategies were applied in combination to design a mid-rise residential building in the City of Toronto that focused on creating adequate opportunities for social interaction to enable human health and well-being and in turn, contribute to the health of the city.

The first principle was the generation of clusters, which responded to the large number of units housed in current condominium developments, which are intimidating and reduce the potential for social interaction. Thus, the generation of clusters focused on managing densities by grouping eight to twelve units together to enable interactions to develop comfortably. Two clusters were created side-by-side, and separated by a floor to allow for visibility between 1 or 2 clusters. In addition, fourteen units were designed to create diversity among demographics and to further increase the potential for interaction among residents. These units were combined to create diversity in the clusters, and in this way each cluster is unique. but carries a similar number of $1-4$ bedroom units to ensure diversity among residents. Furthermore, to help decrease the possibility of residents becoming territorial to their clusters, units were designed to crossover into another cluster. In addition, communal spaces were integrated between units in each cluster to support and accommodate interaction between residents These spaces were designed to accommodate various scales of interaction at which they wished to engage with their neighbours; whether with one or two individuals or all the residents of the community Further to this, transitional spaces were incorporated to encourage residents to flow comfortably from their units and into communal spaces. Through these design moves, the generation of clusters aimed to alleviate the intimidating effects of large populations in high-density developments to create the opportunity for residents to interact with the immediate neighbours in their clusters.

The second principle is the integration of communal spaces, a response to the current condominium developments where amenity spaces are highly segregated from the units. This separation of functions has decreased the use of communal spaces and more importantly, reduced opportunities for social interaction between building residents. As such, the design response in this thesis project focused on the integration of communal spaces with residential units to allow for direct visual and physical access from each cluster. Furthermore, the communal spaces were concentrated to enable them to support and function together. These were placed and designed in response to different age groups and were intended to create opportunities for various activities and ages to work together. Thus, the integration of communal spaces with housing units creates opportunities for interaction between residents form various clusters at the neighbourhood scale.

The third principle is circulation to provide choice and generate encounter; a response to the current approach to circulation networks which are simply regarded as a functional link and movement spaces. 
With the integration of communal spaces in front of units, it was important to incorporate a pass through space in response to human behavior in order to allow people the choice to by pass communal spaces if they did not wish to interact on any given day. Secondly, this principle recognized that social interaction is brief in elevators and interaction in these spaces do not contribute to creating a sense of neighbourliness. As such, it was important to integrate a stair system to link all clusters and communal spaces and encourage residents to use them as opposed to the elevator system. By encouraging people to slow down their speed, it can help them perceive details in a space and actively engage in meaningful social activities. Thus, the role of the circulation in this thesis project was identified as more than a functional link but as a system to respond to human behavior and further facilitate opportunities for social interaction.

Lastly, the fourth principle is to respond to context. Many condominium developments have taken a tabula rasa approach, by either accommodating big franchises or housing private amenities for residents. Yet, neither of these approaches contribute the city or to the surrounding context and are inadequately providing opportunities for interaction. However, it is important to identify and respond to the characteristics of a site and its role within the city and to create opportunities for enabling social interaction at the community scale. In this respect, 581 Bloor Street West was selected. The site is currently home to Honest Ed's and plays a significant role within the city and it was important to maintain its role as a destination point and, to support community needs. As such, spaces were designed to be inviting, open and accessible to the public. Further to this, opportunities for interaction were generated by identifying programs as necessary, optional and social activities and integrating them to create opportunities for interaction between different users and different activities. This involved integrating optional activities such as community support programs, incubators, restaurants and necessary activities for residents such as laundry facilities. The integration of programming for different users creates the opportunity for engagement between a diversity of people at the community scale. In conclusion, this thesis project has demonstrated how a multi-story residential building can be used to foster social interaction to generate a neighbourhood that provides variety in housing to enable for a diverse demographic to reside in the city while generating social contact between people. This thesis project recognized that architectural responses to sustainability should also focus on contributing to human health and well-being by creating adequate opportunities for social interaction in addition to growth through densification. These goals were accomplished when the principles identified in this thesis project were used in tandem through the: generation of clusters, the integration of communal spaces, with housing units. circulation for choice and encounters and lastly with a response to context. 


\section{| 10 | REFLECTION}

This thesis project has challenged the current approach to the design of condominiums in the City of Toronto. The strength of this design project is in its inherent understanding for how spaces should be placed in relationship to one another, to encourage and facilitate social interaction through research and analysis about how people use space, what attracts them to a space and a response to human behaviour.

However, because this project has simply dealt with the design constraints that inhibit social interaction, this thesis has overlooked the economic aspects for the projects development, and the maintenance and management of communal spaces. Thus, further research should investigate how financial constraints would influence the design -- what would be possible, what can stay the same, and what is limited by cost. This also opens the opportunity for greater consideration and design development for cost savings in both unit and communal space design.

The consideration of these factors would be immensely interesting because they will challenge the ideas presented in this thesis, and it would showcase to what extent such spaces can be integrated.

Further to this, if the architecture discussed in this thesis would not be possible due to current financial models, it would open opportunities for greater investigation for cost savings, in design, and even opportunities for government subsidized housing.

More importantly, it would also raise the question, for what is the role of the architect? -- How can architects better use economic models to guide design to better benefit people. It further questions, how can architects and project participants allocate spaces for social interaction which are not necessarily profitable but rather contribute to the overall health and sustainability of cities and residents within? How can architects find ways to design spaces the are more conducive to creating opportunities for interaction?

Thus, this thesis project is a starting point for exploration on how to better introduce spaces for social interaction in condominium design. As such it requires further consideration and development in regards to financial constraints and opportunities. However, in doing so it is critical that the priority to integrate spaces for social interaction is maintained in order to contribute to the health of individuals and in turn, the sustainable growth and development of the cities. 



\section{| 11| LIST OF APPENDICES}

| A | FINAL BUILDING FLOOR PLANS

I B | AREA CALCULATIONS

I C I FINAL PHYSICAL MODEL

| D | DESIGN DEVELOPMENT 
| A | FINAL BUILDING FLOOR PLANS

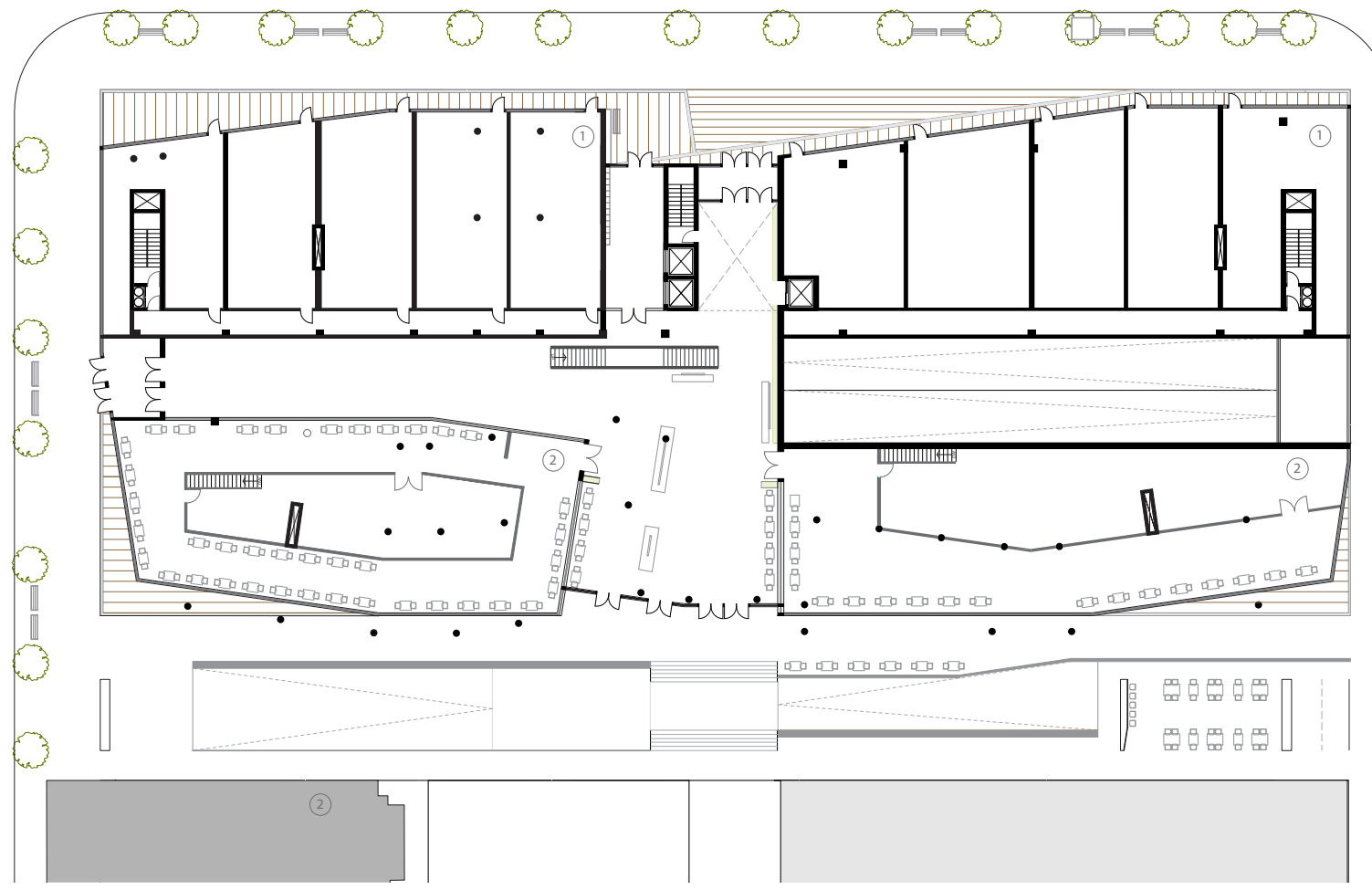

Ground Floor Plan - Scale 1:600

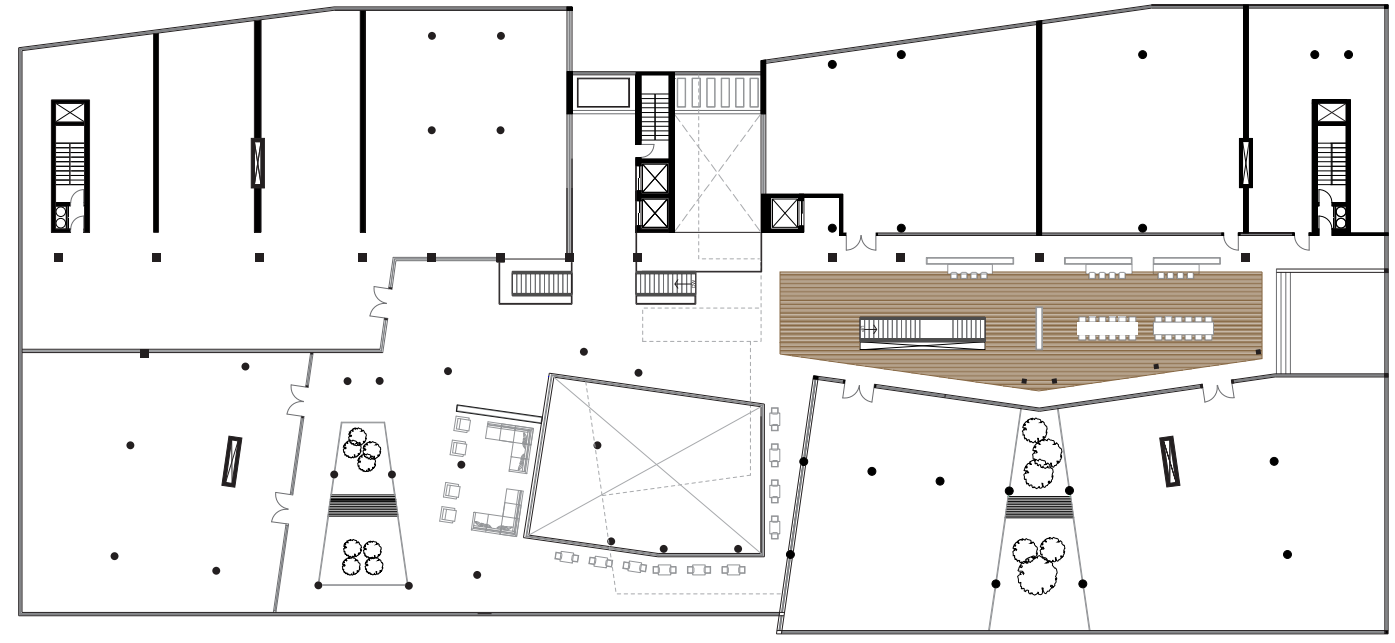

Second Level - Scale 1:600

(Podium - Public) 


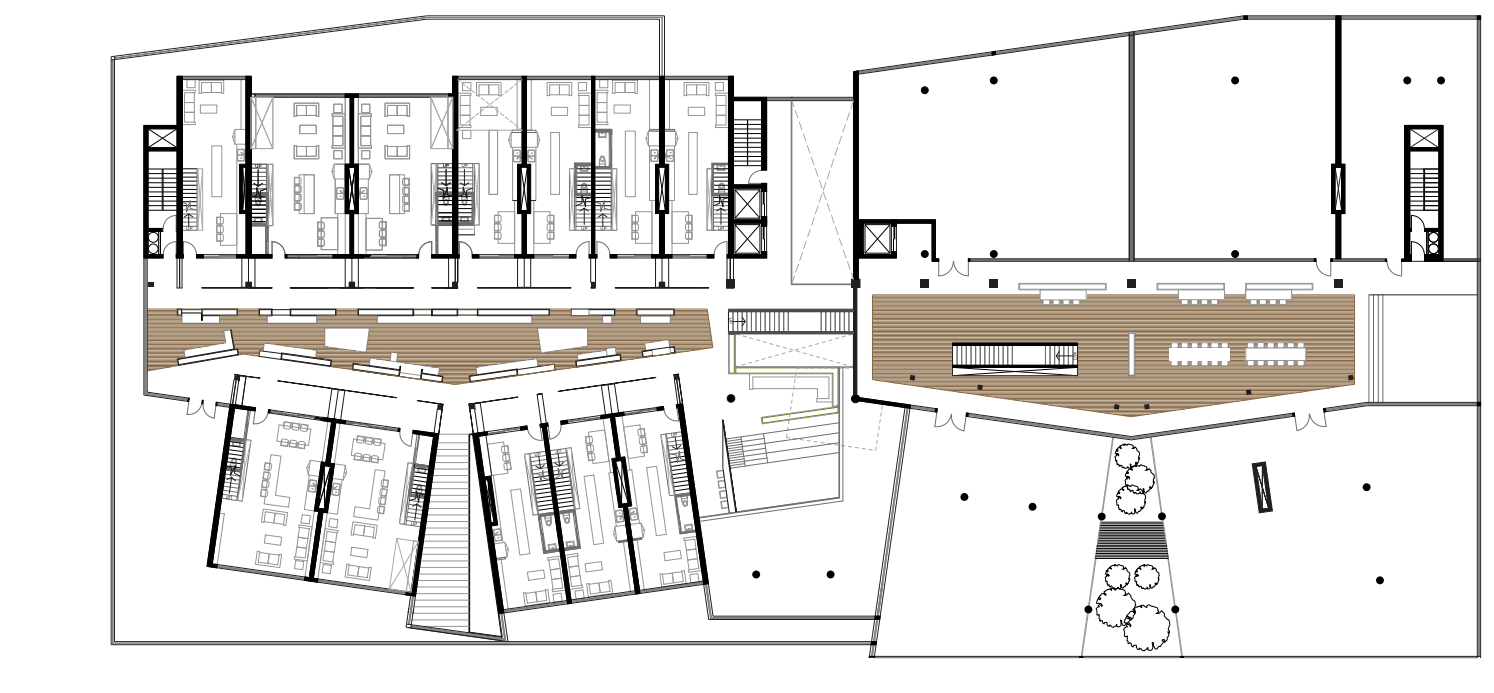

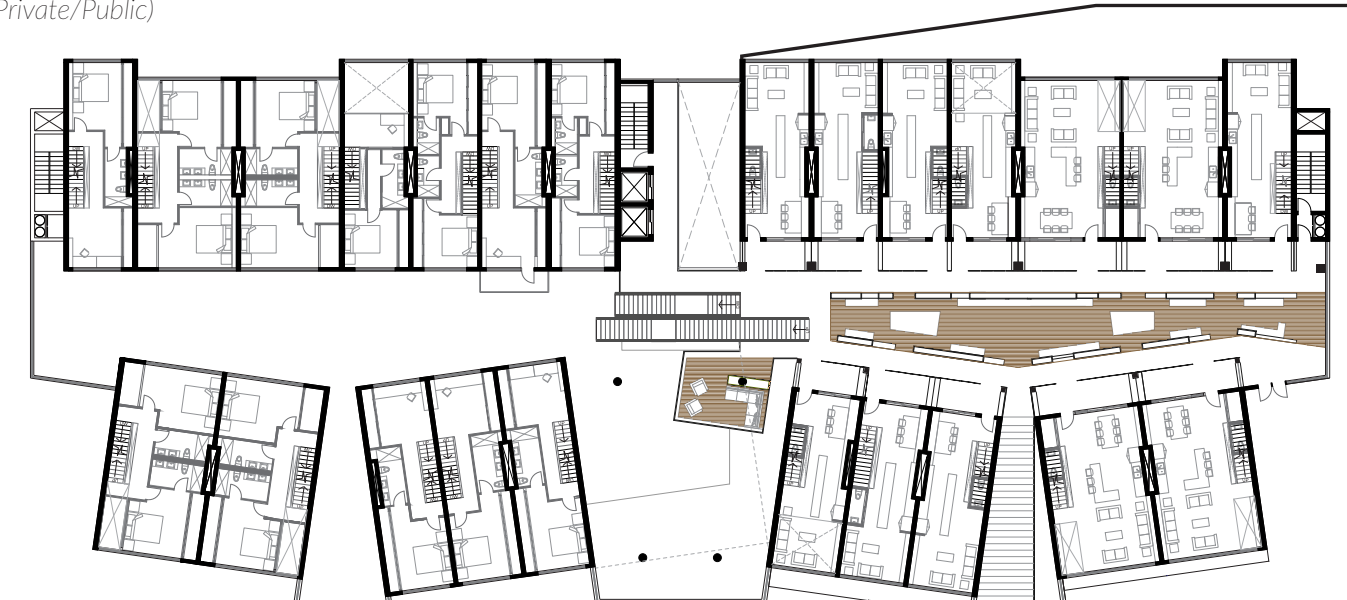

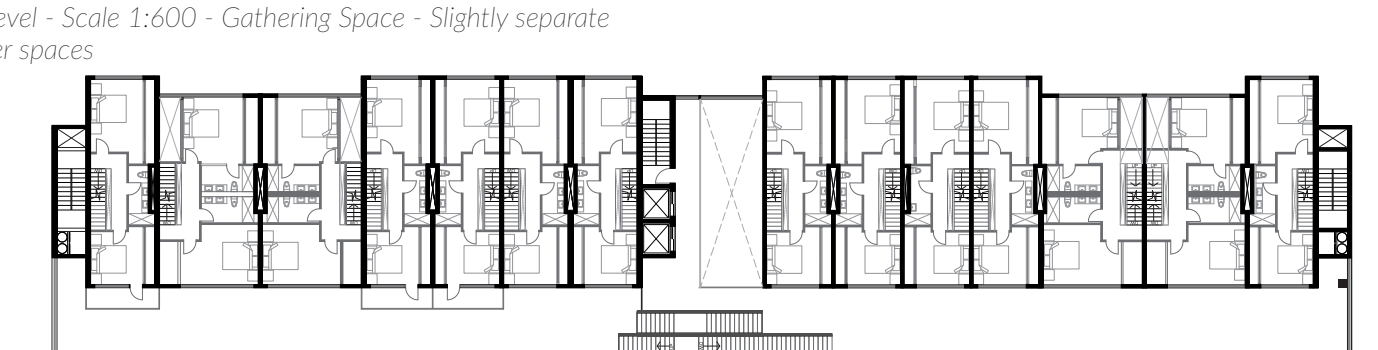

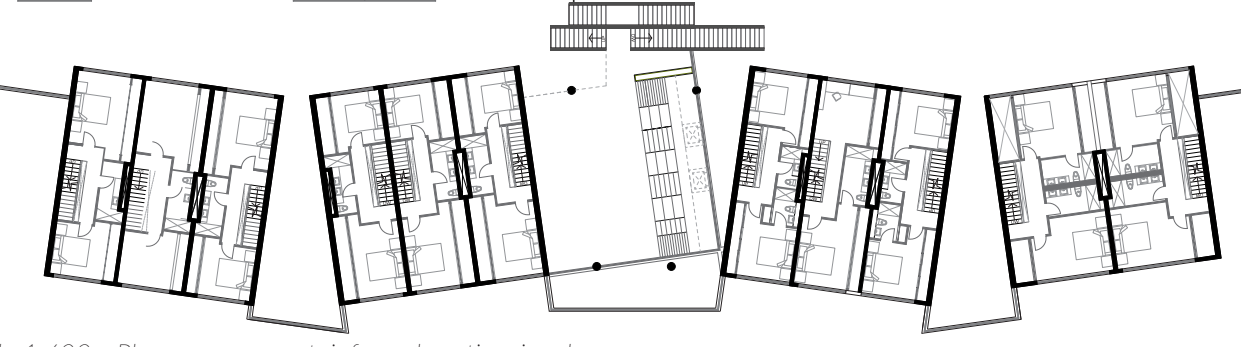




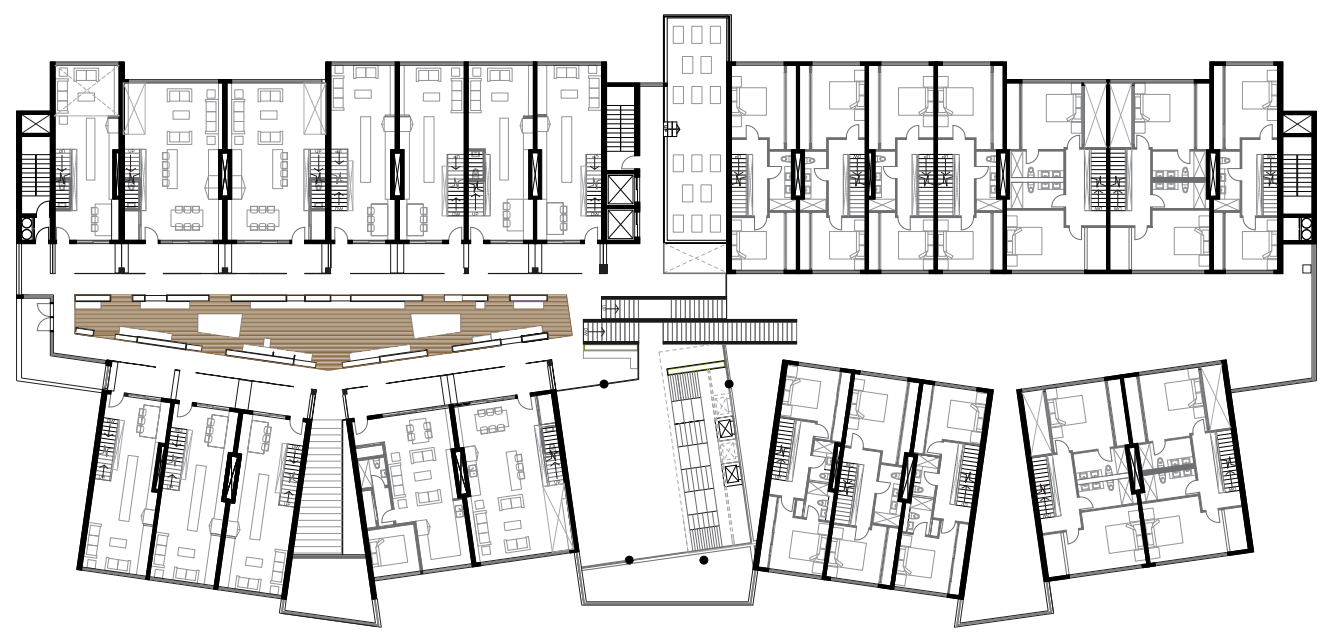

Sixth Level- Scale 1:600 - Play space - court, informal seating, jungle gym, movie screen

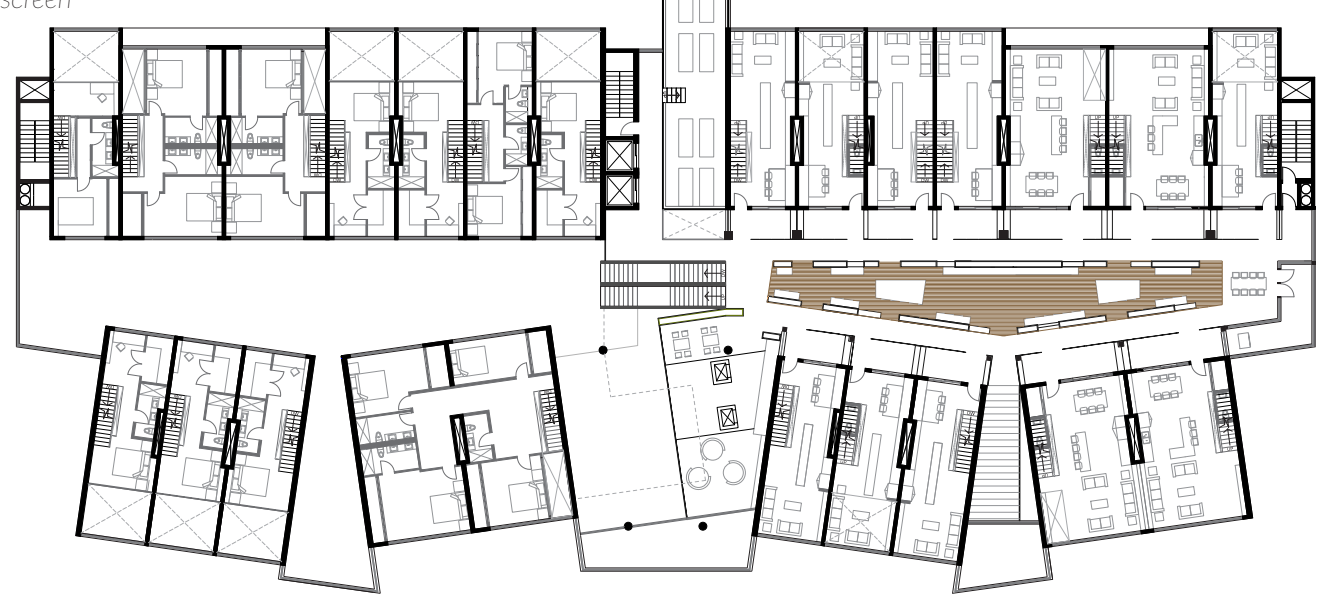

Seventh Level-Scale 1:600 - Play space - court, informal seating,

jungle gym, movie screen

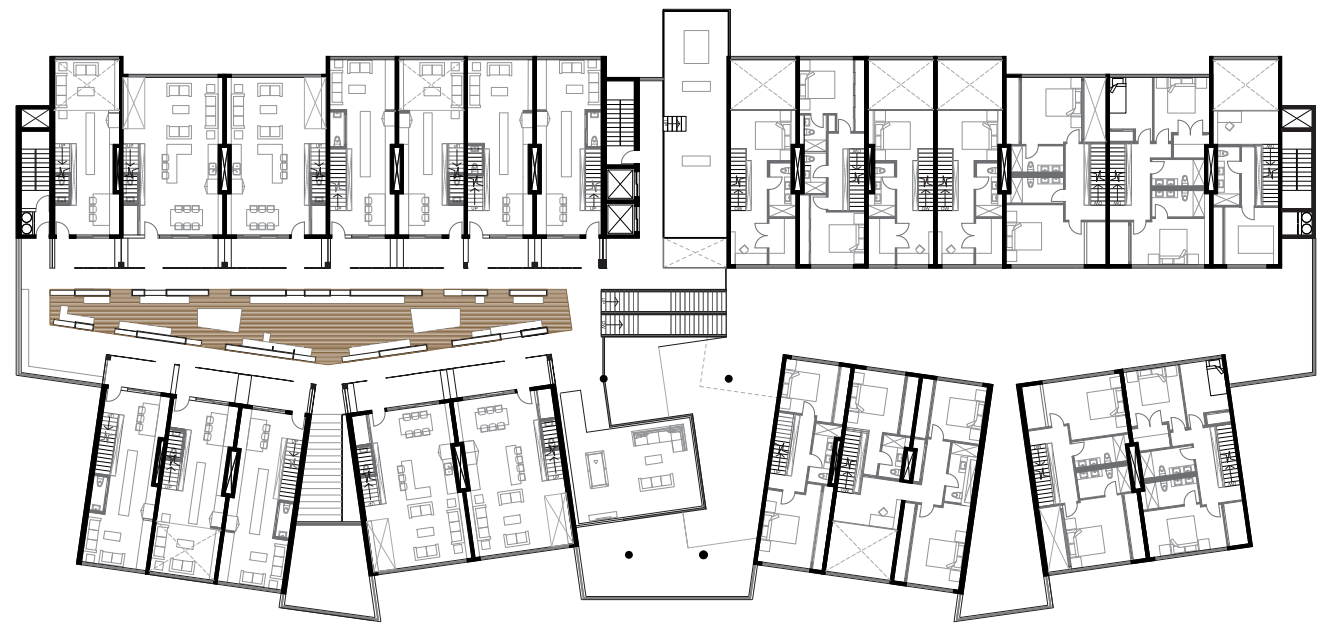

Eighth Level-Scale 1:600 - recreation space - pool table, tv,

proximity to kids space 


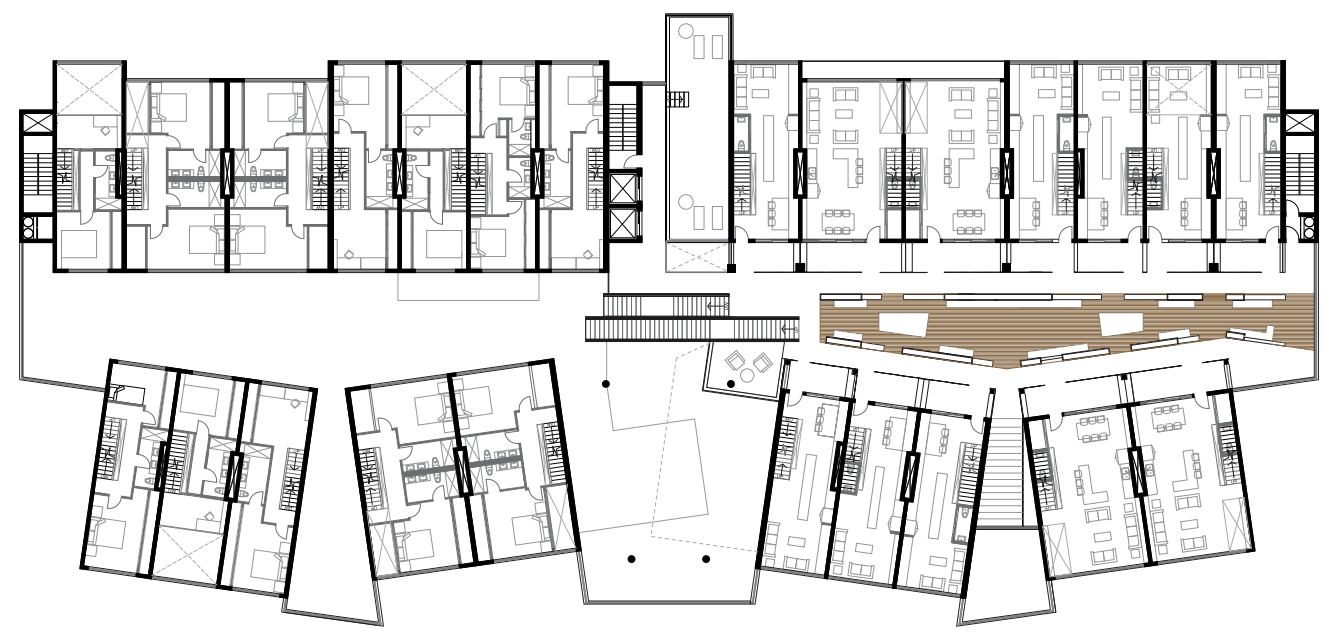

Ninth Level - Scale 1:600 - Gathering Space - Slightly Separate from other spaces

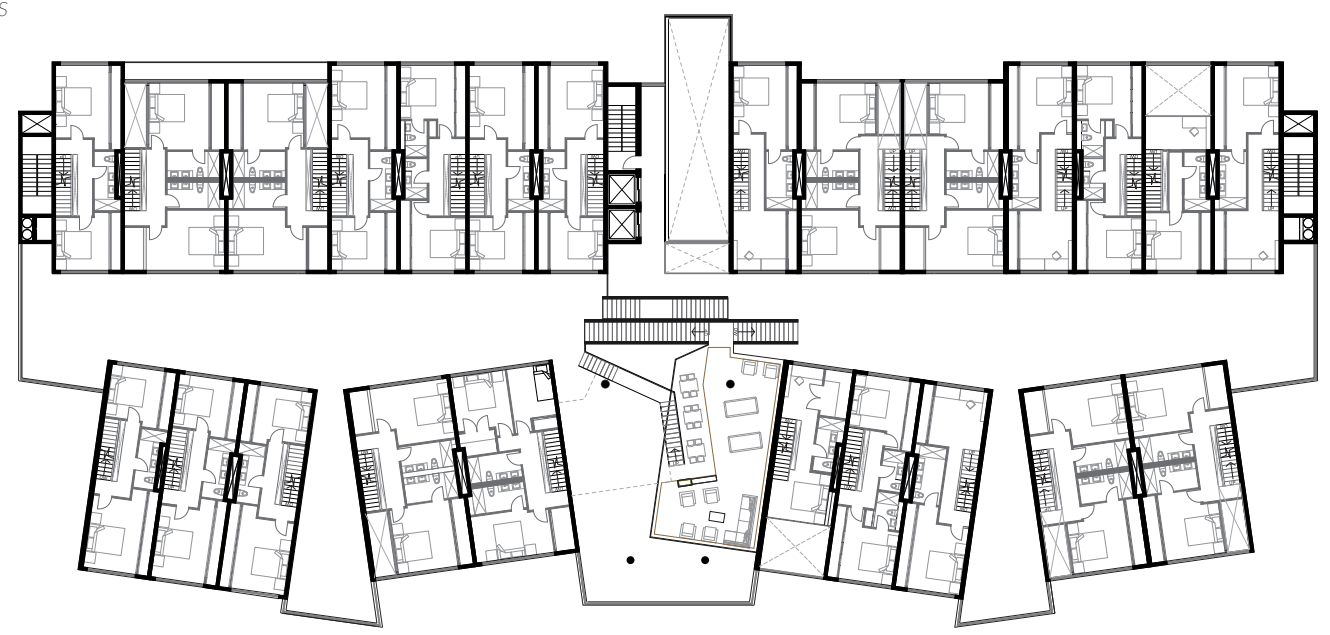

Tenth Level- Scale 1:600 - Game Room

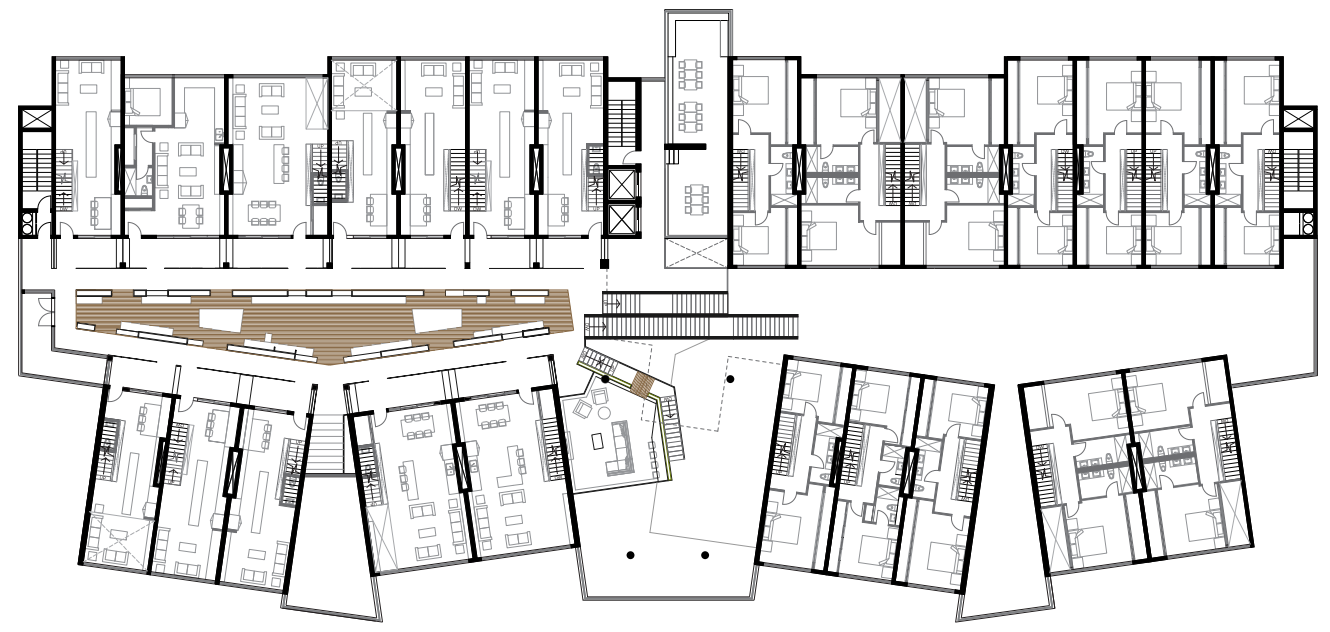

Eleventh Level-Scale 1:600 - Game Room 


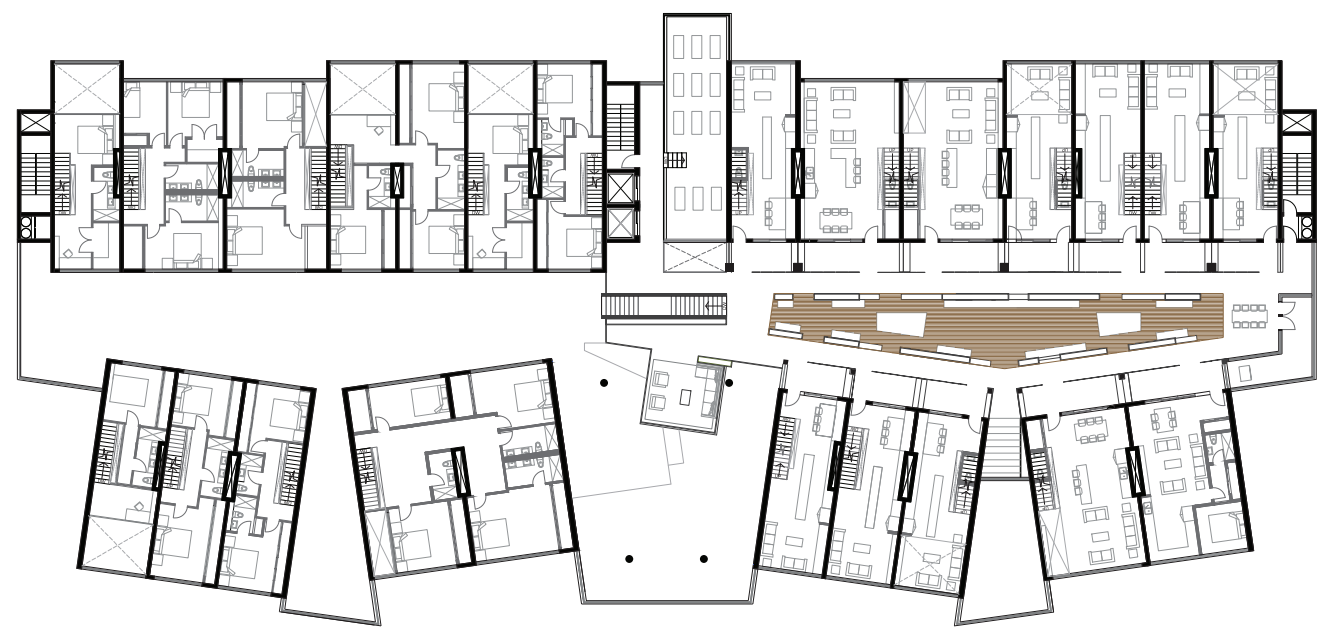

Twelfth Level- Scale 1:600 - Gathering Space - Slightly Separate from other spaces

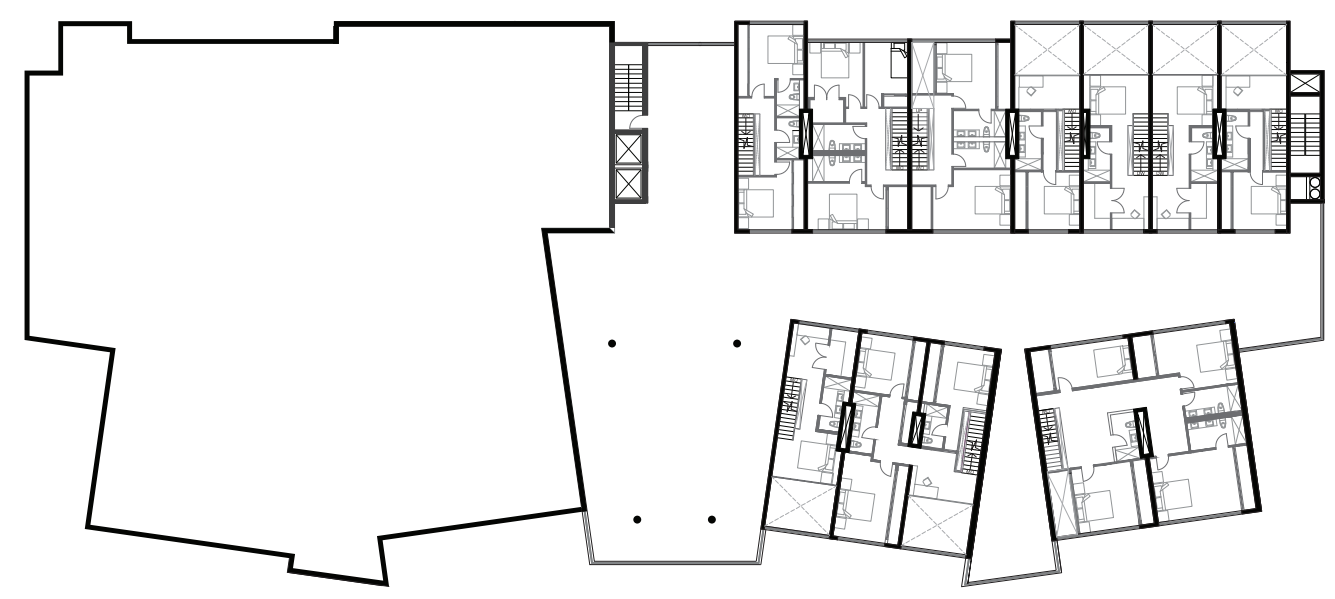

Thirteenth Level-Scale 1:600 


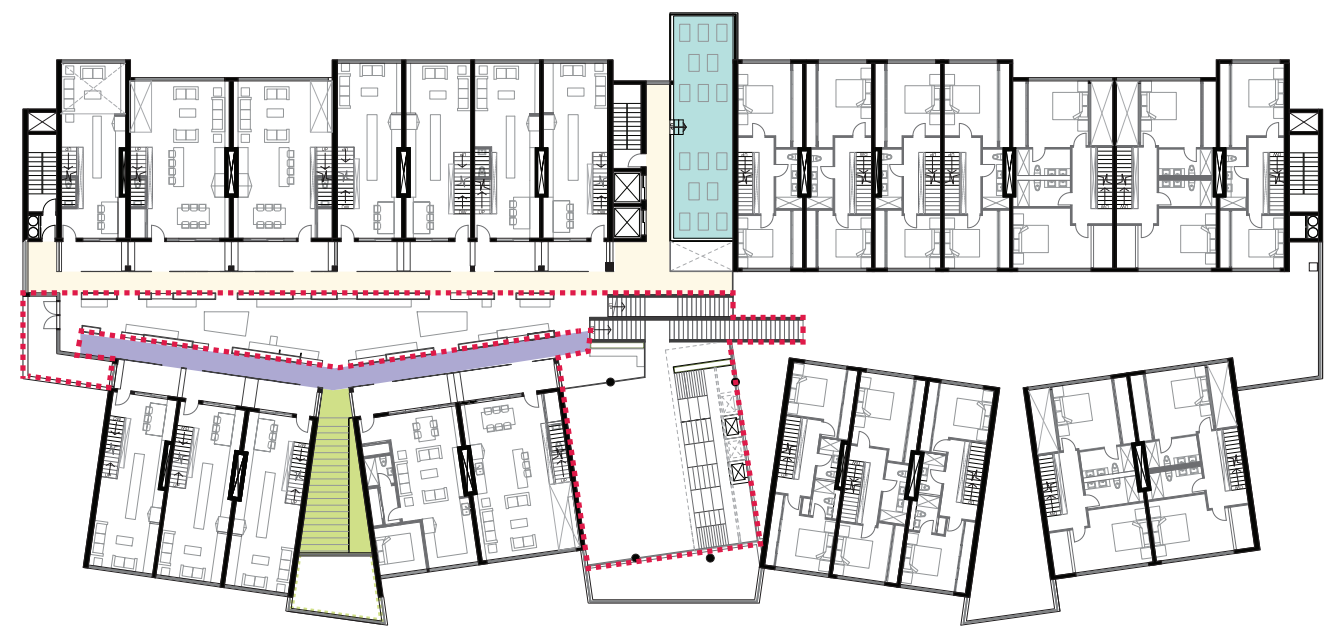

\section{LEGEND}

BLUE-WORKOUT SPACE

PINK - CLUSTER \& COMMUNAL

GREEN - GARDEN

YELLOW - CORRIDOR 1

PURPLE - CORRIDOR 2

\begin{tabular}{|c|c|c|c|c|c|c|}
\hline $\begin{array}{l}\text { RESIDENTIAL } \\
\text { Interior Balconies }\end{array}$ & A & B & C & D & & $\mathrm{F}$ \\
\hline 62.05 & 423 & 151.4 & 165.3 & & & \\
\hline 31.887 & 423 & 151.4 & 165.3 & 423 & 164.9 & 151.4 \\
\hline 26.7 & 436.5 & 165.3 & 165.3 & 423.2 & 165.3 & 151.4 \\
\hline 34.63 & 422.8 & 165.3 & 151.4 & 423.2 & 165.3 & 151.4 \\
\hline 22 & 423.05 & 165.17 & 151.1 & 435.75 & 165.3 & 151.39 \\
\hline 18.8 & 422.8 & 165.3 & 151.37 & 423.06 & 165.3 & 151.4 \\
\hline 87.2 & 421.81 & 165.3 & 151.4 & 423.05 & 164.8 & 151.4 \\
\hline \multirow[t]{2}{*}{50.8} & 422.17 & 165.3 & 151.4 & 421.59 & 165.3 & 151.4 \\
\hline & 423 & 165.3 & 151.46 & 423 & 165.3 & 151.4 \\
\hline \multirow[t]{5}{*}{334.067} & 422.32 & 165.17 & 151.4 & 422.38 & 165.3 & 151.4 \\
\hline & & & & 422.3 & 165.3 & 151.4 \\
\hline & \multirow{2}{*}{\multicolumn{5}{|c|}{ TOTAL RESIDENTIAL }} & 15161.5 \\
\hline & & & & & & 0.696641 \\
\hline & \multicolumn{5}{|c|}{ RESIDENTIAL } & 0.71 \\
\hline
\end{tabular}

\begin{tabular}{|rr|}
\hline CLUSTER & \multicolumn{1}{c|}{ TOTAL CLUSTER AREA } \\
1 & 1189.36 \\
2 & 1160 \\
3 & 1263.84 \\
4 & 1187.9 \\
5 & 1210.37 \\
6 & 1206.4 \\
7 & 1215.08 \\
8 & 1173.8 \\
& 9606.75 \\
& \\
& \\
& \\
\end{tabular}

\begin{tabular}{|rrrr|}
\hline GARDEN SPACE & Workout Spaces & Communal Spaces & TOTAL COMMUNAL \\
\cline { 2 - 4 } 45.9 & & 248 & 293.9 \\
45.9 & & 182 & 227.9 \\
26.7 & 55 & 288 & 369.7 \\
26.5 & 55 & 204.8 & 286.3 \\
20 & 55 & 243 & 318 \\
19.3 & 55 & 235 & 309.3 \\
10.6 & 55 & 246.4 & 312 \\
10.6 & 55 & 207 & 272.6 \\
& & 200 & \\
& & 200 & \\
& & & \\
& & TOTAL COMMUNAL & 0.128181182 \\
& & & 0.11 \\
\hline
\end{tabular}

\begin{tabular}{|c|c|c|c|c|}
\hline Coridor 1 & Corridor 2 & TOTAL CORRIDOR & Fire Stairs & \\
\hline 80.8 & 34.47 & 115.27 & 165.64 & 1325.1 \\
\hline 73.8 & 33.1 & 106.9 & 197.96 & \\
\hline 74.8 & 38.4 & 113.2 & & \\
\hline 80.3 & 34.7 & 115 & & \\
\hline 77 & 34.9 & 111.9 & & \\
\hline 80.3 & 30.9 & 111.2 & & \\
\hline 80.3 & 35.27 & 115.57 & & \\
\hline 80.3 & 34.38 & 114.68 & & \\
\hline & 276.12 & 903.72 & & \\
\hline & & & TOTAL ACCESS & 5812 \\
\hline & & & & 0.175177733 \\
\hline & & & ACCESS & 0.178 \\
\hline
\end{tabular}


| C | FINAL PHYSICAL MODEL

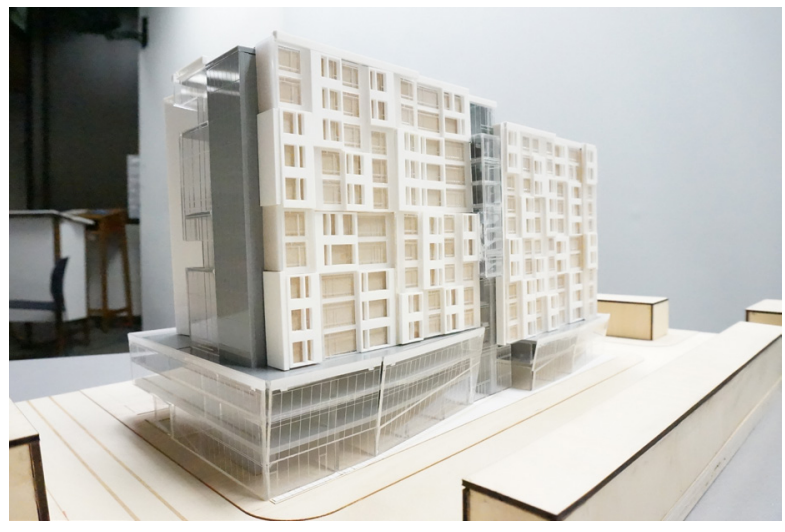

Front View - Looking South - West Bloor Street West \& Bathurst Street

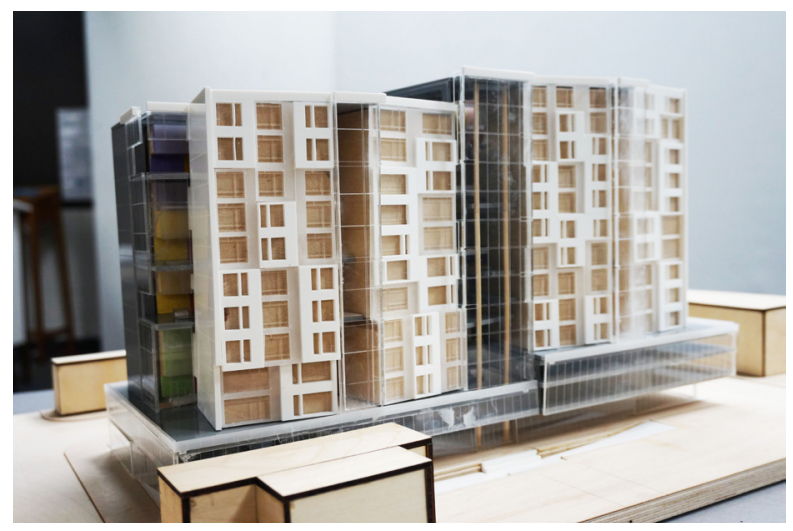

Back View - Looking North - East
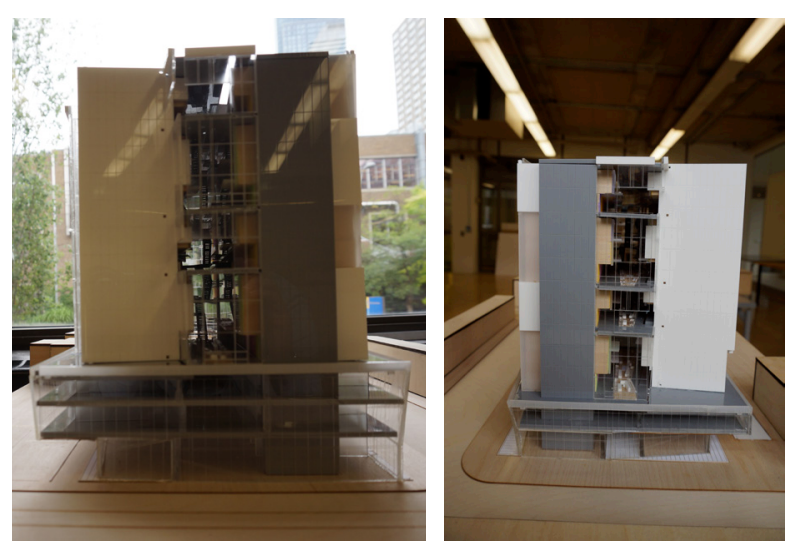

$\mid$ Left - East Face | - |Right - West Face |

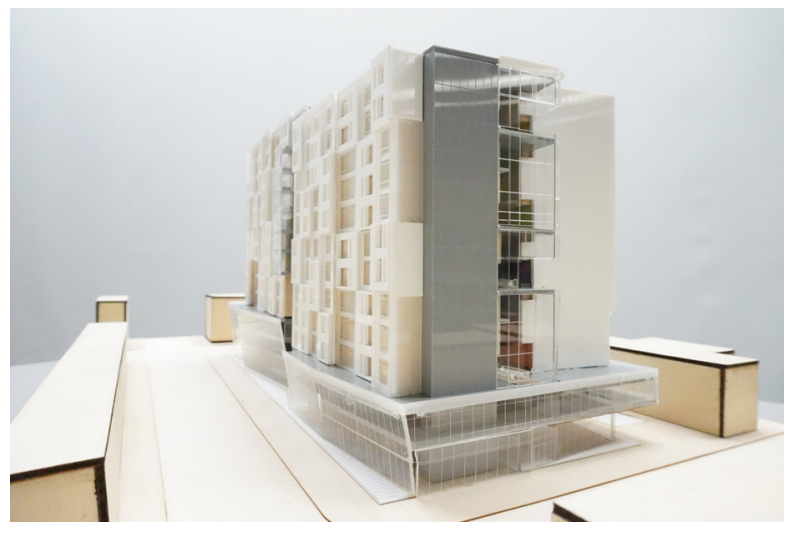

Front View - Looking South - East Bloor Street West \& Markham Street

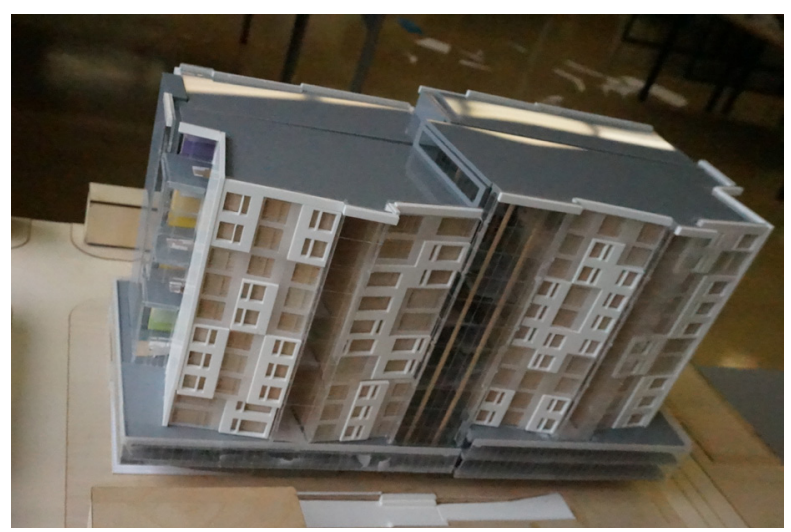

Back View - Looking North - East
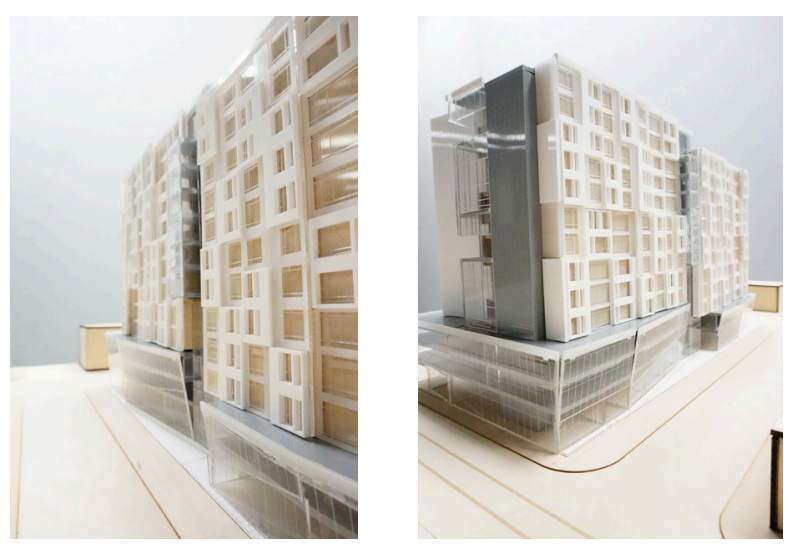

| Right - Looking West on Bloor Street | Left - Looking East on Bloor Street| 


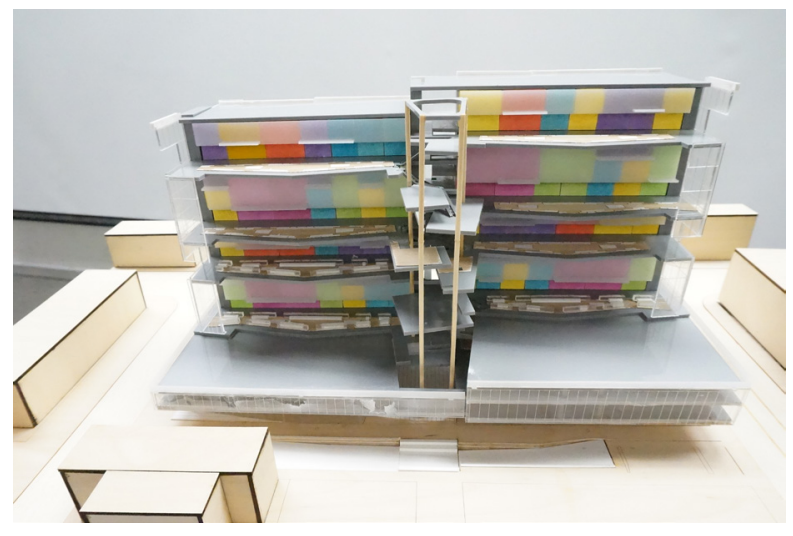

View looking inside of the model - showcasing the different unit types

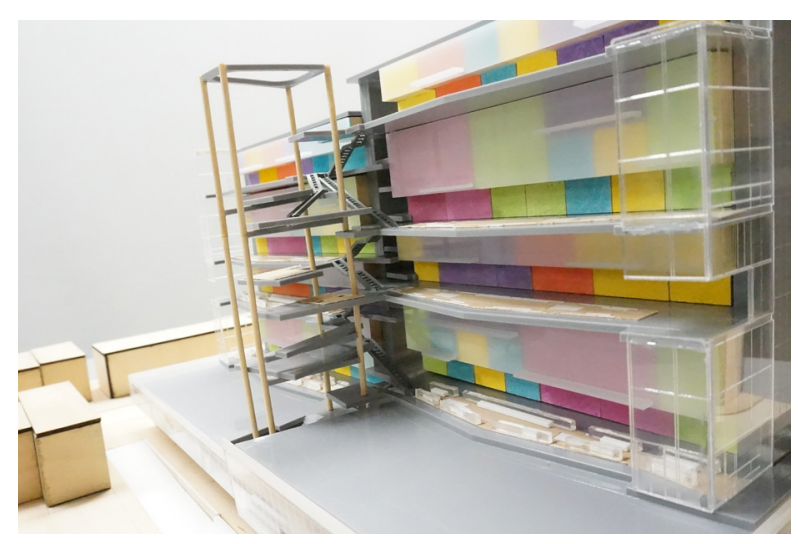

View looking inside of the model - showcasing the circulation connecting clusters \& communal spaces

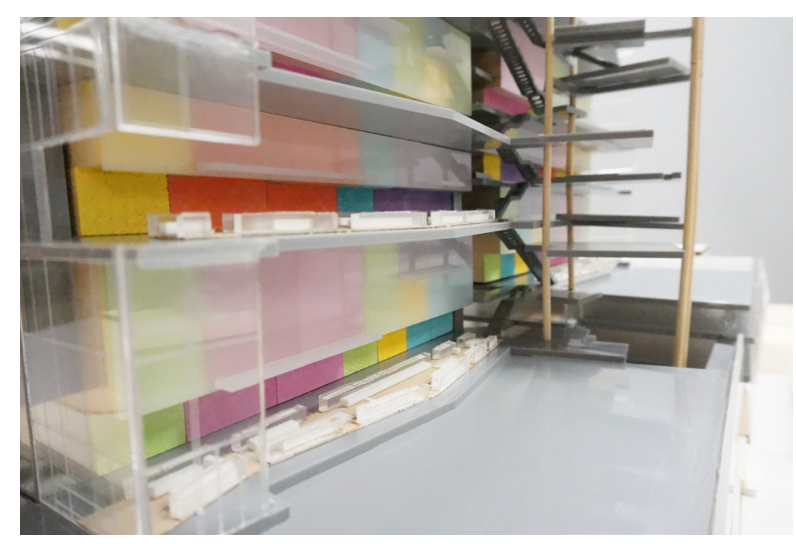

View looking inside of the model - showcasing the circulation connecting clusters \& communal spaces

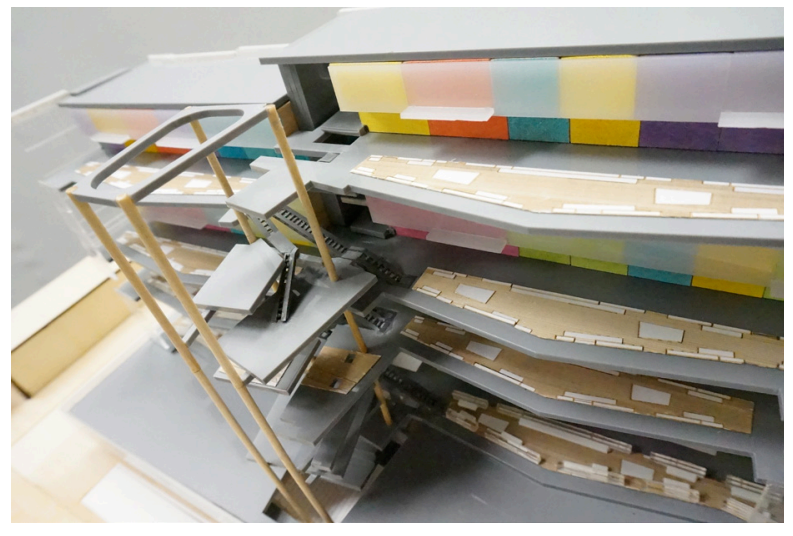

View looking inside of the model - showcasing the the Integration of Communal Spaces
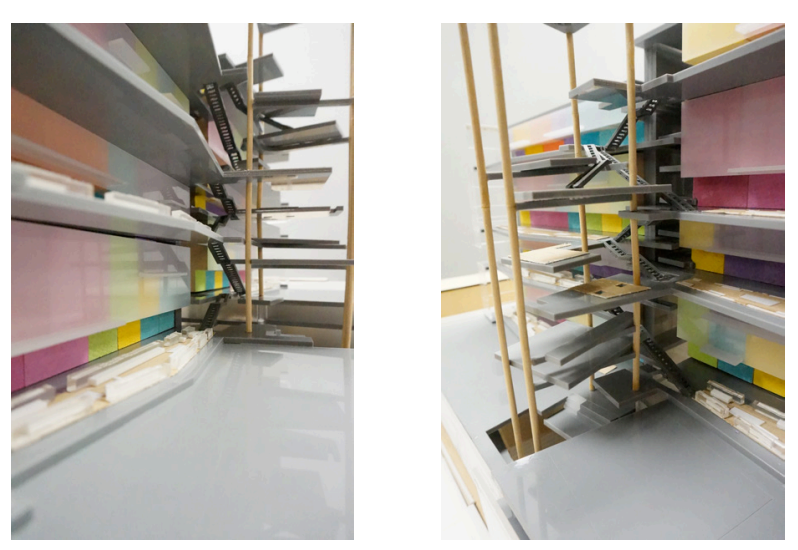

View looking inside of the model - showcasing the circulation connecting clusters \& communal spaces
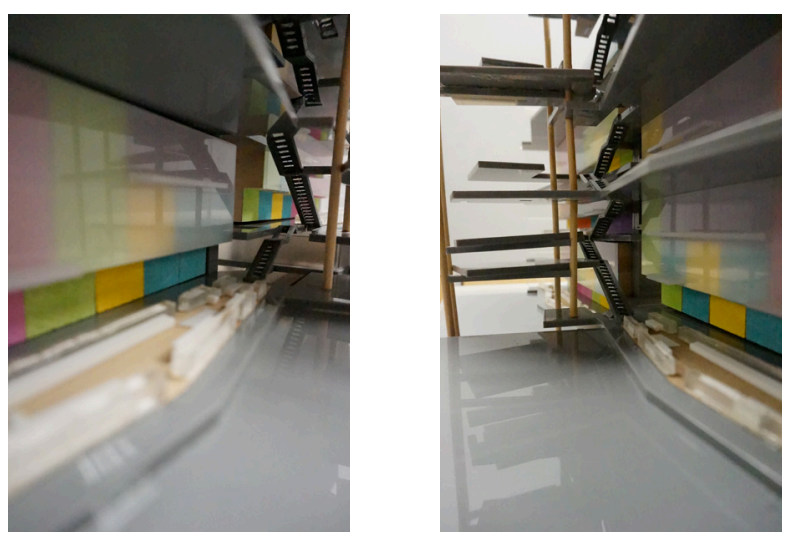

Left - showcasing details in cluster 1 | | Right -showcasing details in cluster 2 
| D | DESIGN DEVELOPMENT
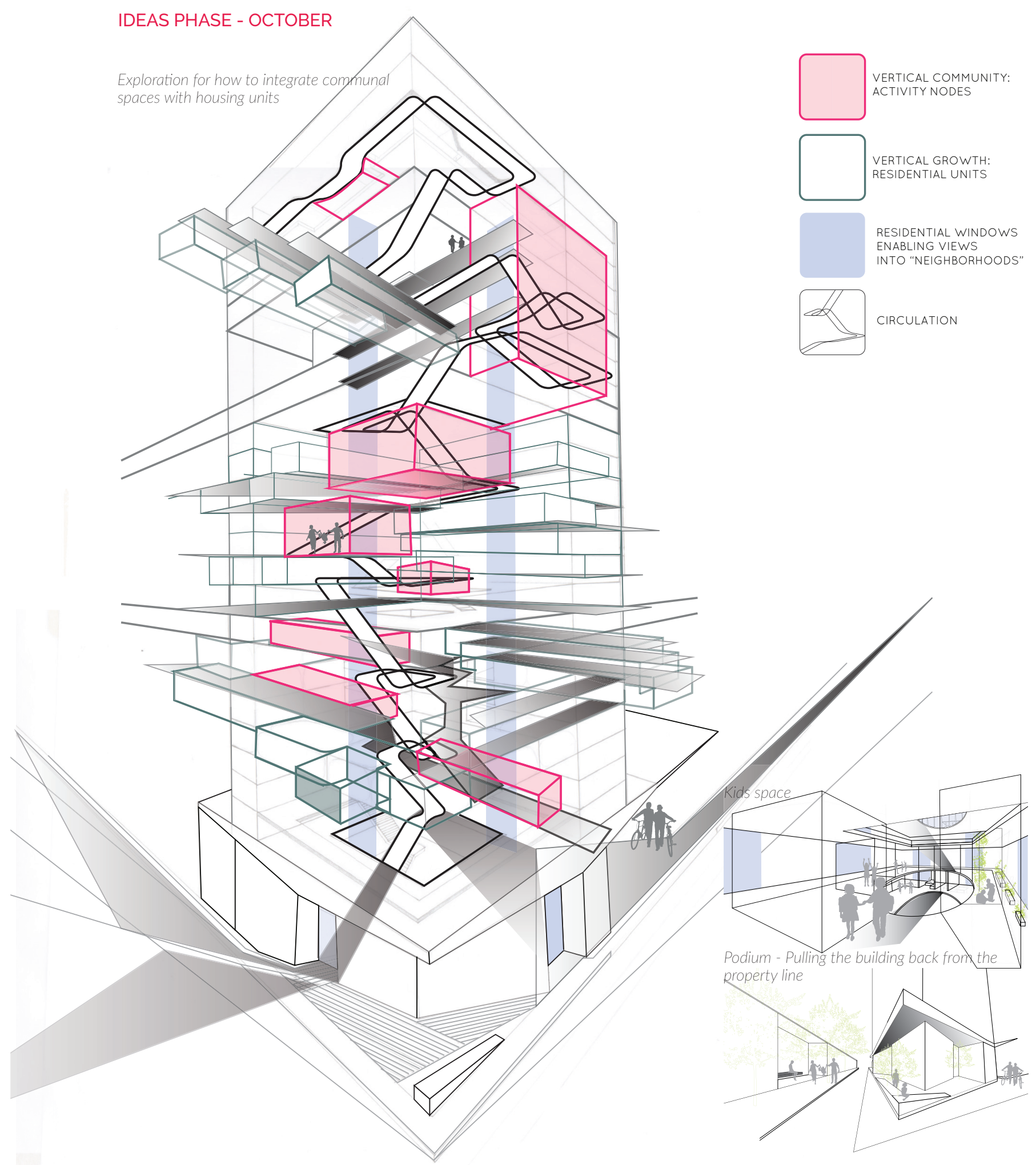
A
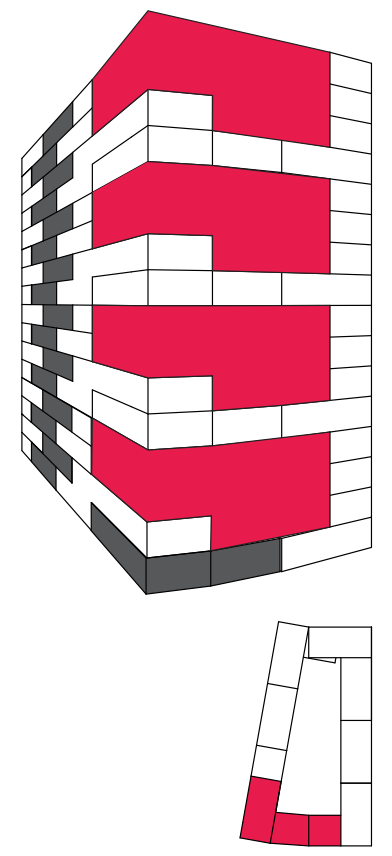

B
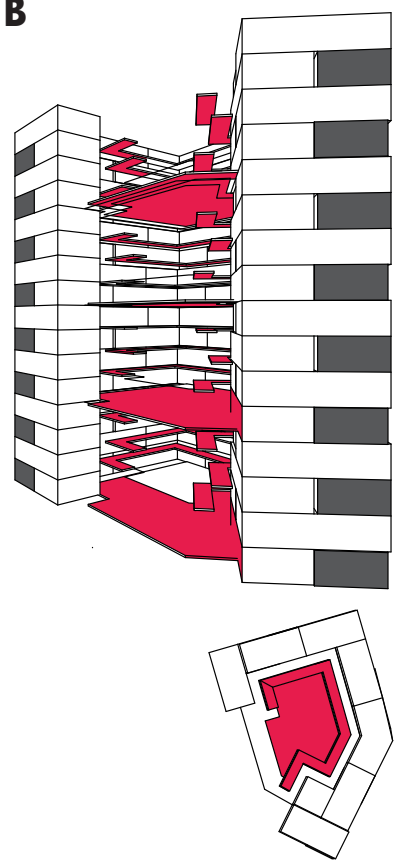

C
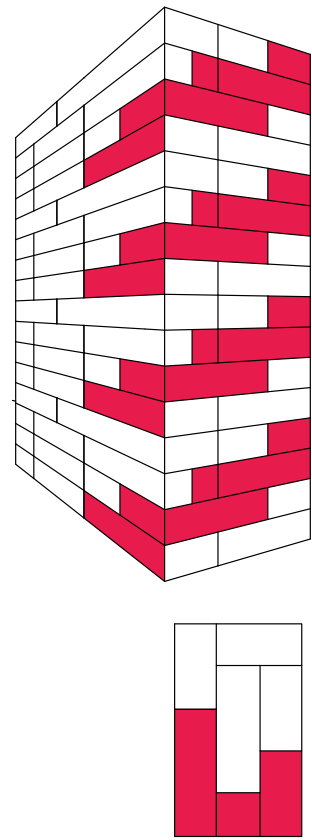

D

Exploration for how to integrate semi-private spaces with "clusters"

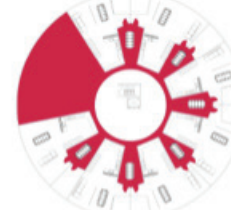

VERTICAL COMMUNITY SPACE 1ST LEVEL, IN CWSTER

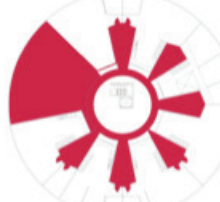

VERTICAL COMMUNITY SPACE 2ND LEVEL IN CWSTER

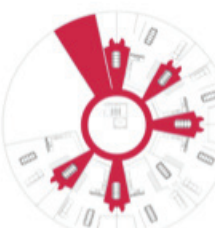

VERTICAL COMMUNITY SPACE 3RD LEVEL IN CUSTER

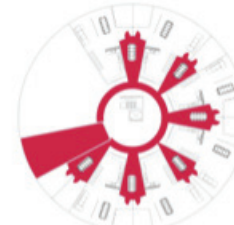

VERTICAL COMMUNITY SPACE ATH LEVEL IN CUSTER

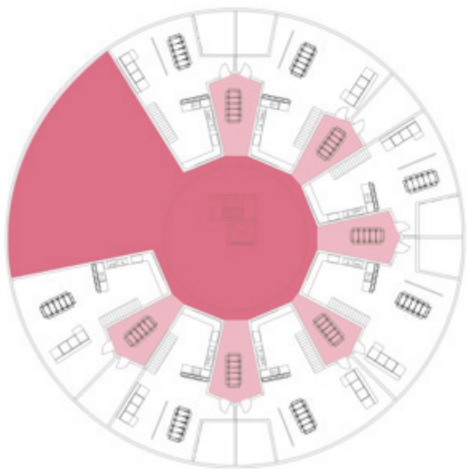

RESIDENTIAL UNITS

SEMI PRIVATE EATING AREA

(SHARED BETWEEN TWO NEIGHBOURS)

COMUNITY SPACE 


\section{D}

Options for integration - Below (a/b/c)
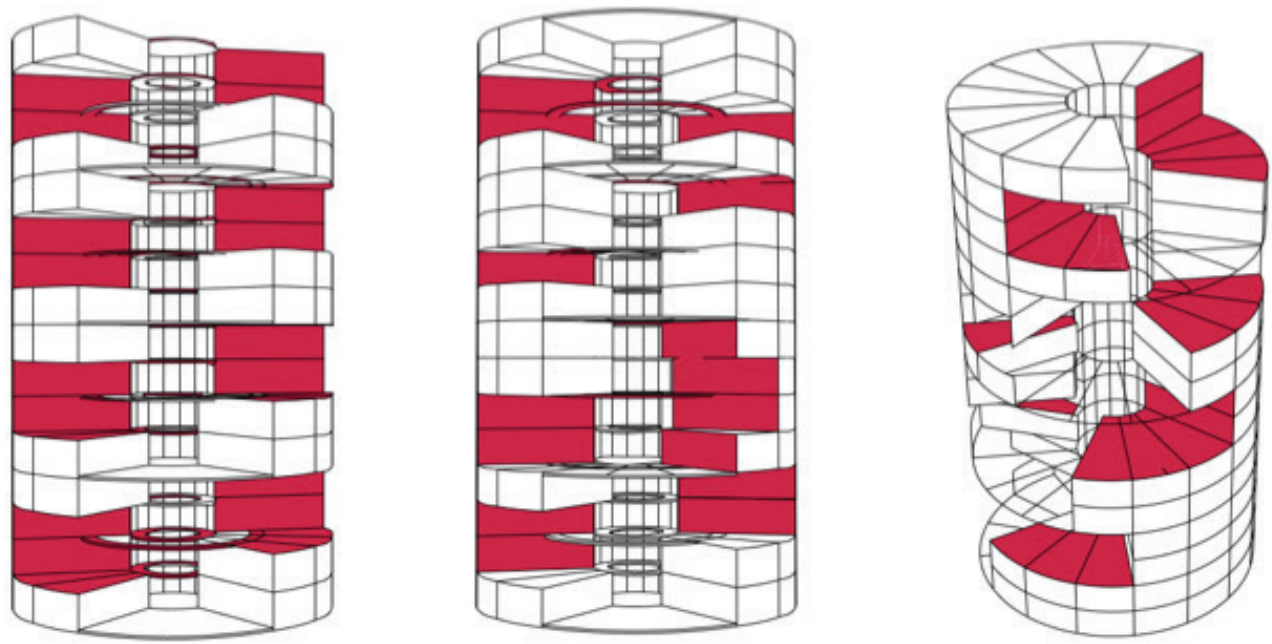

Integration of communal spaces with housing units
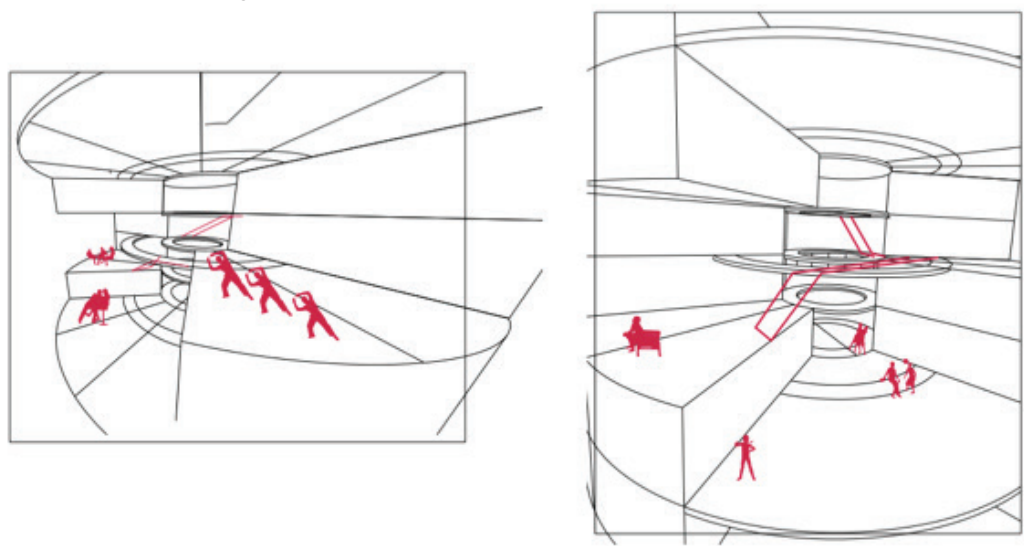

Podium design - opening it to the public - designing to enable people to flow easily into the site

* note same site as final thesis - was only exploring design options on one half
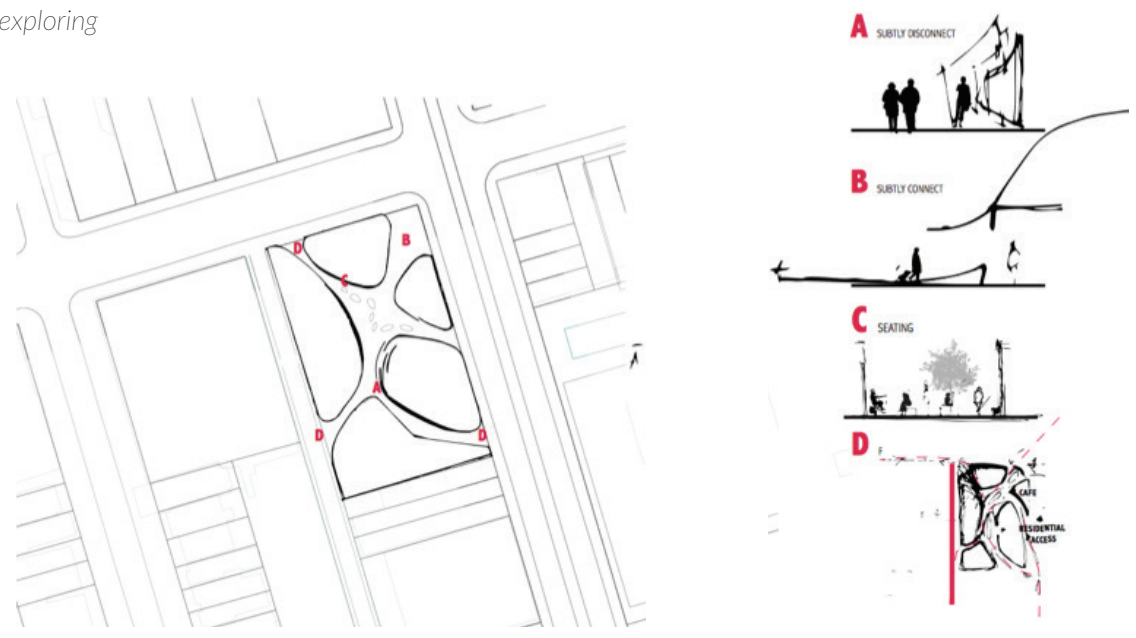
TOO MUCH , TOO SOON - DECEMBER
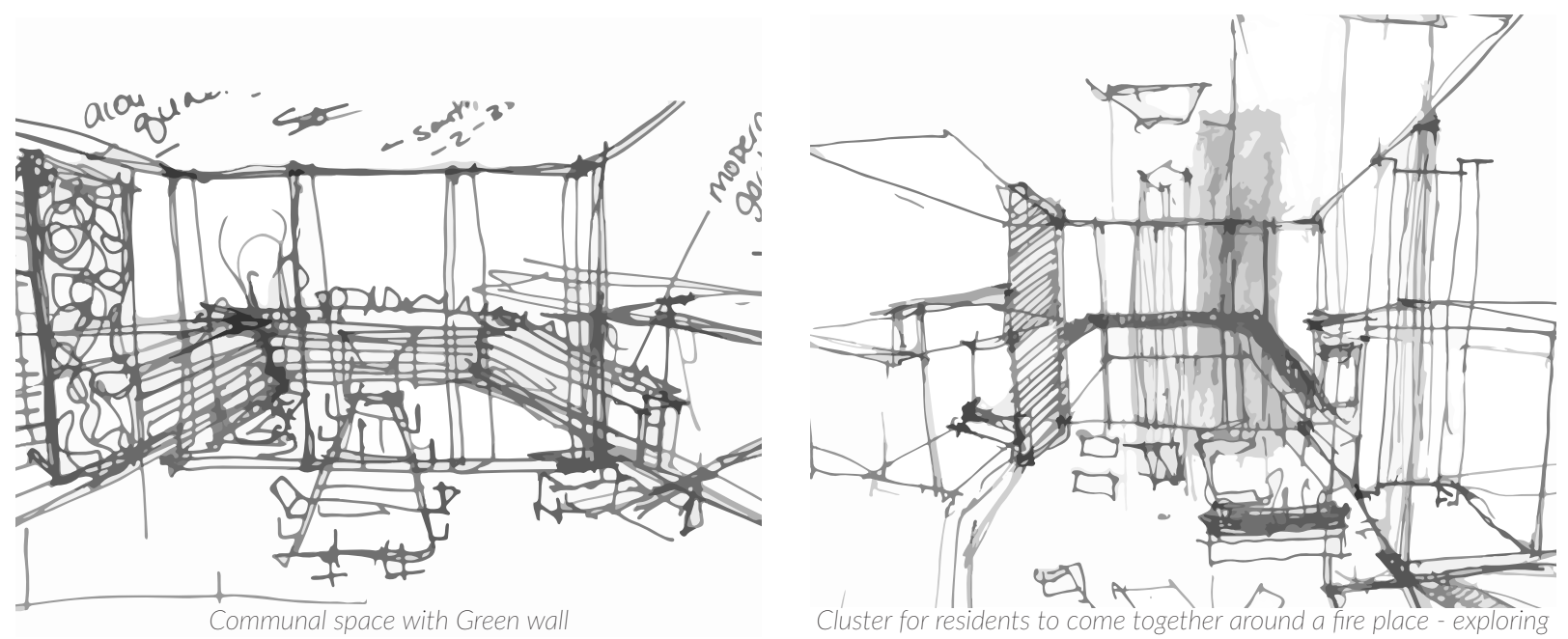

Cluster for residents to come together around a fire place - exploring scales of interaction \& opportunity for parents to watch kids play
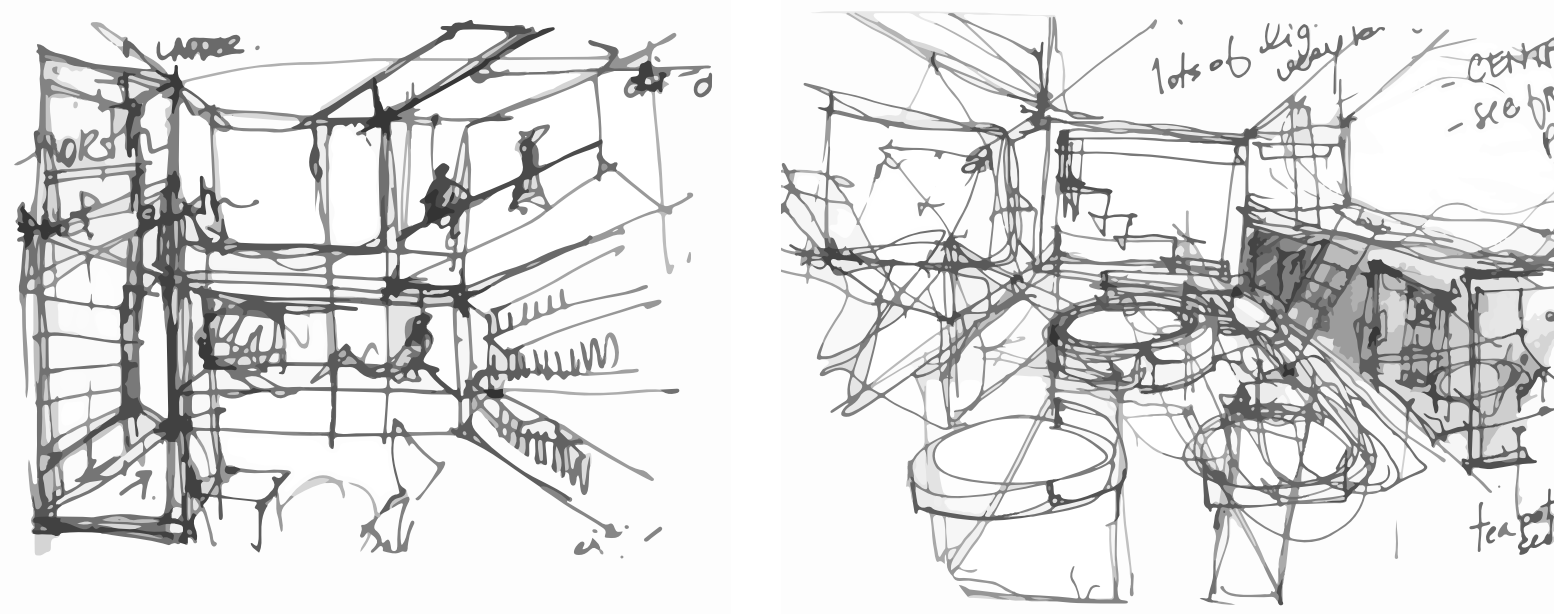

Study Space

Kids play space - adjacent to fire place
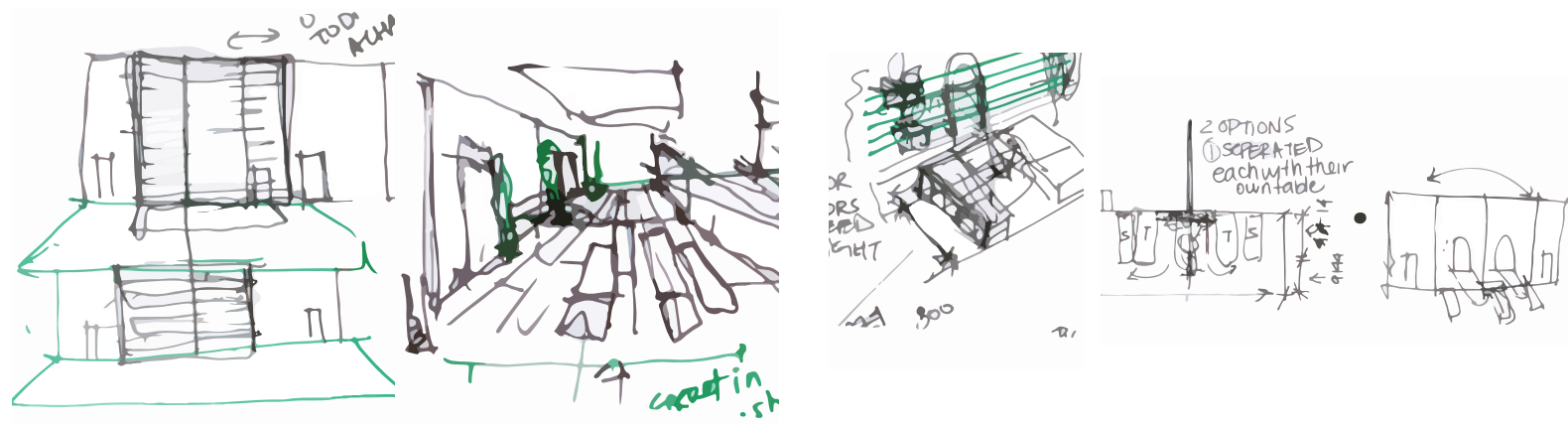

Semi - Private Spaces 
TOO MUCH , TOO SOON - DECEMBER
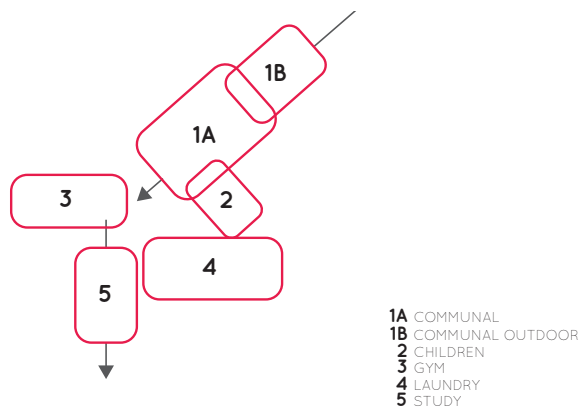

Generation of Form

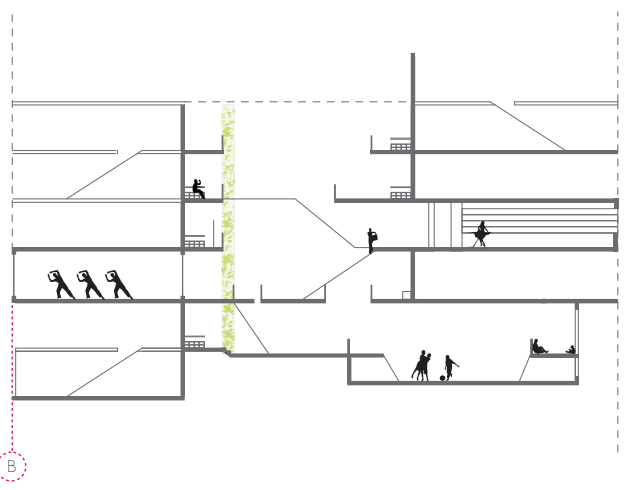

Section: Integration of "communal" program into each "cluster"

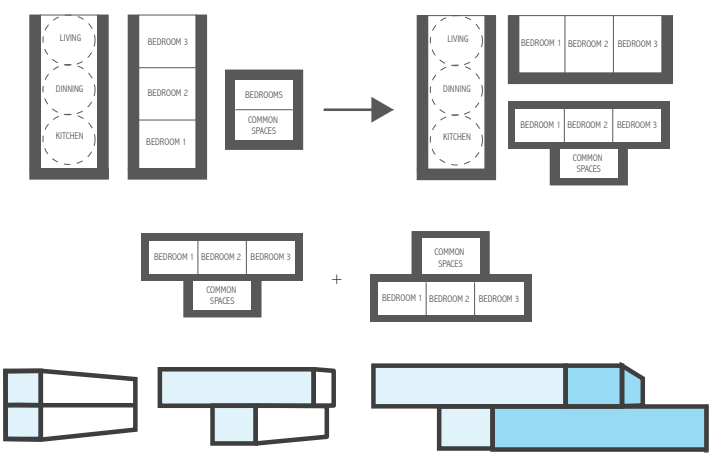

exploration of housing units to maximize light

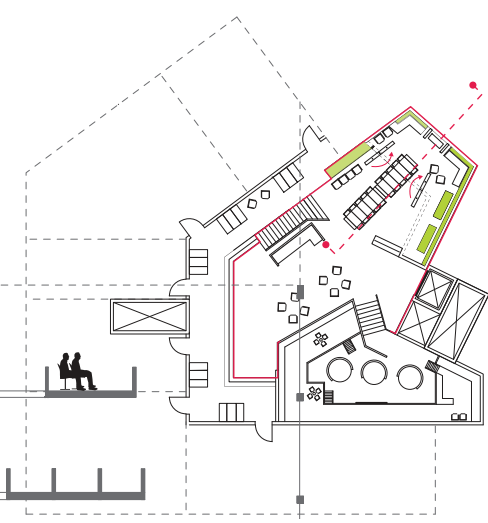

Floor Plan of a typical "cluster" working with 750 sa. $m$ floor plate

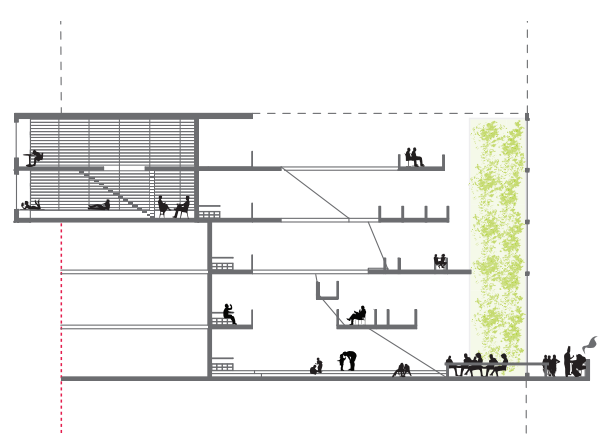

Section: Integration of "communal" program into each "cluster"

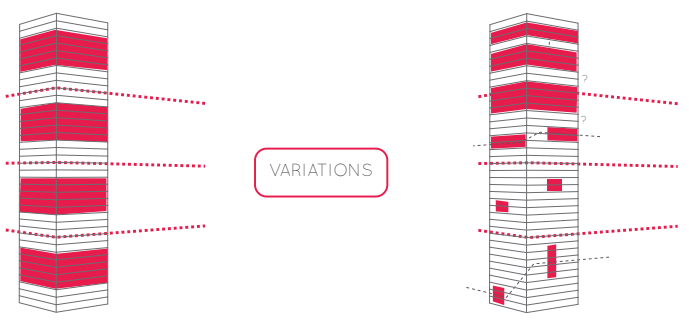

exploration of how to integrate clusters withing a high-rise condominium 
DESIGN THROUGH MODELS PHASE - JANUARY TO FEBRUARY

Beginning with the floor plate of a typical high-rise and opening

up the form to allow light - to connecting clusters - to placing two

clusters in relationship to one another to allow for visibility = mid-rise
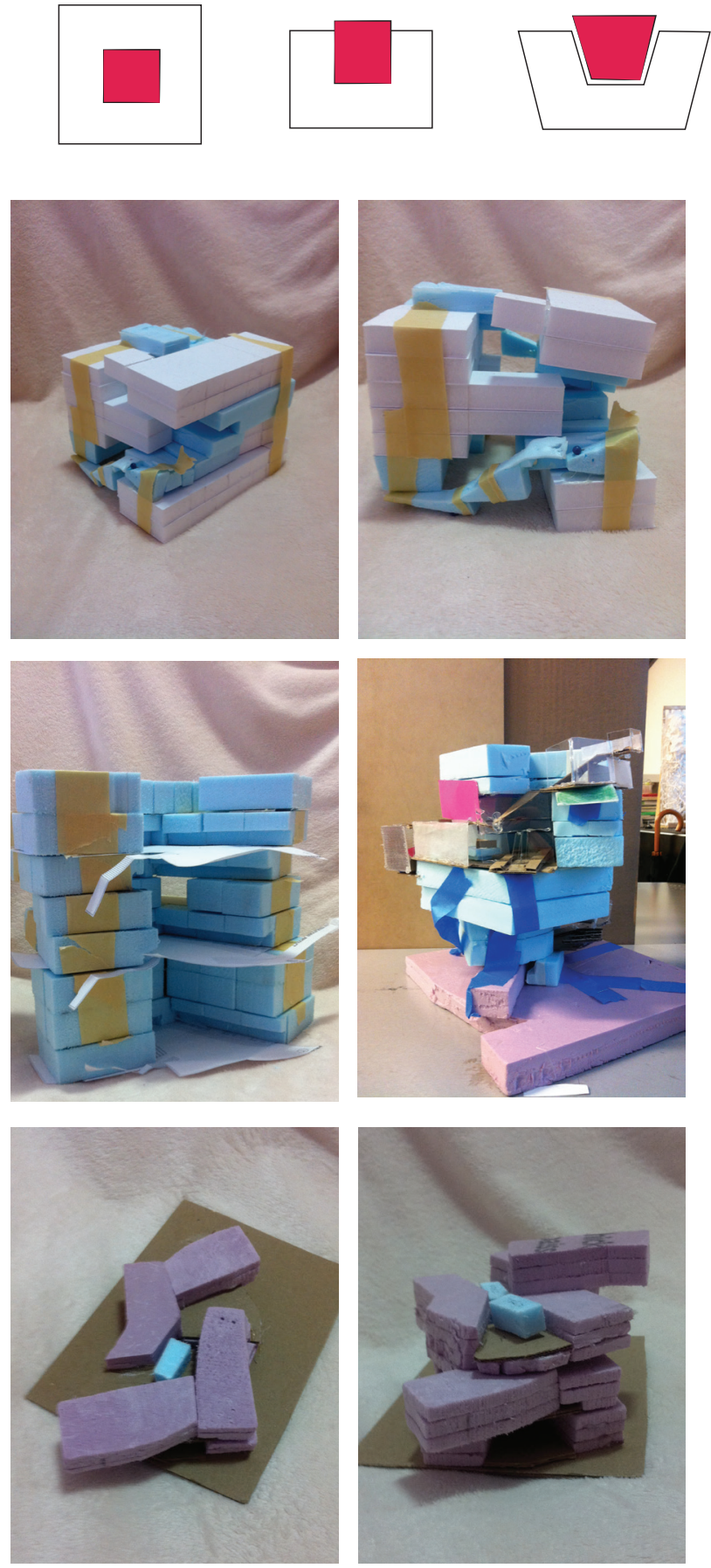
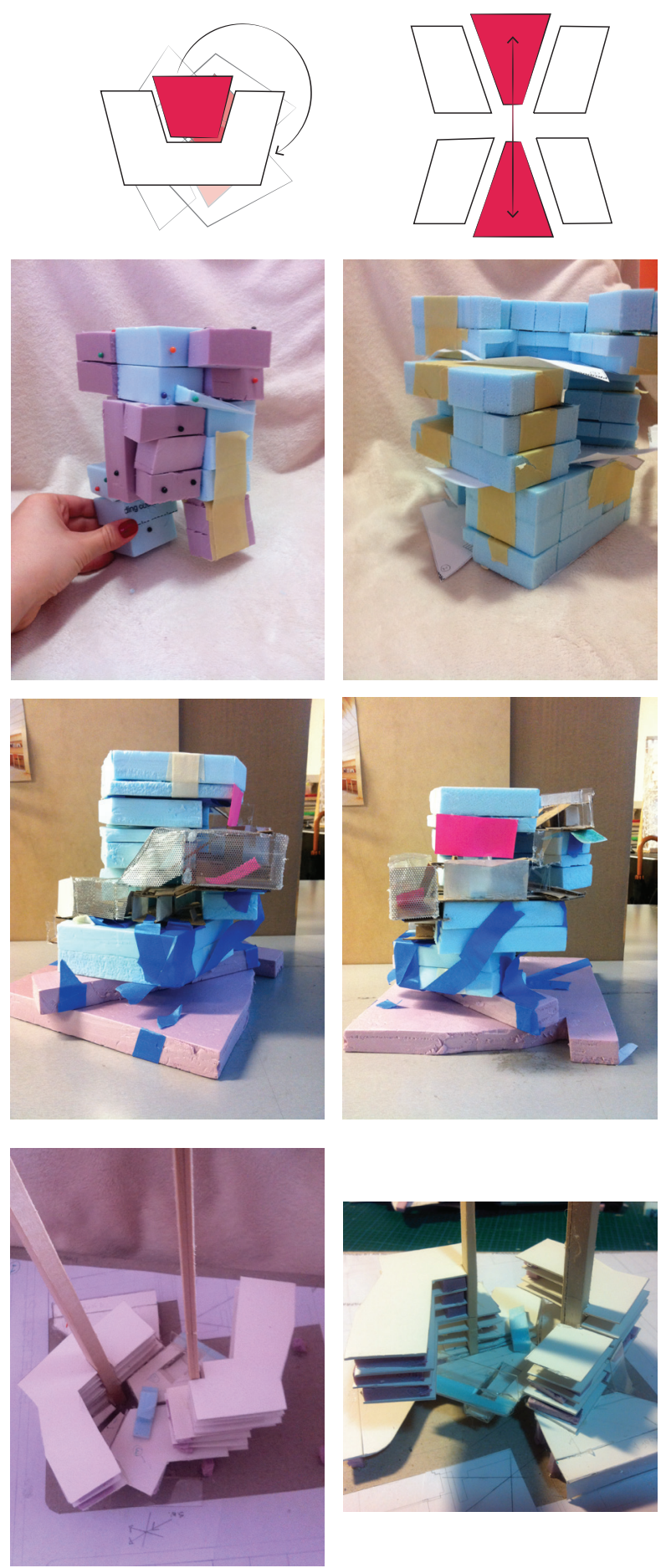
SO CLOSE BUT SO FAR PHASE - MARCH
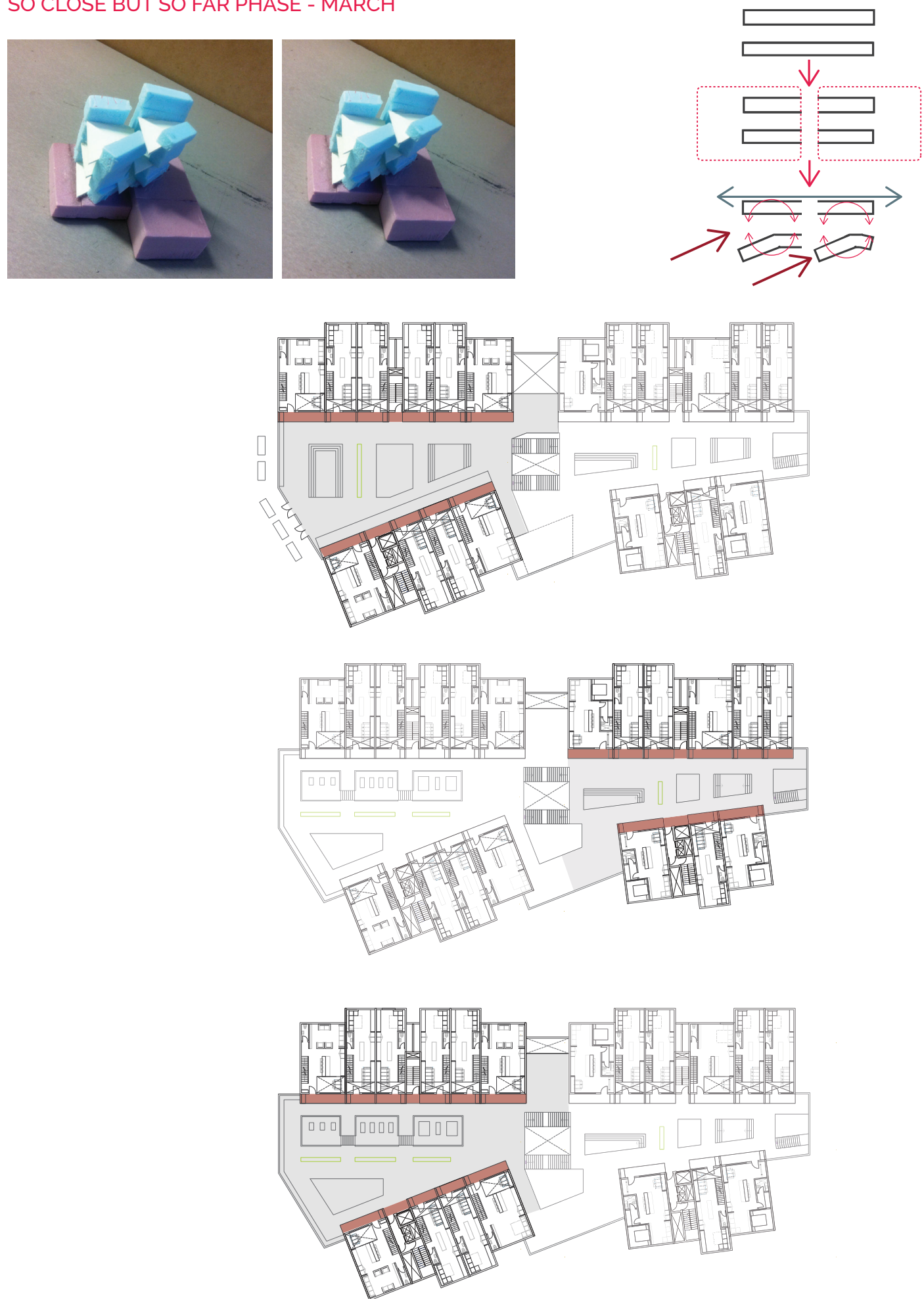
"I THINK I GOT IT" PHASE - APRIL
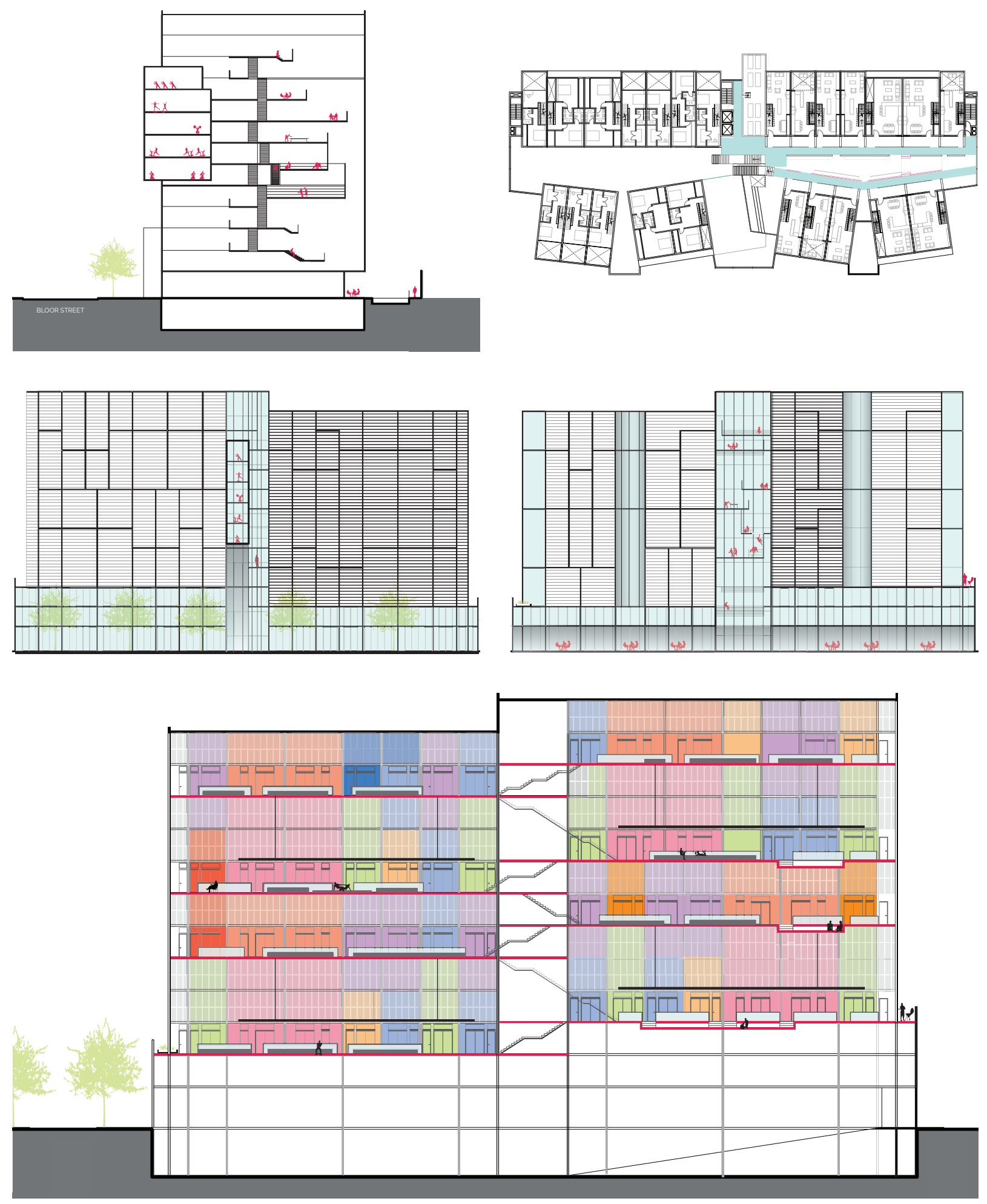



\section{| 12 | LIST OF FIGURES}

\section{| 1 | INTRODUCTION}

Figure 1: View looking inside of the physical model Source: by Author

\section{| 2 | THE SIGNIFICANCE OF SOCIAL INTERACTION}

Figure 2: Abraham Maslow Hierarchy of Needs

Source: http://www.pursuit-of-happiness.org/history-of-happiness/ abraham-maslow/

Figure 3: Manfred Max - Neef

Source: by Author

Figure 4: The "Baby Cage"

Source: http://www.dailymail.co.uk/news/article-2178140/Babytaking-room-Try-solution-1930s--window-CAGE-hanging-airinfant-crawl-in.html

Figure 5: High Rise Residential Towers from the Modernist Movement

Source 1: Unite d'Habitation - http://www.archdaily. com/85971/ad-classics-unite-d-habitation-le-corbusier/ unite_vincent-desjardins6/

Source 2: Robin Hood Gardens - http://farm4.staticflickr.co m/3035/2930889101_587478c355_z.jpg

Source 3: Trellick Tower -http://2.bp.blogspot.com/ROtz6j03Ka4/TjaaEpETjil/AAAAAAAAD64/c5TiyLdQzJE/ s1600/trellick4.jpg

Source 4: Park Hill - http://twentytwentyone.com/news/ wp-content/uploads/2013/05/Park-Hill-Sheffield-19571961.-Architects-Jack-Lynn-and-Ivor-Smith-for-SheffieldCity-Council-300x298.jpg

Figure 6: Health of lindividuals impacts the health of communities and cities

Source: by Author

\section{| 3 | PAST \& PRESENT TRENDS}

Figure 7: Mono-culture In the downtown core Source: Simply Map - http://www.simplymap.com.ezproxy.lib. ryerson.ca/index.htm

Figure 8: | High Rise | Mid-Rise | Low - Rise |

Source: High Rise - http://urbantoronto.ca/database/projects/auracollege-park
Source: Mid-Rise - http://urbantoronto.ca/database/projects/8gladstonevz

Source: Low-Rise - http://www.mattamyhomes.com/gta/images/ Main8.jpg

Figure 9: | High-Rise | Mid-Rise | Low - Rise | Large separation between units and communal spaces Source: by Author

Figure 10: High - Rise condominium floor plan - highlights corridor space

Source: by Author

Figure 11: Mid - Rise condominium floor plan - highlights corridor space

Source: by Author

Figure 12: Low-Rise Suburban Homes - Private car - Private house Source: by Author

Figure 13: Images depict the lack of response to context, as the podium either houses big box stores, or private amenities. Source: 1. http://urbantoronto.ca/database/projects/aura-collegepark

Source 2. http://urbantoronto.ca/news/2014/02/alexandra-parkrevitalization-starts-demolition-and-sq-condos

\section{| 4 | PROPOSING A SOLUTION}

Figure 14: Current Condition vs. Proposed Condition Source: by Author

Figure 15: First Scale of Interaction - Clusters

Source: by Author

Figure 16: Current Condition vs. Proposed Condition Source: by Author

Figure 17: Second Scale of Interaction - Communal Spaces Source: by Author

Figure 18: Current Condition vs. Proposed Condition Source: by Author - Inspired by (Gehl, Life Between Buildings - Using Public Space, 2011, p. 101)

Figure 19: Circulation system linking clusters \& communal spaces Source: by Author

Figure 20: Current Condition vs. Proposed Condition Source: by Author

Figure 21: Third scale of interaction - Podium 
Source: by Author

Figure 22: Held \& Hein Experiment

Source: http://ermwhy.files.wordpress.com/2013/03/

heldandheim1963.jpg

Figure 23.a: Back-to-back orientation vs. Face-to -face orientation Source: by Author - Inspired by (Gehl, Life Between Buildings - Using Public Space, 2011, p. 62)

Figure 23.b: Long distances vs. Short distances

Source: by Author - Inspired by (Gehl, Life Between Buildings - Using Public Space, 2011, p. 62)

Figure 23.c: Elevator vs. stairs

Source: by Author - Inspired by (Gehl, Life Between Buildings - Using Public Space, 2011, p. 62)

Figure 23.d: Seating at edges vs. Standing next to objects

Source: by Author - Inspired by (Whyte, 2000, p. 254)

Figure 24: No choice vs. Choice

Source: by Author

Figure 25: One large space vs. Scales of interaction

Source: by Author

Figure 26: No transition vs. Transition through space

Source: by Author

Figure 27: Response to demographics

Source: by Author

Figure 28: Cross ventilation, vegetation and daylight

Source: by Author

\section{| 5 | GENERATING CLUSTERS}

Figure 29: Unite D'Habitation - double loaded corridor system Source: Modified by Author - (French, 2008, p. 82)

Figure 30: Christopher Alexander natural clustering

Source: by Author - (Alexander, 1977, p. 199)

Figure 31: Reorganizing a typical mid-rise to create clusters

Source: by Author

Figure 32: The different unit types

Source: by Author

Figure 33: Physical Model - Showcasing diversity among units

Source: by Author

Figure 34: Partial transverse section through two clusters-

Allowing units to cross into clusters below

Source: by Author

Figure 35: Smithson's Robin Hood Gardens - "Streets in the Sky" Source: (French, 2008, p. 140)

Figure 36: Illustration of WIlliam's description for row houses at the ends have less access to social interaction

Source: by Author

Figure 37: Robin Hood Gardens Site Plan - "Streets in the Sky" ordinated to face away from one another

Source: (French, 2008, p. 140)

Figure 38: Keeling House - Highlighting the Communal spaces \& circulation system to units

Source: (French, 2008, p. 100)

Figure 39: Separation \& Angeling of Form

Source: by Author

Figure 40: Communal space for cluster indicated by the pink.
Angeling of the form creates a space for "staying"

Source: by Author

Figure 41: Building section demonstrating that all front doors open on the same level (Scale 1:600)

Source: by Author

Figure 42: Flow enabled through unit design -

Dinning room adjacent to communal space.

Source: by Author

Figure 43: Transitional spaces

$\mid$ A. - Private Units $\mid$ B | Semi-Private Space | C | Communal

Source: by Author

Figure 44: Scales of interaction within a cluster

(Scale 1:300)

Source: by Author

Figure 45: Clusters with opportunities to step outside and sit along

Source: by Author

Figure 46: View inside of a cluster

Source: by Author

\section{| 6 | INTEGRATION OF COMMUNAL SPACES}

Figure 47: Unite d'Habitation - Separation of program

Source: Modified by Author - (French, 2008, p. 82)

Figure 48: The 8 House \& The Whale

Source 1: http://www.big.dk/\#projects-8

Source 2: http://www.denooyer.nl/wp-content/gallery/recent/

home8big.jpg

Figure 49: Mirador Apartments, MVRDV

Source 1: http://www.floornature.com/media/photos/30/4606/

mag472_02_popup.jpg

Source 2: http://2.bp.blogspot.com/_mGn4yO1XfL4/

TNc4mmyaoCI/AAAAAAAAAb8/DufhsMJ21bs/s72-c/MVRDV-

EdificioMirador1.jpg

Figure 50: Longitudinal building section illustrating the integration of communal spaces with housing units

Source: by Author

Figure 51: Newton Tower-City Place Condo

Separation of spaces

Source: Modified by Author - http://cityplace.ca/newton/index.asp

Figure 52: Passive \& active leisure

Source: by Author

Figure 53: Verti City - Michael Wallraff

Source: $h$ ttp://www.wallraff.at/details.php? $x p=88 \&$ menu $=r p \& p i c=6$

Figure 54: Transverse section \& partial longitudinal section

(Scale 1:600)

Source: by Author

Figure 55: View of kids space \& workout spaces (spinning \& jogging)

Source: by Author

\section{| 7 | CIRCULATION TO PROVIDE CHOICE \& GENERATE ENCOUNTERS}

Figure 56: Pass through space highlighted in plan-Level 6

Source: by Author 
Figure 57: Partial Transverse Section - Pass through space response to human behaviour

Source: by Author

Figure 58: View of pass through space in a cluster

Source: by Author

Figure 59: View of circulation leading directly out of clusters

Source: by Author

Figure 60: Gathering Space - Level 4

Source: by Author

Figure 61: Play Space-Level 6

Source: by Author

Figure 62: Play Space - Level 7

Source: by Author

Figure 63: Longitudinal Building Section:

Circulation connecting clusters \& communal spaces

Source: by Author

Figure 64: View of circulation connecting clusters \& communal spaces

Source: by Author

\section{| 8 | RESPONSE TO CONTEXT}

Figure 65: Site Context Map

Source: by Author

Figure 66: Adult craft night, story telling, night market \& beer tent

Source1: http://waterlooarchitecture.com/bridge/wp-content/ uploads/2013/05/The-Stop-Night-Market-500x331.jpg

Source 2: http://mirvishvillagebia.com/news.asp

Figure 67: Ground Floor Plan

Source: by Author

Figure 68: View of the building at grade, looking east on

Bloor Street West

Source: by Author

Figure 69: Jan Gehl's Necessary, Optional \& Social Activities Source: (Gehl, Cities for People, 2010, p. 21)

Figure 69: Jan Gehl's Necessary, Optional \& Social Activities Source: (Gehl, Cities for People, 2010, p. 21)

Figure 70: Second Floor

Source: by Author

Figure 71: Third Floor

Source: by Author

Figure 72: Longitudinal Section - Crossovers between residents \& community members (Scale 1:600)

response to human behaviour

Source: by Author

Figure 73: Transverse Section - Crossovers between residents \& community members

Figure 58: View of pass through space in a cluster

Source: by Author

Figure 59: View of circulation leading directly out of clusters

Source: by Author

Figure 60: Gathering Space - Level 4

Source: by Author

Figure 61: Play Space-Level 6
Source: by Author

Figure 62: Play Space - Level 7

Source: by Author

Figure 63: Longitudinal Building Section:

Circulation connecting clusters \& communal spaces

Source: by Author

Figure 64: View of circulation connecting clusters \& communal spaces

Source: by Author

\section{| 8 | RESPONSE TO CONTEXT \\ Figure 65: Site Context Map}

Source: by Author

Figure 66: Adult craft night, story telling, night market \& beer tent

http://waterlooarchitecture.com/bridge/wp-content/ uploads/2013/05/The-Stop-Night-Market-500×331.jpg http://mirvishvillagebia.com/news.asp

Figure 67: Ground Floor Plan

Source: by Author

Figure 68: View of the building at grade, looking east on Bloor Street West

Source: by Author

Figure 69: Jan Gehl's Necessary, Optional \& Social Activities Source: (Gehl, Cities for People, 2010, p. 21)

Figure 70: Second Floor

Source: by Author

Figure 71: Third Floor

Source: by Author

Figure 72: Longitudinal Section - Crossovers between residents \& community members (Scale 1:600)

Source: by Author

Figure 73: Transverse Section - Crossovers between residents \& community members

Source: by Author

Figure 74: 4 Modules - 2xGlass Panels - 2xConcrete Panels Source: by Author

Figure 75: Picture of physical model -

Back View - Showcasing Elevation Modules

Source: by Author

Figure 76: Picture of Physical model -

Front View - Showcasing Elevation Modules

Source: by Author

Figure 77: View at the Back of the Site - New Laneway

Source: by Author

Figure 77: View of the Front of the front of the Building from Bloor Street looking West To Markham Street

Source: by Author

** Please note that all Images in the Appendix are produced by the author 



\section{| 13 | LIST OF REFERENCES}

101 Erskine Condos. (n.d.). Retrieved September 2014. 2014, from Urban Toronto: http://urbantoronto.ca/ database/projects/101-erskine-condos

Aldo van Eyck and the City as Playground. (2013, March 27). Retrieved July 16, 2014, from The World Press: http://merijnoudenampsen.org/2013/03/27/ aldo-van-eyck-and-the-city-as-playground/

Alexander, C. (1977). A Pattern Language. New York: Oxford University Press.

Alison + Peter Smithson. (n.d.). Retrieved from Design at the Design Museum: http://designmuseum.org/ design/alison-peter-smithson

Aura at College Park. (n.d.). from Urban Toronto: http:// urbantoronto.ca/database/projects/aura-collegepark

Blake, E., \& Desai, P. (2008). Is Happiness the Key to unlock sustainability? In J. Wernick (Ed.), Building Happiness: Architecture to make you smile. London, United Kingdom: Black Dog Publishing Limited.

Bradley, K. (2008). The Happiness In-Between. (J. Wernick, Ed.) London, UK: Black Dog Publishing Limited.

(2003). Breeding Architecture. In B. Tschumi, \& I. Cheng (Eds.), The State of Architecture at the Beginning of the 21st Century. New York, New York. United States of America: The Monacelli Press,Inc.
Brillembourg , A., \& Klumner, H. (2012). In MVRDV (Ed.), The Vertical City. Rotterdam.

Burden, A. (2014, March). How public spaces make cities work. Retrieved from TED2014: https://Www. ted.com/talks/amanda_burden_how_public_spaces_ make_cities_work\#t-1081195

Campoli , J., \& MacLean, A. (2007). Visualizing Density. Cambridge, Massachusetts, United States of America: Lincoln Institute of Land Policy.

Carras, G. (2013, July 26). Is the GTA's Condo Boom too much, too little or just right? . Retrieved 2013, from The Star: http://www.thestar.com/life/ homes/2013/07/26/is_gtas_condo_boom_too_much_ too_little_or_just_right.html

Cauter, L. D. (2012). Ask the experts. In MVRDV, \& The Why Factor (Eds.), The Vertical Village. Rotterdam: The Why Factor.

Cheng, K. Y. (2012). The Vertical Village. (W. Maas, Ed.) Rotterdam: JUT Foundation for Arts and Architecture and NAI Publishers.

Chief Planner and Executive Director. City Planning. All Wards. (2007). Encouraging new and protecting existing family-sized units. Retrieved from website: http://www.toronto.ca/legdocs/mmis/2007/pg/ bgrd/backgroundfile-5883.pdf

(2013). City of Toronto Condominium Consultation Comprehensive Report. 
(2013). City of Toronto: Condo Consultation. Toronto.

Dalsgaad, A. M. (Director). (2013). The Human Scale [Motion Picture]. Denmark.

Egelius, M. (1990). Ralph Erskine, Architect. (C. Dymling, Ed.) Stockholm, Sweeden: Byggforlaget.

French, H. (2008). Key Urban Housing of the Twentieth Century: Plans Sections and Elevations. London: Laurence King Publishing Ltd.

Gehl, J. (2010). Cities for People. Copenhagen: Island Press.

Gehl, J. (2011). Life Between Buildings - Using Public Space. (J. Koch, Trans.) Washington, USA: Island Press. Gust, J. (2014).

Hancock, T. (2002). Encyclopedia of Public Health. Retrieved July 3, 2014, from Built Environment: http:// www.encyclopedia.com/doc/1G2-3404000130.html

How Architecture Shapes Behaviour: Mind Your Behaviour. (2010). Copenhagen, Denmark.

Balestra, F. (Performer). (2014). Incremental Strategies for Vertical Neighbourhoods. Toronto, Ontario, Canada.

Keesmaat, J. (n.d.). Own your city: The offical blog of the chief planner of the city of toronto. Retrieved from http://ownyourcity.ca/2013/11/mid-rise-rising/

Kopec, D. (2006). Environmental Psychology for Design . (O. T. Kontzias, Ed.) New York: Fairchild Publications.

Kuitenbrouwer, P. (2013, October 29): After sale of Honest Ed's and Mirvish Village confirmed, tenants wax philosophical. Retrieved from National Post: http://news.nationalpost.com/2013/10/29/peterkuitenbrouwer-after-sale-of-honest-eds-and-mirvishvillage-confirmed-tenants-wax-philosphical/?_federated $=1$

L Tower. (n.d.). Retrieved from Urban Toronto: http:// urbantoronto.ca/database/projects/l-tower

M. O. (2013). Downtown's Toronto's pace of population triples, outpacing suburbs' as echo boomers flock towards urban center. Retrieved from National Post: http://news.nationalpost.com/2013/01/22/ downtown-torontos-pace-of-population-growthtriples-outpacing-suburbs-as-echo-boomers-flocktowards-urban-centre-report/

Maas, W. (2003). Towards a New Urbanism. In B. Tschumi, \& I. Cheng (Eds.), The State of Architecture at the Beginning of the 21st Century. New York, New York, United States of America: The Monacelli Press, Inc.

Marshaall, S. (2008). Cities, Design \& Evolution. Routledge Taylor \& Francis Group.

Maslow. A. H. (1971). The farther reaches of human nature. New York: Penguin Group.

Melanson, T. (2012, September 24). What Toronto's skyline will look like in 2020. Retrieved from Canadian Business: http://wwww.canadianbusiness.com/blogsand-comment/what-torontos-skyline-will-look-likein-2020/

Montgomery, C. (2013, November 28). On the Sunny Side of the Street. Retrieved 2013, from Air Canada enRoute: http://enroute.aircanada.com/en/articles/ book-excerpt-on-the-sunny-side-of-the-street

Neef. M. M. (n.d.). Retrieved from http:// alastairmcintosh.com/general/resources/2007Manfred-Max-Neef-Fundamental-Human-Needs.pdf

Neef, M. M. (2013). Human Needs Matrix. Retrieved from YouTube: http://wwww.youtube.com/ watch?v=jJTvdoYgahk

Nelson, S. C. (2012, Dec 7). Baby Cage: The 1937 Parenting Solution For Londoners Short on Space. Retrieved Nov 15, 2013, from The Huffington Post: http://www.huffingtonpost.co.uk/2012/07/24/babycage-the-1937-parenting-solution-for-londoners- 
short-on-space-pictures_n_1697878.html

Oldfield, D. P. (2013. September 30). Successful High Rise means building gardens and streets in the sky, too. Retrieved October 20, 2013, from The Guardian: http://www.theguardian.com/housing-network/2013/ sept/30/successful-high-rise-gardens-streets

Pasquarelli, G. (2003). Architecture Beyond Form. In B. T. Cheng (Ed.), The State of Architecture at the Beginning of the 21st Century (p. 24). New York: The Monacelli Press Inc \& The Trustees of Columbia.

Sally Augustin, P. (2009). Place Advantage: Applied Psychology for Interior Architecture. Hoboken, New Jersey, USA: John Wiley \& Sons Inc.

Scott, S. (2010). Architecture for Children. (E. Webb. Ed.) Australia : ACER Press.

Shaftoe, H. (2008). Convivial Urban Spaces: Creating Effective Public Spaces. London, Sterling, VA: Earthscan.

Sherwood, R. (1981). Modern Housing Prototypes.

Sorkin, M. (2003). The Advant- Garde in Time of War. In B. Tschumi, \& I. Cheng (Eds.). The State of Architecture at the Beginning of the 21st Century. New York, USA: The Monacelli Press.

Spuybroek, L. (2003). Textile Tectonics. In B. Tshumi, \& I. Cheng (Eds.), The State of Architecture at the Beginning of the 21st Century. New York, United States of America: The Monacelli Press.

Steidle, O. (1994). Structures for Living. (F. Kossak, Ed., \& I. Taylor, Trans.) Munich, Germany: Artemis.

Stern, R. (2003). Urbanism is About Human Life. In B. Tshumi, \& Irene Cheng (Eds.), The State of Architecture at the Beginning of the 21th Century. New York, USA: The Monacelli Press Inc.

Structuralism - Architecture. (2010, 08 31). Retrieved 07 16. 2014, from Wikipedia: http://en.wikipedia.org/
wiki/Structuralism_(architecture)

The Pursuit of Happiness. (2013). Retrieved November 2013, from Bringing the Science of Happiness to Life. Toronto City Planning. (2012). Who Lives in Downtown and the Centres. City of Toronto , Toronto City Planning , Toronto.

Toronto City Planning. (2012). Who Lives in Downtown and the Centres. City of Toronto , Toronto City Planning ,Toronto.

Toronto Condo News and Updates: Should developers be forced to build 3-bedroom condos in Toronto. (2012. July 19). Retrieved from Lifestyles Reality Source: http://blog.lifestylesrealty.com/ bid/191915/Should-Developers-Be-Forced-To-Build3-Bedroom-Condos-in-Toronto

Toronto has the most high-rise buildings under construction in North American. Sustainable?11? (2011, Oct 4). Retrieved from Retrieved from http://www. buzzbuzzhome.com/chat/general-chit-chat/739/ toronto-has-the-most-highrise-buildings-underconstruction-in-north-america-sustainable

Toy, S., \& Guite, H. (2008). Social and Physical Factors for Building Happiness. In J. Wernick (Ed.), Building Happiness: Architecture to Make you Smile. London, United Kingdom: Black Dog Publishing Limited.

Victory Condo. (n.d.), from Urban Toronto: http:// urbantoronto.ca/database/projects/victory-condos

Wallraff, M. (2012). Vertical Public Space. (M. Wien, Ed.) Vienna: Verlog fur Moderne Kunst.

Weston, R. 100 Ideas that Changed Architecture. 2011: Laurence King Publishing

Whyte, W. H. (2000). The Essential William H. Whyte. (A. LaFarge, Ed.) New York: Forham University Press.

Williams, J. (2005, June). Designing Neighbourhoods for Social Interaction: The Case of Co-housing . Journal of Urban Design . 
